\title{
Mechanism of the Degradation of Polyamides
}

\author{
Bernard G. Achhammer, Frank W. Reinhart, and Gordon M. Kline
}

\begin{abstract}
Films of polyamides were exposed to heat, ultraviolet radiant energy, and different atmospheric conditions. The degradation products were collected in some cases and analyzed by mass spectrometric techniques. The unexposed and exposed specimens were examined by the following techniques to obtain information concerning the changes in chemical and physical structure of the polymer: infrared absorption, ultraviolet absorption, viscosity of solutions, measurement of dielectric constant and dissipation factor, photomicrography, X-ray diffraction, electron microscopy, electron diffraction, and effect of organic liquids. In addition, pyrolysis studies were made and some physical properties were determined. The results of the investigation show clearly that no single method gives a complete picture but that the results from several of the methods give an insight into the mechanism of degradation of polyamides.

Polyamide molecules are relatively unaffected by exposure to moderate temperature $\left(60^{\circ} \mathrm{C}\right)$. However, loss of water and other volatile materials may cause changes in physcial properties. The effects of exposure to ultraviolet radiant energy are more pronounced, and degradation of the polyamide molecule occurs with accompanying loss of water and other volatile materials that act as plasticizers.

The results of this investigation show that the general course of the degradation of polyamides is as follows:

1. The polymer molecules break at the $\mathrm{C}-\mathrm{N}$ bond of the peptide group creating smaller polymer molecules with the same unit of chemical structure. The fragments broken out are evolved as carbon dioxide, carbon monoxide, water, and hydrocarbons.

2 . The degree of crystallinity or local order changes, including alterations in hydrocarbon packing, dipole rearrangement, and hydrogen bridging.

3 . The amount of strongly bound water and/or organic liquids changes. These materials are probably bound by hydrogen bridging to the oxygen of the peptide group. They act as plasticizers for the polyamides.
\end{abstract}

\section{Introduction}

One of the major problems facing the plastics industry is the degradation of some plastics when exposed to certain service conditions. This problem has been investigated extensively by accelerated tests involving one or more physical properties. While empirical investigations of this type give information of value, they yield little or no information on the basic changes in the material. As a result, the value of the information now available is not only limited, but in too many instances the information cannot be used to predict behavior in actual service [1]. ${ }^{1}$ The physical changes observed during degradation may result from (1) changes in the chemical structure of the plastic material, and (2) loss or changes in the compounding ingredients. The logical method of attack is to determine the specific chemical reactions involved in the degradation of the plastic and how these reactions are affected by the intensity of the conditions encountered.

The degradation of the plastic type of polyamides was investigated as part of a general research program to determine the mechanism or fundamental chemical reactions that occur when organic high polymeric materials are exposed to degrading forces such as heat, ultraviolet radiant energy, and constituents of the ambient atmosphere. The term degradation is used in this paper to describe irreversible changes in the chemical structure of the polymer as a result of exposure to external forces.

\footnotetext{
${ }_{1}$ Figures in brackets indicate the literature references at the end of this paper.
}

Boulton and Jackson $[2,3]$ found that treatment with sulfuric acid, exposure to ultraviolet radiant energy from a carbon arc, and exposure to sunlight, degrade nylon. The degradation was followed by measurement of tensile strength and the viscosity of solutions in $m$-cresol and formic acid. They found that a loss of over 50 percent in tensile strength is accompanied by a relatively small change in relative viscosity. A smaller decrease in viscosity for a given loss in tensile strength was observed for the materials degraded photochemically than for those degraded by the acid.

Hosino [4] reported that heating nylon with concentrated hydrochloric acid for $12 \mathrm{hr}$ causes almost complete hydrolysis of the polymer into adipic acid and hexamethylenediamine.

Taylor [5] reported that ammonia is produced during the degradation of nylon. Peterson [6] depolymerized polyamides by heating them with an equal amount of water in an autoclave at $200^{\circ}$ to $210^{\circ} \mathrm{C}$ and $300 \mathrm{psi}$.

Fuller [7] found that heating linear polyamides for a short period of time to a suitable temperature in the presence of air or oxygen increases their toughness, flexibility, and resistance to embrittlement on aging. The temperature used, which must be above the melting point of the polyamide but below the decomposition temperature, may vary from $125^{\circ}$ to $450^{\circ} \mathrm{C}$, depending on the chemical structure of the polyamide. To obtain this effect the polyamide must be in the form of thin cross sections; otherwise the oxygen reacts with the material on the surface, leaving the interior unaffected. 
TABLE 1. Description of polyamides

\begin{tabular}{|c|c|c|c|c|c|}
\hline $\begin{array}{c}\text { Sample } \\
\text { designation }\end{array}$ & Chemical composition & $\begin{array}{l}\text { Code desig- } \\
\text { nation for } \\
\text { chemical } \\
\text { composition }\end{array}$ & $\begin{array}{l}\text { Nominal } \\
\text { thickness }\end{array}$ & $\begin{array}{l}\text { Approximate } \\
\text { melting } \\
\text { point in air }\end{array}$ & $\begin{array}{l}\text { Approximate } \\
\text { discoloration } \\
\text { point in air. }\end{array}$ \\
\hline $\begin{array}{l}4405 \\
4406 \\
4407 \\
4408 \\
4409 \\
4410\end{array}$ & $\begin{array}{l}\text { Hexamethylenediamine-adipic acid salt, } 50 \% \text {; } \epsilon \text {-caprolactam, } 50 \% \\
\text { Hexamethylenediamine-adipic acid salt, } 50 \% \text {-caprolactam, } 50 \% \\
\text { Hexamethylenediamine-adipic acid salt, } 60 \% ; \epsilon \text {-caprolactam, } 40 \% \\
\text { Hexamethylenediamine-adipic acid salt, } 60 \% ; \epsilon \text {-caprolactam, } 40 \% \\
\text { Hexamethylenediamine-adipic acid salt; hexamethylenediamine-sebacic } \\
\text { acid salt; } \epsilon \text {-caprolactam a } \\
\text { Hexamethylenediamine-adipic acid salt; hexamethylenediamine-sebacic } \\
\text { acid salt; } \epsilon \text {-caprolactam (more than in } 4409)\end{array}$ & $\begin{array}{l}66 / 6-50: 50 \\
66 / 6-50: 50 \\
66 / 6-60: 40 \\
66 / 6-60: 40 \\
66 / 610 / 6 \mathrm{~A} \\
66 / 610 / 6 \mathrm{~B}\end{array}$ & $\begin{array}{l}\text { in. } \\
0.002 \\
.004 \\
.002 \\
.003 \\
.002 \\
.002\end{array}$ & $\begin{array}{l}\circ C \\
179 \text { to } 180 \\
179 \text { to } 180 \\
188 \text { to } 190 \\
186 \text { to } 190 \\
165 \text { to } 167 \\
161 \text { to } 163\end{array}$ & $\begin{array}{r}{ }^{\circ} \mathrm{r} \\
172 \\
174 \\
177 \\
177 \\
160 \\
158\end{array}$ \\
\hline
\end{tabular}

a The percentage composition of sample 4409 is estimated to be $60 \%$ of 66 salt, $20 \%$ of 610 salt, and $20 \%$ of caprolactam.

\section{Materials}

The polyamide materials used in this investigation were copolymers of nylon salts with $\epsilon$-caprolactam and are described in table 1 . The samples were obtained in the form of commercial films, 0.002 to 0.004 in. thick, which were presumably cast from hot ethanol solutions. There were some differences among the samples in transparency, attributable to differences in rates of cooling.

The discoloration and melting points reported in table 1 were determined in air by the following procedure: The nylon film was cut into very small squares with a razor blade and the small pieces placed in a glass melting point tube. The tube was attached in the usual manner to a thermometer and the assembly placed in an agitated bath of silicone oil, which was heated by an electric coil heater. The temperature of the bath was raised at a fairly rapid rate to about $150^{\circ} \mathrm{C}$ and then at $1 \mathrm{deg} \mathrm{C} / \mathrm{min}$. The behavior of the nylon specimen was observed with a magnifying glass. Duplicate tests were made with all samples.

The thickness of the films was measured with a Mikrokator gage, which has a scale range of 0.0014 in. with graduations of 0.00002 in. The film was placed between gage blocks, 1 in. square, for measurement. The total force on the film was about $11 \mathrm{oz}$. Particular care must be taken to prevent contamination with grease, dirt, and dust in order to measure the thickness of the films to $\pm 0.00001 \mathrm{in}$.

It was necessary for some experiments to have thinner films. The following procedure was used for recasting the films: The nylon was dissolved in warm (above $45^{\circ} \mathrm{C}$ ) ethanol. The warm solution, 2 to 4 percent, was poured on to a warm glass plate and spread to a uniform thickness with a doctor blade. In an alternate procedure the solution was poured into a brass ring on a warm glass plate and allowed to spread to a uniform thickness. This assembly was placed in a closed vessel with an ethanol-air atmosphere and maintained at $45^{\circ} \mathrm{C}$ for $1 \mathrm{hr}$. At the end of this time the vessel was opened and the ethanol was allowed to evaporate. The films were then washed in running water to free them of ethanol and dried over calcium chloride. The nylon films produced were clear and nearly free of surface defects. The film thickness was controlled by varying the concentration and depth of the solution. The films ranged in thickness from 0.0001 to 0.0008 in.

A dipping technique was developed to recast the films for the work with the electron microscope, since films for this purpose must be less than 0.00004 in. $\left(\begin{array}{ll}1 & \mu\end{array}\right)$ thick to permit sufficient transmission of the electron beam. The films were made by heating a 1.5 -percent solution of the polyamide in 95-percent ethanol to $50^{\circ}$ to $60^{\circ} \mathrm{C}$ and immersing a warm glass microscope slide in the solution. The glass slide was removed, held vertically for a couple of seconds, and then placed under a bell jar in an atmosphere of ethanol. The thin polyamide film on one side of the glass slide was removed by rubbing with a damp cloth after the film had dried. The glass slide, bearing the thin film on one side, was partially immersed in a dish of water. The immersed portion of the film was freed from the glass by the water and allowed to float free. Five 200-mesh stainless-steel specimen-supporting screens ( $1 / 8 \mathrm{in}$. in diameter) were placed on the submerged portion of the glass slide, so that upon removal from the water the free floating portion of the film fell back in place over the screens on the glass slide. This procedure made it unnecessary to apply tension on the film to remove it from the glass and place it on the screens as would be the case in the usual stripping and transfer technique.

\section{Apparatus and Procedures}

\section{Apparatus to Produce Controlled Degradation}

The apparatus designed to degrade polymeric materials by exposure to controlled conditions of heat, ultraviolet radiant energy, and ambient atmosphere is shown in figures 1 and 2 . It consists of three integrated units: (1) a gas purification train, (2) an exposure chamber suitable for exposing polymer films to ultraviolet radiant energy at controlled temperatures, and (3) a gas-collection trap suitable for collecting samples for mass spectrometric analysis of the gaseous degradation products. Equipment of a somewhat similar nature was used successfully by Stillings and Van Nostrand [8] in a study of the action of ultraviolet radiant energy on cellulose.

The atmosphere in the exposure chamber was conditioned by the purification train, 1-9, shown schematically in figure 1. Any gas that is cylinderpacked could be used as the atmosphere. The gas 


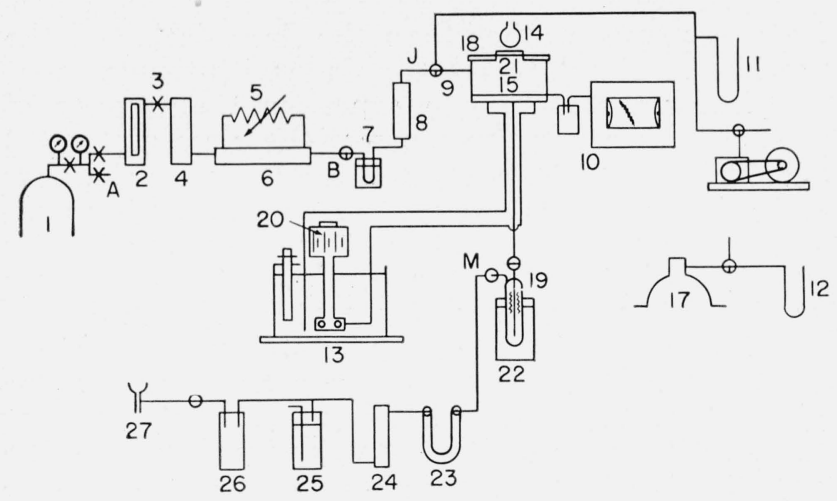

Figure 1. Apparatus to produce controlled degradation.

1, Gas cylinder; 2, flowmeter; 3 , needle valve; 4 , drying tube; 5 , rheostat; 6 , copper gauze furnace; 7 , cold trap $\left(-78^{\circ} \mathrm{C}\right) ; 8$, carbon dioxide absorption tube 9 , three-way stopcock; 10 , automatic temperature recorder with thermocouple cold junction; 11, manometer; 12, manometer; 13 , constant-temperature bath; 14 source of ultraviolet radiant energy; 15, heating platen; 16, Pyrex ring (shown in fig. 2) used to hold film flat on heating platen; $15 ; 17$, desiccator lid placed on 18 during evacuation to protect thin glass, 21 , by evacuating both sides simultaneous ly; 18, Pyrex plate; 19, gas collection trap; 20, immersion pump; 21, ultraviolet transmitting glass; 22 , cooling Dewar; 23 , carbon dixoide absorbent; 24 , dryin? tube; 25 , reverse bubbler for pressure regulation; 26 , water trap; 27 , aspirator $\mathrm{A}-\mathrm{B}$, bypass valve; J, end of purification train and start of exposure chamber unit; $\mathrm{M}$, beginning of water aspirator and flow control apparatus.

was passed from the cylinder, 1, through a flow meter, 2. A flow of approximately $20 \mathrm{ml} / \mathrm{min}$ was maintained by manipulation of a needle valve. The outlet pressure on the gage attached to the gas cylinder was kept at about 2 psi. The gas passed from the flow meter through a needle valve, 3 , which was used to close the system during evacuation. The gas then passed through a calcium chloride-copper sulfate tower, 4, to remove water, a copper gauze furnace, 6, to remove oxygen, a cold trap, 7, an ascarite-anhydrone tower, 8, to remove carbon dioxide, and finally into the exposure chamber through a three-way stopcock, 9. The temperature of the copper gauze furnace was controlled by a rheostat, 5. The furnace was removable from the train for regeneration of the copper. Sections of the purification train could be bypassed by attachment of rubber tubing from the gas cylinder at $\mathrm{A}$ to the three-way stopcocks B or 9. The gas used determined the type and amount of purification required. The mercury manometer, 11, connected to threeway stopcock 9, showed the pressure in the exposure chamber. The other manometer, 12, was used to maintain a pressure differential, which will be described subsequently.

A Brown potentiometer, 10, recorded the temperature of the platen on which the film was supported. The Dewar flask alongside the potentiometer was the cold junction for the copper constantan thermocouple embedded in the platen of the exposure chamber. The temperature of this platen was controlled by circulating silicone oil (DC-500) from the bath, 13, with an immersion pump, 20. The oil was circulated through a series of baffles and returned to the bath.

The exposure chamber 15 is shown in figures 1 and 2. It consists of an open-top brass cylinder 10 in. in diameter and $4 \mathrm{in}$. in height. The inside of the chamber was gold plated because most other metals

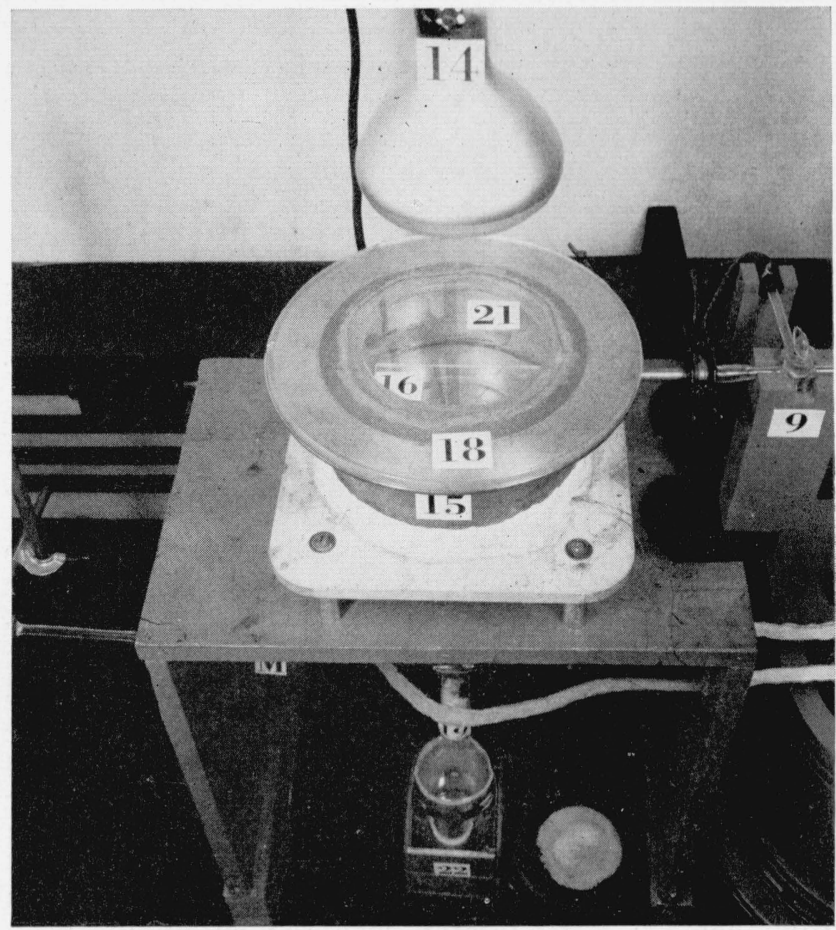

Figure 2. Exposure chamber, vertical view, assembled for operation.

act as catalysts and might cause reactions between the degradation products formed. Concentric grooves, 0.02 in. deep and 0.04 in. wide, on the floor of the exposure chamber are connected by radial grooves of the same dimensions to the outlet tube. A glass ring, 16, placed on the edge of the film to be studied prevented curling of the film. A Pyrex plate, 18 , with a 5 -in. aperture supported the Corex D window, 21, which was $2 \mathrm{~mm}$ thick and 6 in. in diameter. This Pyrex plate was sealed to the exposure chamber by a ground glass to ground brass seal and silicone stopcock grease. The Corex D window was sealed to the Pyrex glass with beeswaxrosin mixture or with silicone grease. An RS sunlamp, 14, was supported about 8 in. from the film to be studied. This type of sunlamp was convenient to use as a source of ultraviolet radiant energy. A blower (not shown) kept the temperature of the sunlamp, Corex D, and Pyrex sections down during irradiation.

The following assembly was used during evacuation of the system: A desiccator lid, 17, was placed on the ground surface of the Pyrex plate, 18 . Because the Corex D window was so thin, it was necessary to evacuate both sides of the window simultaneously. A pressure differential was obtained by manipulation of suitably placed stopcocks. One manometer, 12, was used to read the pressure in the lid, 17, while another manometer, 11, gave the pressure in the chamber. By keeping the pressure slightly greater in the top section it was possible to maintain a good vacuum seal.

Gaseous products of the treatment were collected in a trap, 19, designed for simple attachment to the 
mass spectrometer by means of spherical joints. The Dewar flask, 22, filled with acetone-carbon dioxide slush or liquid air, was used to condense the gaseous products in the collection trap. A U-tube, 23, containing ascarite-anhydrone and calcium chloride-copper sulfate was used to trap carbon dioxide that passed through the collection trap, 19 . The calcium chloride-copper sulfate column, 24, prevented water vapor from entering the system. The inverse bubbler, 25, regulated the water supply so that a constant suction could be applied to the system. A trap, 26, was inserted to collect the water that might flow back into the apparatus if the water aspirator, 27, should not function properly.

The following procedure is representative of that used to make a typical exposure: The polyamide film, which was previously dried at room temperature in a desiccator and weighed, was placed in the exposure chamber. For study in an inert atmosphere, such as nitrogen, the exposure chamber was sealed and the system evacuated with a vacuum pump from point $M$ to point 3 . The system was then filled with purified nitrogen. This cycle was repeated several times. The entire system was then flushed with purified nitrogen at a rate of 500 $\mathrm{ml} / \mathrm{min}$ for about $1 / 2 \mathrm{hr}$. The collection trap was then cooled; the sunlamp was turned on and the nitrogen flow was adjusted to $200 \mathrm{ml} / \mathrm{min}$.

On completion of an exposure of a specimen to heat, to ultraviolet radiant energy, or to a combination of those factors, either of two procedures was followed: (1) The entire system was evacuated through the cold collection trap, 19 , to point 3 , and the evacuated collection trap was removed; or (2) the system was flushed with nitrogen and the collection trap removed under a slight positive pressure of nitrogen. The gaseous products were analyzed with a mass spectrometer. The treated film was examined by suitable analytical methods to detect changes.

The mass spectrometer is so sensitive that the presence of small amounts of volatile compounds is readily detected. This made it necessary to ensure that the experiments were made under conditions such that no volatile compounds were introduced

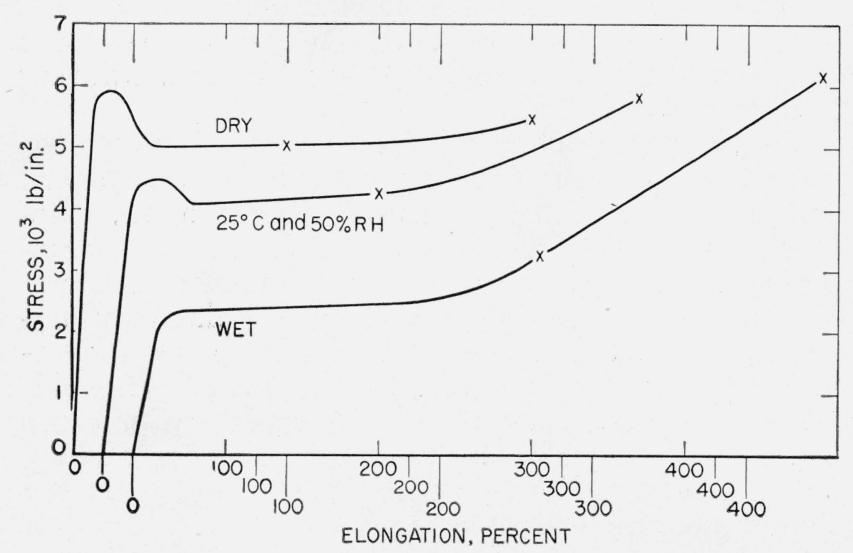

Figure 3. Typical tensile stress-strain characteristics polyamide sample 4409. from any source other than the degradation of the specimen. Blank tests were made with the degradation equipment. In one experiment an excess of silicone grease was used to seal the glass plates (18 and 21 in fig. 2) to the top of the exposure chamber and the chamber (15 in fig. 2 ) was exposed to radiation from an RS sunlamp for $6 \mathrm{hr}$ while nitrogen gas was passed through the equipment. The mass spectrometric analysis of the material in the collection trap (19 in fig. 1) indicated the presence of no gases other than nitrogen. The results were also satisfactory in another blank experiment made at $25^{\circ} \mathrm{C}$ for $6 \mathrm{hr}$ while nitrogen was passed through the equipment with a silicone grease seal at 18 in figure 2 and a beeswax-rosin seal at 21 in figure 2 .

\section{Accelerated Weathering and Outdoor Exposure}

Accelerated weathering was conducted in accordance with Method No. 6021 of Federal Specification $\mathrm{L}-\mathrm{P}-406 \mathrm{a}$ [9], involving cyclic exposure to the radiant energy from an $\mathrm{S}-1$ sunlamp and to fog. The total period of exposure to these two conditions is divided into multiples of $20 \mathrm{hr}$ of sunlamp radiation to $4 \mathrm{hr}$ of fog.

Outdoor exposure was accomplished by placing specimens fastened to glass frames on outdoor racks at $45^{\circ}$ facing south from Feb. 17 to Apr. 18, 1947 . During this period of 61 days there were 12 clear, 23 partly cloudy, and 26 cloudy days. The precipitation was 4.36 in. The temperature varied from $15^{\circ}$ to $86^{\circ} \mathrm{F}$ and the relative humidity from 22 to 100 percent. The total sunshine was $530 \mathrm{hr}$.

\section{Mechanical Properties and Weathering Resistance}

With J. J. Lamb, B. A. Hall, and C. Brown

The tensile strength, elongation at failure in the tensile tests, tearing strength, resistance to accelerated weathering, and resistance to exposure outdoors of the six polyamide samples were determined.

Tensile strength and elongation were determined at various temperatures and humidities after conditioning the specimens. The test specimens were cut with die $\mathrm{D}$ [10]. The results obtained utilizing two different machines are described in tables 2 and 3. A typical stress-strain curve obtained with an autographic strain gage system is shown in figure 3 .

No significant differences were observed in tensile strength and elongation between the two orientations of the specimens of each sample, or between the various samples at $25^{\circ} \mathrm{C}$ and 50 -percent relative humidity. At $-29^{\circ} \mathrm{C}$ and 100-percent relative humidity, the differences between the samples are significant; the tensile strengths of samples 4405 and 4406 are slightly lower than those of samples 4407 and 4408 and higher than those of samples 4409 and 4410 ; the scatter in the elongation values as indicated by the coefficient of variation is so great that the differences are apparently not significant. The tensile strengths at $-29^{\circ} \mathrm{C}$ are higher than 
TABLE 2. Tensile properties ${ }^{\text {a }}$ of polyamides

\begin{tabular}{|c|c|c|c|c|c|c|c|c|c|c|c|c|}
\hline \multirow{3}{*}{$\begin{array}{l}\text { Sample desig- } \\
\text { nation d }\end{array}$} & \multicolumn{6}{|c|}{ Tests at $25^{\circ} \mathrm{C}$ and 50 -percent relative humidity b } & \multicolumn{6}{|c|}{ Tests at $-29^{\circ} \mathrm{C}$ and 100 -percent relative humidity $\mathrm{c}$} \\
\hline & \multicolumn{3}{|c|}{ Tensile strength } & \multicolumn{3}{|c|}{ Elongation } & \multicolumn{3}{|c|}{ Tensile strength } & \multicolumn{3}{|c|}{ Elongation } \\
\hline & Average & $\mathrm{SE}$ e & $\mathrm{CV} \mathrm{f}$ & Average & SE e & $\mathrm{CV} \mathrm{f}$ & Average & SE e & $\mathrm{CV}_{\mathrm{f}}$ & Average & $\mathrm{SE}$ e & $\mathrm{CV}:$ \\
\hline 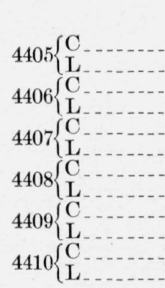 & $\begin{array}{l}l b / i n .^{2} \\
8,400 \\
7,700 \\
7,800 \\
8,400 \\
8,500 \\
9,400 \\
7,400 \\
7,900 \\
9,400 \\
9,200 \\
7,200 \\
8,700\end{array}$ & $\begin{array}{c}l b / \text { in. } \\
240 \\
120 \\
150 \\
170 \\
310 \\
330 \\
190 \\
120 \\
150 \\
320 \\
500 \\
290\end{array}$ & $\begin{array}{r}\% \\
8 \\
4 \\
6 \\
6 \\
12 \\
11 \\
8 \\
5 \\
5 \\
11 \\
22 \\
11\end{array}$ & $\begin{array}{l}\% \\
440 \\
440 \\
440 \\
430 \\
390 \\
380 \\
430 \\
430 \\
440 \\
430 \\
390 \\
460\end{array}$ & $\begin{array}{r}\% \\
8 \\
6 \\
6 \\
7 \\
10 \\
9 \\
10 \\
6 \\
5 \\
5 \\
21 \\
9\end{array}$ & $\begin{array}{r}\% \\
5 \\
4 \\
4 \\
5 \\
8 \\
7 \\
7 \\
4 \\
4 \\
4 \\
17 \\
6\end{array}$ & $\begin{array}{r}l b / \text { in. } \\
13,500 \\
12,800 \\
11,300 \\
13,100 \\
14,100 \\
15,300 \\
11,700 \\
13,200 \\
10,800 \\
9,400 \\
10,500 \\
10,700\end{array}$ & $\begin{array}{c}\text { lb/in. }{ }^{2} \\
340 \\
230 \\
130 \\
100 \\
200 \\
380 \\
350 \\
190 \\
480 \\
580 \\
460 \\
230\end{array}$ & $\begin{array}{r}\% \\
8 \\
6 \\
4 \\
2 \\
4 \\
8 \\
10 \\
4 \\
14 \\
20 \\
13 \\
6\end{array}$ & $\begin{array}{r}\% \\
10 \\
16 \\
10 \\
7 \\
10 \\
10 \\
10 \\
5 \\
10 \\
18 \\
7 \\
12\end{array}$ & $\begin{array}{l}\% \\
0 \\
2 \\
2 \\
1 \\
1 \\
1 \\
1 \\
1 \\
2 \\
6 \\
1 \\
1\end{array}$ & $\begin{array}{r}\% \\
0 \\
36 \\
70 \\
30 \\
17 \\
29 \\
40 \\
40 \\
80 \\
100 \\
37 \\
22\end{array}$ \\
\hline
\end{tabular}

a Determined on a constant-speed spring-balance testing machine, 20-lb range, in accordance with Federal Specification ZZ-R-601a, Section II-5. Each average value was obtained with 10 specimens.

b Specimens conditioned for at least $48 \mathrm{hr}$.

c Specimens conditioned for at least $0.5 \mathrm{hr}$

d Code for orientation of specimens: $\mathrm{C}=$ crosswise; $\mathrm{L}=$ lengthwise. e Standard error.

coefficient of variation.

TABLE 3. Tensile properties a of polyamides at $25^{\circ} \mathrm{C}$

\begin{tabular}{|c|c|c|c|c|c|c|}
\hline \multirow{2}{*}{$\begin{array}{c}\text { Sample } \\
\text { desig- } \\
\text { nation }\end{array}$} & \multicolumn{3}{|c|}{ Tensile strength } & \multicolumn{3}{|c|}{ Elongation } \\
\hline & Average & $\mathrm{SEb}$ & $\mathrm{CV}^{\circ}$ & Average & $\mathrm{SE}^{\mathrm{b}}$ & $\mathrm{CV}^{\circ}$ \\
\hline \multicolumn{7}{|c|}{ CONDITIONED AT 50-PERCENT RELATIVE HUMIDITY d } \\
\hline $\begin{array}{l}4408 \\
4409\end{array}$ & $\begin{array}{c}l b / \text { in }^{2} \\
7,000 \\
6,000\end{array}$ & $\begin{array}{c}l 5 / \text { in } .{ }^{2} \\
170 \\
330\end{array}$ & $\begin{array}{r}\% \\
6 \\
13\end{array}$ & $\begin{array}{c}\% \\
350 \\
280\end{array}$ & $\begin{array}{r}\% \\
4 \\
25\end{array}$ & $\begin{array}{r}\% \\
2 \\
20\end{array}$ \\
\hline \multicolumn{7}{|c|}{ WET (IMMERSED IN WATER) e } \\
\hline $\begin{array}{l}4408 \\
4409\end{array}$ & $\begin{array}{l}3,700 \\
5,400\end{array}$ & $\begin{array}{l}530 \\
640\end{array}$ & $\begin{array}{l}34 \\
29\end{array}$ & $\begin{array}{l}330 \\
360\end{array}$ & $\begin{array}{l}45 \\
24\end{array}$ & $\begin{array}{l}30 \\
15\end{array}$ \\
\hline \multicolumn{7}{|c|}{ DRY (DRIED OVER CALCIUM CHLORIDE) $f$} \\
\hline $\begin{array}{l}4408 \\
4409\end{array}$ & $\begin{array}{l}8,300 \\
6,600\end{array}$ & $\begin{array}{l}430 \\
660\end{array}$ & $\begin{array}{l}14 \\
24\end{array}$ & $\begin{array}{r}36 \\
136\end{array}$ & $\begin{array}{l}24 \\
52\end{array}$ & $\begin{array}{r}147 \\
84\end{array}$ \\
\hline
\end{tabular}

a Determined on a Baldwin MTE testing machine, 50-1b range, in accordance with Federal Specification ZZ-R-601a, Section II-5. Each average value reported was obtained with 6 specimens.

b Standard error.

Coefficient of variation

Specimens conditioned for at least $96 \mathrm{hr}$.

e Tests made immediately after removal of specimens from water at $25^{\circ} \mathrm{C}$ in which they were immersed for $24 \mathrm{hr}$.

Tests made immediately on removal of the specimens from a desiccator charged with dry calcium chloride in which they were stored for 1 week.

those observed at $25^{\circ} \mathrm{C}$; the increase on going to the low temperature is greater for samples 4405 , 4406, 4407, and 4408 than for samples 4409 and 4410. The elongation values are much lower at $-29^{\circ} \mathrm{C}$ than they are at $25^{\circ} \mathrm{C}$. The tensile strengths of the samples were reduced by exposure outdoors for 2 months. Except for sample 4410, the elongations at break were also reduced by the exposure outdoors.

The tensile strength of sample 4408 increases with a decrease in water content. Although a similar trend is apparent for sample 4409, it is not statistically significant. The elongations at break for samples 4408 and 4409 wet and at 50-percent relative humidity are not statistically different. The elon- gations of the dry specimens are much lower than those of the wet specimens of both samples. Thus it appears that water acts as a plasticizer. The stressed specimens of sample 4408 became cloudy, but those of 4409 remained clear.

The tensile stress-strain curves show marked differences in characteristics between the wet and dry specimens. As the water content is reduced, the modulus of elasticity is reduced and the elongation at break is decreased. The failures were quick brittle breaks, particularly for the dry specimens. The shape of the stresss-strain curves is typical of materials that undergo an instantaneous elastic response when stressed and that also work-harden when stressed beyond the yield point [11 and 12]. The character of the yield point is also different for the wet and dry specimens. A comparison of the curves for the wet and dry specimens suggests that the crystalline order is different for the different conditions near the breaking point, but the character of this difference is not known. The curves for samples 4408 and 4409 indicate that these materials probably have different degrees of crystallinity.

The tearing strengths [13] of the polyamides at $25^{\circ} \mathrm{C}$ and 50-percent relative humidity and at $-29^{\circ} \mathrm{C}$ and 100 -percent relative humidity are reported in table 4 . There is no difference in the tearing strengths of the crosswise and lengthwise directions of samples 4405, 4407, 4409, and 4410 at $25^{\circ} \mathrm{C}$ and 50-percent relative humidity, and of all the samples at $-29^{\circ} \mathrm{C}$ and about 100 -percent relative humidity. There is a significant difference between the crosswise and lengthwise directions for samples 4406 and 4408 at $25^{\circ} \mathrm{C}$ and 50-percent relative humidity. The tearing strengths at $-29^{\circ} \mathrm{C}$ are markedly less than those at $25^{\circ} \mathrm{C}$. As the thicknesses of samples 4405, 4407, 4409, and 4410 are approximately the same, the results of the tearstrength tests show that samples 4405 and 4410 are inherently stronger in tearing strength at ordinary temperatures than samples 4406 and 4409 . 
TABLE 4. Tearing strength of polyamides

\begin{tabular}{|c|c|c|c|c|c|c|}
\hline \multirow{3}{*}{$\begin{array}{l}\text { Sample desig- } \\
\text { nation } b\end{array}$} & \multicolumn{6}{|c|}{ Elmendorf tearing strength per sheet a } \\
\hline & \multicolumn{3}{|c|}{$\begin{array}{l}\text { Tests at } 25^{\circ} \mathrm{C} \text { and } 50 \text {-percent } \\
\text { relative humidity }\end{array}$} & \multicolumn{3}{|c|}{$\begin{array}{l}\text { Tests at }-29^{\circ} \mathrm{C} \text { and } 100- \\
\text { percent relative humidity }\end{array}$} \\
\hline & A verage & $\mathrm{SE} \cdot$ & $\mathrm{CV} d$ & A verage & $\mathrm{SE} \cdot$ & $\mathrm{CV} \mathrm{d}$ \\
\hline 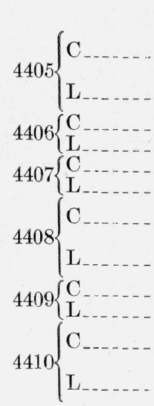 & 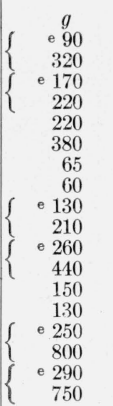 & $\begin{array}{c}g \\
11 \\
69 \\
30 \\
27 \\
37 \\
33 \\
14 \\
3 \\
10 \\
50 \\
30 \\
10 \\
18 \\
17 \\
40 \\
50 \\
29 \\
85\end{array}$ & $\begin{array}{l}\% \\
27 \\
47 \\
38 \\
24 \\
37 \\
19 \\
46 \\
10 \\
16 \\
53 \\
26 \\
5 \\
28 \\
29 \\
34 \\
12 \\
22 \\
25\end{array}$ & $\begin{array}{c}g \\
40 \\
-40 \\
70 \\
60 \\
40 \\
35 \\
60\end{array}$ & \begin{tabular}{r}
$g$ \\
6 \\
\hdashline 2 \\
\hdashline 19 \\
25 \\
2 \\
10 \\
25 \\
-1 \\
-1 \\
-0 \\
4 \\
1 \\
-1 \\
-1
\end{tabular} & $\begin{array}{c}\% \\
39 \\
-10 \\
10 \\
-63 \\
97 \\
12 \\
49 \\
55 \\
52 \\
0 \\
18 \\
8 \\
6 \\
-\end{array}$ \\
\hline
\end{tabular}

a Tests made with Elmendorf Tear Tester in accordance with ASTM Method of Test D 689-44 [13]. Each average value reported was obtained with 5 specimens.

b Code for orientation of specimens: $\mathrm{C}=$ crosswise; $\mathrm{L}=$ lengthwise.

- Standard error.

d Coefficient of variation.

e These values for samples 4405, 4408, and 4410 were obtained by placing the specimens in the grips of the Elmendorf Tear Tester and folding the free end to the left. All the other values for these samples were obtained with the free end folded to the right. The values for samples 4406, 4407, and 4409 did not depend on the way the test specimens were folded over in the test grips.

The effects of accelerated weathering and outdoor exposure on some properties on polyamide films are shown in tables 5 and 6 . The accelerated weathering test conditions caused all the polamide samples to become more brittle. The outdoor exposure tests show that the resistance to weathering of samples 4406 and 4408 is superior to that of the other samples. The greater resistance of samples 4406 and 4408 to the action of the ultraviolet radiant energy is attributed to their greater thickness, and infers a surface degradation that may retard further degradation in the interior of the films.

Marked differences in the strength properties of the various polyamides are indicated in the results reported in this section. Various techniques were utilized to obtain data relating the observed changes in physical properties with changes in chemical structure of the polyamides. The results of these studies are described in the subsequent sections of this report.

\section{Mass Spectrometry}

\section{With C. E. Wise, R. M. Reese, and L. M. Williamson}

Polyamide samples 4406, 4407, and 4409 were exposed to controlled conditions of heat, ultraviolet radiant energy, and ambient atmosphere in the apparatus described previously in section III. The gaseous products were analyzed with a model 21-102 Consolidated Engineering mass spectrometer.

The experimental procedure is described in section III. Some of the experiments were made with the nylon samples in the film form in which they were received and others with recast films. Most of these
TABLE 5. Effects of sunlamp-fog accelerated weathering test on the properties of polyamides

\begin{tabular}{|c|c|c|c|}
\hline \multirow{3}{*}{$\begin{array}{l}\text { Sample } \\
\text { designa- } \\
\text { tion }\end{array}$} & \multicolumn{3}{|c|}{ Effects of accelerated weathering test a } \\
\hline & \multicolumn{2}{|c|}{ Change in- } & \multirow{2}{*}{$\begin{array}{c}\text { Condition (after } 240 \mathrm{hr} \text {, unless otherwise } \\
\text { noted) }\end{array}$} \\
\hline & Width & Length & \\
\hline 4405 & $\%$ & $\%$ & \multirow{4}{*}{$\begin{array}{l}\text { Very brittle and weak; fell apart at } \\
180 \mathrm{hr} \text {. } \\
\text { Slightly brittle; edges curled. } \\
\text { Very brittle and weak; fell apart. } \\
\text { Slightly brittle along edges nearest to } \\
\text { sunlamp. } \\
\text { Very brittle and weak; fell apart. } \\
\text { Do. }\end{array}$} \\
\hline $\begin{array}{l}4406 \\
4407\end{array}$ & -3.4 & -2.6 & \\
\hline 4408 & -1.3 & -1.7 & \\
\hline $\begin{array}{l}4409 \\
4410\end{array}$ & & & \\
\hline
\end{tabular}

a Three specimens of each sample were tested.

TAвLE 6. Tensile properties a of polyamides b at $25^{\circ} \mathrm{C}$ and 50-percent relative humidity after exposure outdoors for 2 months

\begin{tabular}{|c|c|c|c|c|c|}
\hline \multirow{2}{*}{$\begin{array}{c}\text { Sample } \\
\text { designa- } \\
\text { tion }\end{array}$} & \multirow{2}{*}{$\begin{array}{l}\text { Orientation of } \\
\text { specimens }\end{array}$} & \multicolumn{2}{|c|}{ Tensile strength } & \multicolumn{2}{|c|}{ Elongation } \\
\hline & & Average & Range & Average & Range \\
\hline $\begin{array}{l}4408 \ldots \\
4410\end{array}$ & $\begin{array}{l}\left\{\begin{array}{l}\text { Crosswise } \\
\text { Lengthwise }\end{array}\right. \\
\text { \{rosswise } \\
\text { Lengthwise } \\
\text { \{rosswise } \\
\text { Lengthwise } \\
\text { Lengthwise }\end{array}$ & $\begin{array}{r}l b / \text { in }^{2} \\
5,700 \\
5,000 \\
5,400 \\
5,300 \\
5,400 \\
4,800 \\
6,200\end{array}$ & $\begin{array}{c}l b / \text { in }^{2} \\
4,600 \text { to } 7,000 \\
4,300 \text { to } 7,200 \\
5,200 \text { to } 5,800 \\
4,400 \text { to } 6,700 \\
5,000 \text { to } 5,600 \\
4,600 \text { to } 5,000 \\
4,400 \text { to } 7,400\end{array}$ & $\begin{array}{l}\% \\
350 \\
240 \\
200 \\
280 \\
280 \\
190 \\
400\end{array}$ & $\begin{array}{c}\% \\
290 \text { to } 450 \\
50 \text { to } 450 \\
50 \text { to } 325 \\
200 \text { to } 360 \\
140 \text { to } 350 \\
110 \text { to } 300 \\
300 \text { to } 470\end{array}$ \\
\hline
\end{tabular}

a Determined on a constant-speed spring-balance testing machine, $20-1 \mathrm{~b}$ range, in accordance with Federal Specification $\mathrm{ZZ}-\mathrm{R}-601 \mathrm{a}$, Section II-5. range, in accordance with Federal specification $Z Z-R-601 a$,

b Specimens of samples 4405 and 4409 were not in satisfactory condition to make tensile tests.

films were dried in a vacuum at room temperature for $16 \mathrm{hr}$ prior to use in the experiments.

The results of the experiments with the nylon samples are presented in table 7 . Only water, carbon dioxide, and ethanol were found in the volatile products obtained from specimens of sample 4406 at $30^{\circ} \mathrm{C}$ with and without exposure to ultraviolet radiant energy (experiments 1 and 2 ). In experiment 3, a specimen of sample 4406 was dried in vacuum and then exposed as in experiment 1 ; the loss in weight was markedly less $(0.2 \%$, compared to $2.6 \%$ ). It is apparent that part of the changes in properties observed in experiments 1,2 , and 3 can be attributed to the loss of absorbed water. Loss of the absorbed water causes the films to become brittle and crack readily.

Specimens of sample 4406 were exposed to ultraviolet radiant energy at $35^{\circ}$ and $50^{\circ} \mathrm{C}$ for $20 \mathrm{hr}$ (experiments 4 and 5). Water, carbon dioxide, ethanol, and hydrocarbons were found in the volatile products from these experiments. Carbon dioxide, water, ethanol, and hydrocarbons were obtained in all the experiments with specimens of samples 4407 and 4409 (experiments 9 to 13).

Carbon monoxide was evolved in all the experiments in which the specimens were exposed at temperatures of $90^{\circ}$ to $100^{\circ}$ C. Hydrocarbons were found in all experiments in which carbon monoxide 


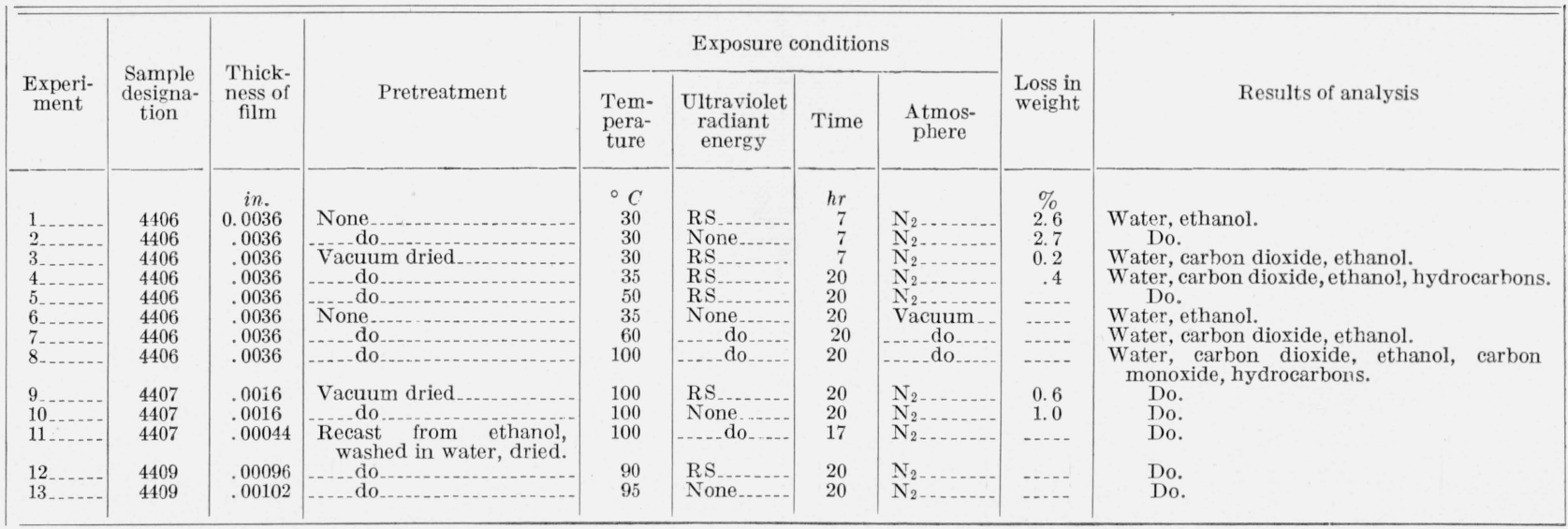

was detected and in experiments 4,5 , and 13 , in which no carbon monoxide was found.

It is apparent that a large part of the water given off in experiments $1,2,6,7,8,11,12$, and 13 is absorbed water. However, the results of experiments $3,4,5,9$, and 10 indicate that some of the water is bound more strongly than normally absorbed water, since it was not removed by vacuum drying; the amount appears to be slightly greater for sample 4407 than for sample 4406 .

A more detailed analysis of two experiments, 12 and 13 , is presented in table 8 . More than 15 individual hydrocarbon compounds were detected in each case. The results also indicate that when the proportion of carbon dioxide is high, no detectable quantity of carbon monoxide was found. When carbon monoxide was found, the proportion of carbon dioxide was lower than in the former case. The principal component in the volatile products in all experiments was water. This compound reduces the sensitivity and accuracy of the mass spectrometric analysis markedly and for this reason the hydrocarbons are not reported separately.

TABLE 8. Mass spectrometric analysis of volatile products obtained in experiments 12 and 13

\begin{tabular}{|c|c|c|}
\hline Component & $\begin{array}{l}\text { Experiment } \\
12,20 \mathrm{hr} \text { ul- } \\
\text { traviolet }\end{array}$ & $\begin{array}{c}\text { Experiment } \\
13,20 \mathrm{hr} \text { at } \\
95^{\circ} \mathrm{C}\end{array}$ \\
\hline Carbon dioxide. & $\begin{array}{c}\text { Mole percent a } \\
24\end{array}$ & $\begin{array}{c}\text { Mole percent a } \\
71\end{array}$ \\
\hline $\begin{array}{l}\text { Ethanol } \\
\text { Carbon monoxide and nitrogen } \mathrm{b}\end{array}$ & $\begin{array}{r}7 \\
63\end{array}$ & \\
\hline Nitrogen $b$ & $\begin{array}{l}00 \\
--\end{array}$ & $1 \overline{6}$ \\
\hline $\begin{array}{l}\text { Organic compounds, mainly hydrocar- } \\
\text { bons }\end{array}$ & 6 & \\
\hline
\end{tabular}

a On a water-free basis. The principal component in the volatile products was water.

$\mathrm{b}$ These experiments were performed in a nitrogen atmosphere.

\section{Pyrolysis}

With S. L. Madorsky, S. Straus, and L. A. Wall

Polyamide samples 4407 and 4409 were pyrolyzed at $400^{\circ} \mathrm{C}$, the products separated into fractions, and the gaseous products analyzed with the mass spectrometer. These experiments were made (a) to obtain reference patterns to assist in the interpretation of the mass spectrometric analysis patterns of the products obtained on exposure to heat and to ultraviolet radiant energy, and (b) to determine what bonds are broken when nylon molecules are ruptured by heat.

Specimens of nylon samples 4407 and 4409 weighing approximately $40 \mathrm{mg}$ were conditioned at $150^{\circ} \mathrm{C}$ for $2 \mathrm{hr}$ in a vacuum of about $10^{-6} \mathrm{~mm}$ $\mathrm{Hg}$ to remove sorbed water and gases. The specimens were then heated to $400^{\circ} \mathrm{C}$ for $30 \mathrm{~min}$ in a vacuum of about $10^{-6} \mathrm{~mm} \mathrm{Hg}$ and the products fractionated in the apparatus shown schematically in figure 4. The material in the form of sections of thin film about 2 to $5 \mathrm{~mm}$ square, was placed on the platinum tray, $\mathrm{H}$, shown in the bottom of the tube on the extreme right and heated by the platinum wire coil, $K$. A solid residue remaining in the tray was designated fraction I. Most of the volatile fractions condensed on the walls of the heating chamber and on the liquid air condenser, B. The material volatile at the temperature of liquid air (about $-190^{\circ} \mathrm{C}$ ) was collected in the gaseous fraction receiver and designated as fraction $\mathrm{V}$. After the pyrolysis, the liquid air was removed from condenser $B$ and replaced with a carbon dioxideacetone mixture (about $-78^{\circ} \mathrm{C}$ ). The volatile fraction was collected at liquid air temperature and designated as fraction IIIA. The carbon dioxideacetone mixture was then removed and the condenser allowed to come to room temperature (About $\left.25^{\circ} \mathrm{C}\right)$. The volatile fraction was also collected at liquid air temperature and designated as fraction IIIB. The waxlike material remaining on the condenser and on the walls of the heating chamber was designated as fractions II and IV, respectively. The apparatus and the procedure are described in more detail in [14]. The results of the analyses are presented in table 9 . 
TABLE 9. Results of pyrolyses of polyamides and mass spectrometric analyses of volatile fractions

\begin{tabular}{|c|c|c|c|c|c|}
\hline \multirow{3}{*}{ Fraction } & \multirow{3}{*}{ Product } & \multicolumn{4}{|c|}{$\begin{array}{l}\text { Weight percentage of } \\
\text { original specimen }{ }^{\mathrm{a}}\end{array}$} \\
\hline & & \multicolumn{2}{|c|}{ Polyamide 4407} & \multicolumn{2}{|c|}{ Polyamide 4409} \\
\hline & & Exp. 1 & Exp. 2 & Exp. 3 & Exp. 4 \\
\hline I & $\begin{array}{l}\text { Residue; dirty-brown flakes, } \\
\text { slightly soluble in warm } \\
\text { ethanol. }\end{array}$ & 7.87 & 5.89 & 2.09 & 2.37 \\
\hline \multirow[t]{4}{*}{$\begin{array}{l}\text { II and } \\
\text { IV. }\end{array}$} & $\begin{array}{l}\text { Semiliquid resinous mass, } \\
\text { fairly soluble in warm } \\
\text { ethanol. }\end{array}$ & 86. 71 & 88.77 & 92.87 & 93.12 \\
\hline & $\left(\begin{array}{l}\text { Volatile at }-75^{\circ} \mathrm{C} \\
\text { Carbon dioxide }\end{array}\right.$ & $\begin{array}{l}\text { 1. } 72 \\
1.67\end{array}$ & $\begin{array}{l}1.80 \\
1.75\end{array}$ & $\begin{array}{r}0.19 \\
.18\end{array}$ & $\begin{array}{r}0.59 \\
.56\end{array}$ \\
\hline & Hydrocarbons........ & 0.05 & 0.05 & .00 & .02 \\
\hline & Methane & .00 & .01 & .00 & .00 \\
\hline \multirow{14}{*}{ IIIA .... } & Ethane......... & .00 & .01 & .00 & .01 \\
\hline & Propane....... & .00 & .01 & .00 & .00 \\
\hline & Butanes......... & .00 & .00 & .00 & .01 \\
\hline & Ethylene & .00 & .01 & .00 & .00 \\
\hline & Butenes............ & .00 & .01 & .00 & .00 \\
\hline & ( Cyclopentanone & .00 & .00 & .01 & .01 \\
\hline & (Volatile at room temperature & 3.48 & 3.34 & 4. 56 & b 3.69 \\
\hline & Carbon dioxide & 1.48 & 1.89 & 4. 38 & -...- \\
\hline & Hydrocarbons.............. & 0.39 & 0.30 & 0.18 & -..- \\
\hline & Methane & .00 & .00 & .02 & $\ldots$ \\
\hline & Ethane & .01 & .00 & .01 & ...- \\
\hline & Butanes........ & .03 & .03 & .00 & $-\ldots$ \\
\hline & Pentanes......... & .00 & .00 & .02 & ...- \\
\hline & $n$-Hexane & .00 & .00 & .02 & .... \\
\hline \multirow[t]{13}{*}{ IIIB $\ldots$} & Ethylene.............. & .00 & .00 & .03 & -..- \\
\hline & Propene........ & .07 & .05 & .00 &..- \\
\hline & Butenes.......... & .12 & .13 & .03 & .... \\
\hline & Pentenes.......... & .03 & .03 & .01 & -... \\
\hline & Cyclohexene..... & .02 & .00 & .00 & .... \\
\hline & Pentadiene & .00 & .03 & .00 & .... \\
\hline & Cyclopentadiene......... & .00 & .02 & .00 & -..- \\
\hline & Benzene & .11 & .01 & .00 &..- \\
\hline & ( Cyclopentanone & 1.61 & 1.15 & .04 & .... \\
\hline & Gaseous fraction & 0.22 & 0.20 & c. 29 & .23 \\
\hline & Carbon monoxide & .09 & .12 & ...- & .00 \\
\hline & Carbon dioxide & .13 & .07 & ...- & .20 \\
\hline & Methane & .00 & .01 & $-\ldots$ & .03 \\
\hline \multirow{5}{*}{ V } & Summary on dry basis: & & & & \\
\hline & Carbon monoxide & .09 & .12 & .00 & .00 \\
\hline & Carbon dioxide & 3.28 & 3. 71 & 4. 56 & --- \\
\hline & $\begin{array}{l}\text { Hydrocarbons } \\
\text { Cyclopentanone }\end{array}$ & $\begin{array}{l}0.44 \\
1.61\end{array}$ & $\begin{array}{l}0.36 \\
1.15\end{array}$ & $\begin{array}{r}0.18 \\
.05\end{array}$ & -1 \\
\hline & Water-a & 1.67 & 1. 66 & $\dot{<} .1$ & $<.1$ \\
\hline
\end{tabular}

a On a dry basis, except for percentage of water.

b Peaks on mass spectrometer off scale; detailed analysis not possible.

- Sample tube broken.

The total amount of products in fractions IIIA, IIIB, and V from nylon samples 4407 and 4409 is about the same, 5 percent (by weight) of the original sample. However, a comparison of the distribution of the amounts of the various compounds among the fractions shows that the degradation of the two types of nylons is not the same, although similar. It is interesting to note that the solid residue obtained with sample 4409 is much less than that obtained with sample 4407 . The semiliquid resin obtained with sample 4409 is greater than that obtained with sample 4407. The total solid and semiliquid materials obtained with both samples are not very different.

Sample 4407 produced appreciable amounts of carbon dioxide and cyclopentanone, and smaller amounts of carbon monoxide and hydrocarbons. Sample 4409 produced an appreciable amount of carbon dioxide and no carbon monoxide. The amounts of hydrocarbon and particularly cyclopentanone produced by sample 4409 were appreciably less than those produced by sample 4407 .

The production of the cyclopentanone on heating the nylon samples was not expected. However, it is well known [15] that cyclopentanone can be synthesized in high yields by the thermal decomposition of adipic acid in accordance with the following reaction:<smiles>C[13CH]CCC(=O)O</smiles>

Adipic acid<smiles>O=CCC1CCCC1</smiles>

\section{Cyclopentanone}

(bp $130.6^{\circ} \mathrm{C}$ )

A sample of adipic acid was pyrolyzed, and the products formed were analyzed with the mass spectrometer. The pattern obtained matched the pattern of cyclopentanone obtained from the products of the pyrolysis of the nylon samples.

The distribution of the total oxygen in the gaseous products from both polyamide samples is shown in table 10. No significance should be attached to the agreement between the total figures, since it is observed from studying the data of the individual experiments that these results could not be duplicated this closely. The significant point is the difference in distribution of the oxygen between the two polymers.

TABLE 10. Distribution of oxygen in gaseous products formed on pyrolysis of polyamides

\begin{tabular}{|c|c|c|c|c|}
\hline \multirow{2}{*}{ Source of oxygen } & \multicolumn{4}{|c|}{ Amount of oxygen in- } \\
\hline & \multicolumn{2}{|c|}{ Sample 4407} & \multicolumn{2}{|c|}{ Sample 4409} \\
\hline $\begin{array}{l}\text { Carbon dioxide } \\
\text { Carbon monoxide } \\
\text { Cyclopentanone. } \\
\text { Water }\end{array}$ & $\begin{array}{c}\text { Mole } \\
\text { percent } \\
2.55 \\
0.06 \\
.30 \\
1.48\end{array}$ & $\begin{array}{c}\text { Percent. } \\
\text { age of total } \\
16.8 \\
0.4 \\
2.0 \\
9.7\end{array}$ & $\begin{array}{c}\text { Mole } \\
\text { percent } \\
3.33 \\
0.00 \\
.01 \\
<.09\end{array}$ & $\begin{array}{c}\text { Percentage } \\
\text { of total } \\
23.5 \\
0.0 \\
.0 \\
<.6\end{array}$ \\
\hline Total_ & 4. 39 & 28.9 & 3.43 & 24.1 \\
\hline
\end{tabular}

The results of an elemental analysis of the nylon samples presented in table 11 shows that the amount of oxygen absorbed by this polymer is negligible. Consequently, all the oxygen in the volatile products must come from the polymer and water in the polymer.

It is interesting to note that there were no nitrogen compounds in the gaseous fractions as might be expected. 


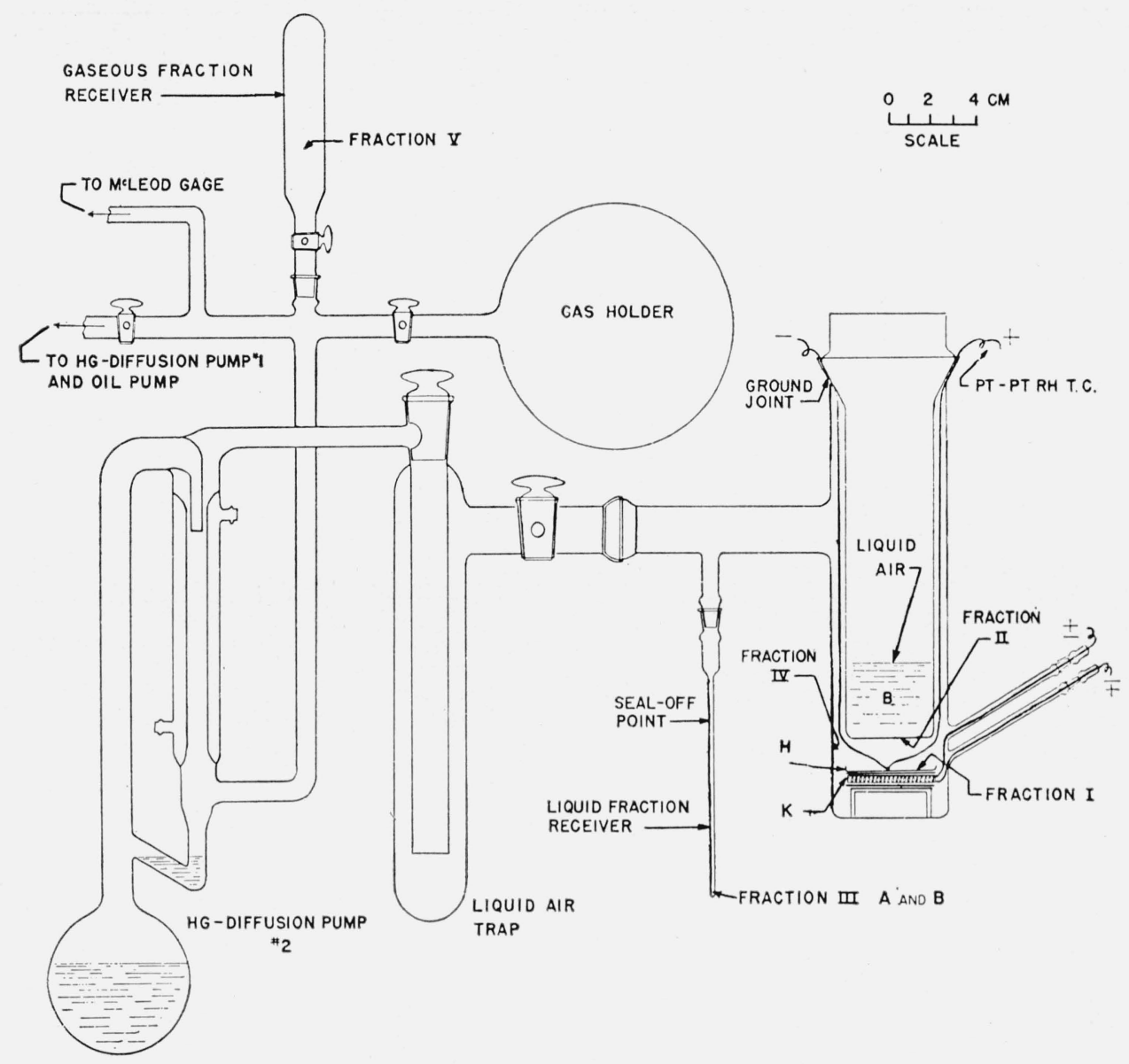

Figure 4.-Molecular still for pyrolysis of high polymers.

TABLE 11. Elemental analysis of polyamides

\begin{tabular}{|c|c|c|c|c|c|}
\hline \multirow{2}{*}{$\begin{array}{c}\text { Sample } \\
\text { designa- } \\
\text { tion }\end{array}$} & \multirow{2}{*}{ Source } & \multicolumn{4}{|c|}{ Elemental analysis } \\
\hline & & Carbon & $\begin{array}{c}\text { Hydro- } \\
\text { gen }\end{array}$ & $\begin{array}{c}\text { Nitro- } \\
\text { gen }\end{array}$ & $\underset{\text { gen }}{\text { Oxy- }}$ \\
\hline $4409 \mathrm{~b}$ & $\left\{\begin{array}{l}\text { Chemical analysis } \\
\text { Caluecatated dry } \\
\text { Calculated conditioned a } \\
\left\{\begin{array}{l}\text { Chemical analysis } \\
\text { Calculated dry } \\
\text { Calculated conditioned }\end{array}\right. \\
\end{array}\right.$ & $\begin{array}{c}\text { Percent } \\
63.1 \\
63.7 \\
62.1 \\
64.2 \\
64.8 \\
63.2\end{array}$ & $\begin{array}{c}\text { Percent } \\
9.6 \\
9.7 \\
9.7 \\
10.2 \\
10.0 \\
10.0\end{array}$ & $\begin{array}{c}\text { Percent } \\
12.1 \\
12.4 \\
12.1 \\
11.4 \\
11.8 \\
11.5\end{array}$ & $\begin{array}{c}\text { Percent } \\
15.2 \\
14.2 \\
16.1 \\
14.2 \\
13.5 \\
15.4\end{array}$ \\
\hline
\end{tabular}

a Water content at $25^{\circ} \mathrm{C}$ and 50-percent relative humidity assumed to be 2.5 percent of total weight.

Composition estimated to be 60 percent of 66 salt, 20 percent of 610 salt, and 20 percent of caprolactam.

\section{Ultraviolet Spectrometry}

With M. J. Reiney and L. A. Dunlap

The ultraviolet transmission characteristics of polyamides 4407 and 4409 , subjected to various controlled conditions of heat, ultraviolet radiant energy, and ambient atmosphere, were determined with a model DU Beckman photoelectric quartz spectrophotometer, range 220 to $1,000 \mathrm{~m} \mu$.
A critical factor in comparative ultraviolet transmission measurements is the thickness of the specimens. The thicknesses of specimens of sample 4407 were measured; one set of the films was heated in air at $100^{\circ} \mathrm{C}$ for $20 \mathrm{hr}$, and another set was exposed to ultraviolet radiant energy from an RS sunlamp for $24 \mathrm{hr}$ at $45^{\circ} \mathrm{C}$ in a nitrogen atmosphere. The changes in thickness were less than 0.00004 in. The maximum change in ultraviolet transmission that could be attributed to this change in thickness was calculated to be 2 percent at $280 \mathrm{~m} \mu$, which is considerably less than the observed changes in ultraviolet transmission.

The ultraviolet transmission curves of untreated films of the polyamides show an absorption band between wavelengths of 260 and $330 \mathrm{~m} \mu$ with maximum absorption at approximately $280 \mathrm{~m} \mu$ (figs. 5, $6,7)$. Transmission in this region is increased by exposure to ultraviolet radiant energy, as shown by curve B of figures 5 and 6 . The greater portion of the absorption band is eliminated during the first hour of exposure to the ultraviolet radiant energy and the band is entirely eliminated after exposure for $20 \mathrm{hr}$. Heat alone tends to decrease the over-all transmission of the films, although the shape of the 


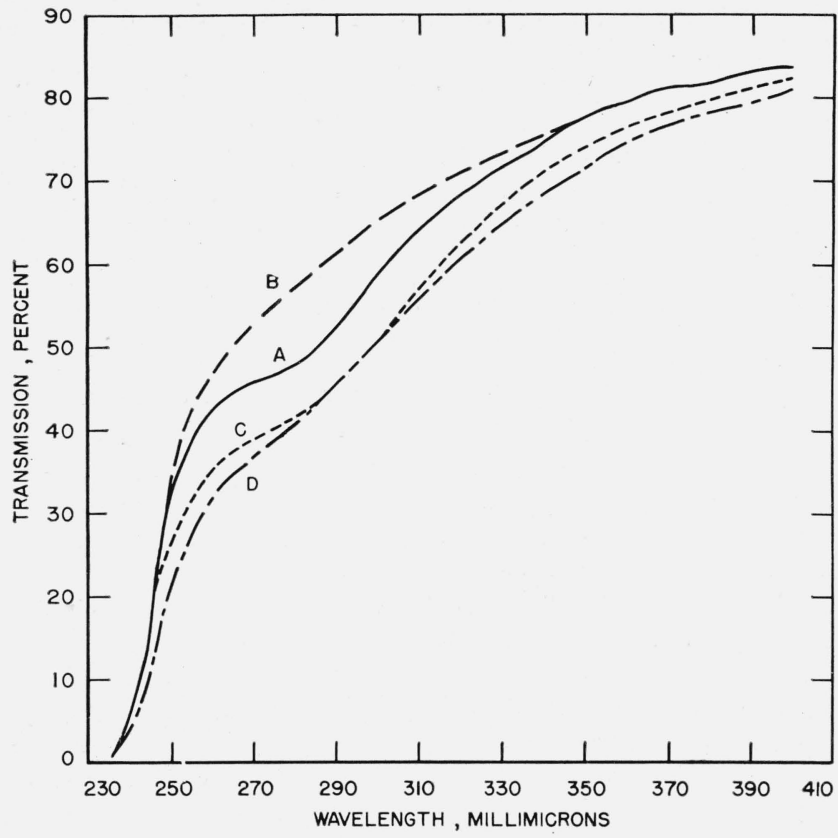

FiguRE 5. Ultraviolet transmission of polyamide 4.407 before and after exposure to ultraviolet radiant energy and/or heat.

A, Untreated $4407 ; \mathrm{B}$, after 20 -hr exposure to ultraviolet at $50^{\circ} \mathrm{C}$ in nitrogen $\mathrm{C}$, after $20 \mathrm{hr}$ at $95^{\circ} \mathrm{C}$ in air oven; D, after 20 -hr exposure to ultraviolet at $50^{\circ} \mathrm{C}$ in nitrogen and $20 \mathrm{hr}$ at $95^{\circ} \mathrm{C}$ in air oven.

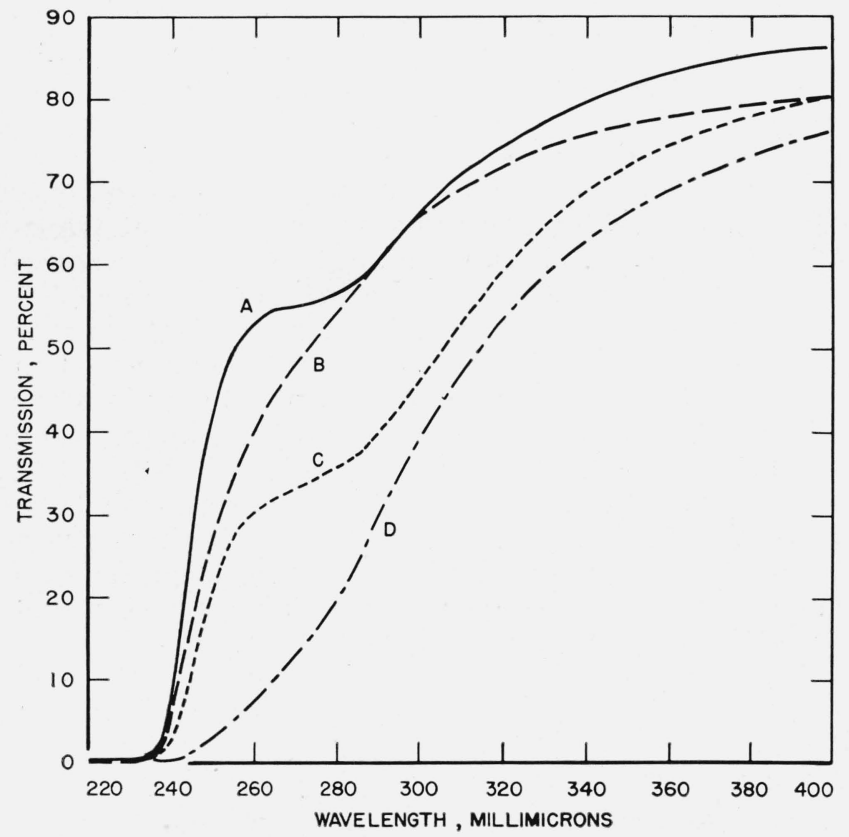

FIGURE 7. Ultraviolet transmission of polyamides 4407 and 4409 before and after 120-hr accelerated weathering.

A, Untreated 4407; B, 4407 after accelerated weathering; C, untreated 4409; D, 4409 aiter accelerated weathering.

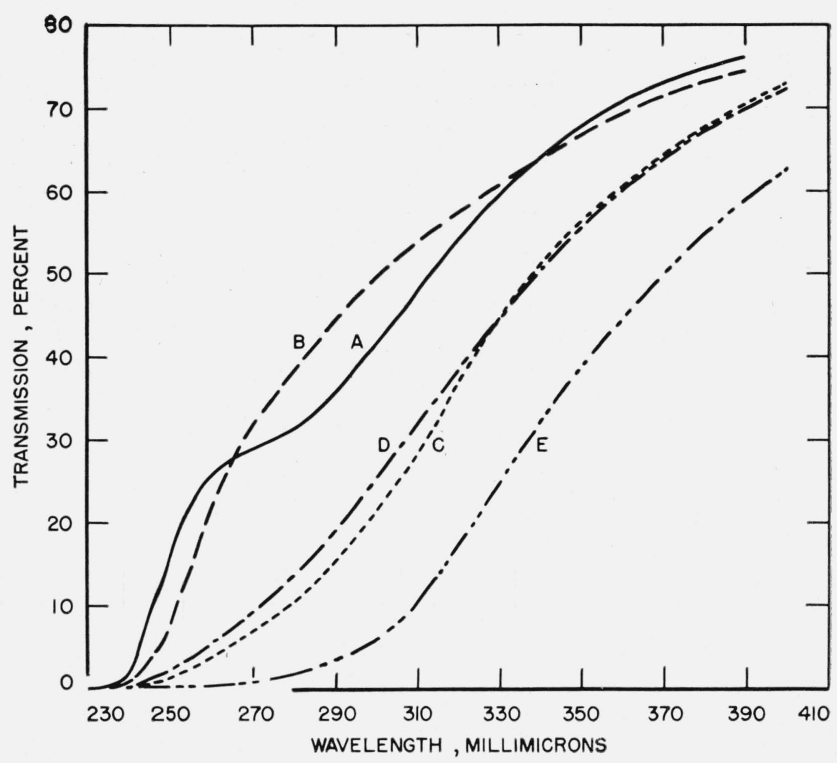

FIGURE 6. Ultraviolet transmission of polyamide 4409 before and after exposure to ultraviolet radiant energy and/or heat.

A, Untreated 4409; B, 25-hr exposure to ultraviolet at $40^{\circ} \mathrm{C}$ in nitrogen; C, after $20 \mathrm{hr}$ at $100^{\circ} \mathrm{C}$ in air oven; D, after 25 -hr exposure to ultraviolet radiant energy at $40^{\circ} \mathrm{C}$ in nitrogen and 20 -hr heat at $100^{\circ} \mathrm{C}$ in air oven; $\mathrm{E}$, after 95 -hr heat at $100^{\circ} \mathrm{C}$ in air oven.

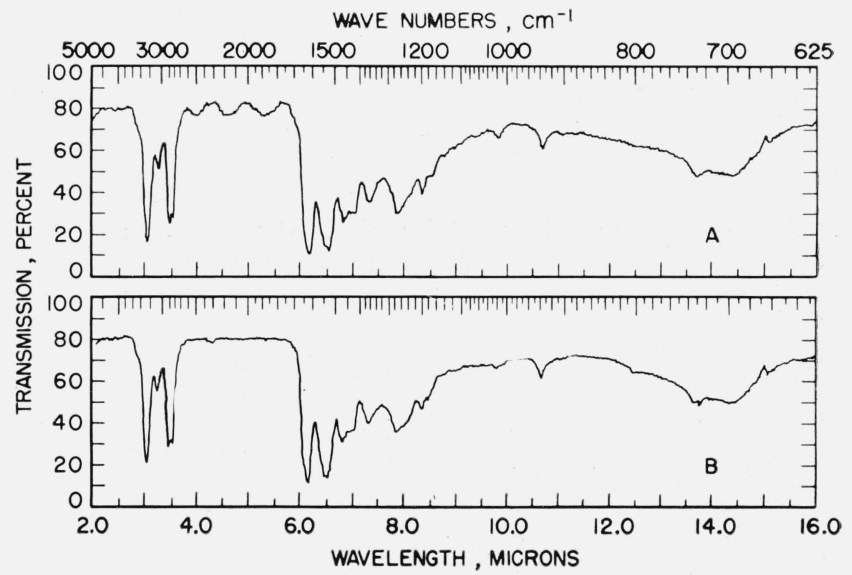

FIGURE 8. Infrared transmission of untreated polyamides 4407 and 4409 .

A, 4407, 0.0008 in. thick; B, 4409, 0.0009 in. thick. 
curve for sample 4407 is not changed, as shown in curve C of figure 5. Treatment with ultraviolet radiant energy followed by heating results in an ultraviolet curve representative of the effects of both treatments, as shown by curve $\mathrm{D}$ of figures 5 and 6 .

Specimens of nylon samples were subjected to a $120-\mathrm{hr}$ accelerated weathering test. The effects of this treatment, shown in figure 7 , are similar to the combined effects of separate exposures to ultraviolet radiant energy and to heat. The decrease in transmission in sample 4409 is much greater than that in sample 4407.

After 3 weeks at room conditions, treated specimens of sample 4407 showed changes of less than 1 percent in ultraviolet transmission values from those made immediately after the treatments.

Experiments were made with samples 4407 and 4409 to determine the effect of absorbed water and ethanol on the ultraviolet transmission characteristics. Immersing specimens in water at $60^{\circ} \mathrm{C}$ for $72 \mathrm{hr}$ caused the absorption band for sample 4407 to become stronger at approximately $280 \mathrm{~m} \mu$ and had no appreciable effect on the absorption for sample 4409. The wet specimens were subjected to vacuum drying at $40^{\circ} \mathrm{C}$ for $22 \mathrm{hr}$, which caused a slight decrease in the transmission of both samples; the absorption band for sample 4407 became more pronounced and that for sample 4409 remained about the same shape. The dried specimens were next immersed in 95-percent ethanol for $17 \mathrm{hr}$, which resulted in a marked increase in transmission for both samples; the shape of the curve for sample 4407 remained about the same, and the absorption band for sample 4409 became more pronounced.

Exposure to ultraviolet radiant energy for $2.5 \mathrm{hr}$ was nearly sufficient to remove the absorption band for both the untreated specimens of samples 4407 and 4409 and specimens soaked in water for $72 \mathrm{hr}$ or in ethanol for $17 \mathrm{hr}$.

Specimens of samples 4407 and 4409 that had been exposed to $20 \mathrm{hr}$ of ultraviolet radiant energy were immersed in water and in ethanol, respectively, for $72 \mathrm{hr}$. The absorption band in the curves for the untreated specimens did not return. Even films recast from ethanol solutions of specimens that had been exposed to $20 \mathrm{hr}$ of ultraviolet radiant energy did not show the absorption band.

No differences were observed in the results of experiments conducted in oxygen and nitrogen, respectively.

\section{Infrared Spectrometry}

\section{With M. J. Reiney and E. K. Plyler}

Recast polyamide films were subjected to heat and to ultraviolet radiant energy and the infrared transmission characteristics measured before and after exposure to determine changes in chemical structure. A change of at least 2 percent in the amount of a chemical group is required for detection by the infrared spectrometers used in this investigation. Recast films were used for this phase of the investigation because the original films were too thick to distinguish individual characteristic transmission bands.

Typical infrared transmission curves obtained with a Baird recording spectrophotometer are shown in figure 8. Curves $\mathrm{A}$ and $\mathrm{B}$ show that polyamide samples 4407 and 4409 give essentially the same infrared transmission, although there is a difference in the number of methylene groups in the repeating units of the polymer chain.

Treatment of the polyamide films by heating and by exposure to RS sunlamp radiant energy for various periods up to 2 weeks in the presence of air and in nitrogen produced no extensive changes in the infrared spectrum of the films, that is, no new bands were created or former bands destroyed as a result of the treatments. Slight decrease in absorption at $3.2 \mu$ suggested possible changes in intermolecular bridging in some experiments; but the slight changes observed were considered to be within experimental error.

Specimens were exposed for periods of $120 \mathrm{hr}$ and $217 \mathrm{hr}$ to accelerated weathering. The $217-\mathrm{hr}$ test consisted of $179 \mathrm{hr}$ of exposure to ultraviolet radiant energy and $38 \mathrm{hr}$ of exposure to fog. The test was stopped at $217 \mathrm{hr}$ because the films were water spotted, had white spots of undetermined origin, and were split. No changes in appearance were observed in the $120-\mathrm{hr}$ test. The infrared spectrum after 217-hr exposure showed that no appreciable changes in chemical structure occurred as a result of this treatment. The slight decrease in transmission observed between 2.8 and $16.0 \mu$ is attributed to experimental error.

Specimens of sample 4407 were exposed outdoors for 2 months (Feb. to Apr.). At the end of this period, the films were torn, the surfaces were badly scarred, and particles of dirt were imbedded in the film. The specimens were dissolved in warm ethanol, the solution centrifuged to remove the dirt particles, and recast films made by the usual technique. No appreciable changes occurred in chemical structure as a result of this treatment.

The results obtained with nylon sample 4409 parallel very closely those observed with nylon sample 4407. It was observed in the accelerated weathering treatment that the splitting of the films of sample 4409 was more severe than the splitting of the films of sample 4407.

Film specimens of the polyamide samples were soaked in ethanol, removed, and allowed to dry in air, and the infrared transmission characteristics measured. No appreciable changes from the original films were observed.

\section{Viscosity}

\section{With C. C. Chang, N. Dominguez, and S. G. Weissberg}

Polyamide sample 4410 was subjected to controlled conditions of heat, ultraviolet radiant energy, and relative humidity, and to outdoor exposure and the degradation of the polymer chains determined from the measurement of the viscosities of dilute solutions of the exposed nylon specimens in $m$-cresol. This 
procedure can be used to determine whether or not the polymer chains are broken or crosslinked but will not reveal any other changes in chemical structure $[2,5]$. The viscosities of the solutions were measured at $30^{\circ} \mathrm{C}$, using calibrated Ostwald-Fenske viscometers $[16,17]$. Duplicate parallel runs were made, using the average of five efflux time measurements determined to the nearest 0.1 sec.

The viscosity data for the various nylon specimens are presented in table 12 and figures 9 to 11, inclusive. Not enough data were obtained on the treated nylon specimens to determine the curvatures of the plots of $\left(\ln \eta_{r}\right) / c$ versus $c$ and of $\eta_{s p} / c$ versus $c$. Since these plots for the untreated specimens show distinct curvature, the plots have been drawn as curved lines, as shown in figures 10 and 11 , simply to indicate the general tendency, but they are by no means representative of the exact shape of the plots.

The relation between the intrinsic viscosity of polyamide sample 4410 and the time of exposure to heat and to ultraviolet radiant energy is shown in figure 12. This shows that the viscosity is decreased as the period of exposure to the degradation conditions is increased.

A study of the moisture sorption of nylon samples $4406,4407,4408,4409$, and 4410 showed that at 50 -percent relative humidity the films contained 2 to 3 percent of water. The data observed for the materials used in this study do not show increased water sorption with decreased crystallinity. However, the levels of crystallinity were not determined experimentally, and these results may be indicative of a balancing factor in the changing total concentration of polar groups. It has been reported that for a given concentration of dipoles of a certain type increase in crystallinity markedly decreases moisture sorption in polyamides $[18,19]$. As these types of nylon with varying compositions and degrees of crystallinity all contain between 2 and 3 percent of water in equilibrium with a relative humidity of 50 percent, and as a reduction in the water content of

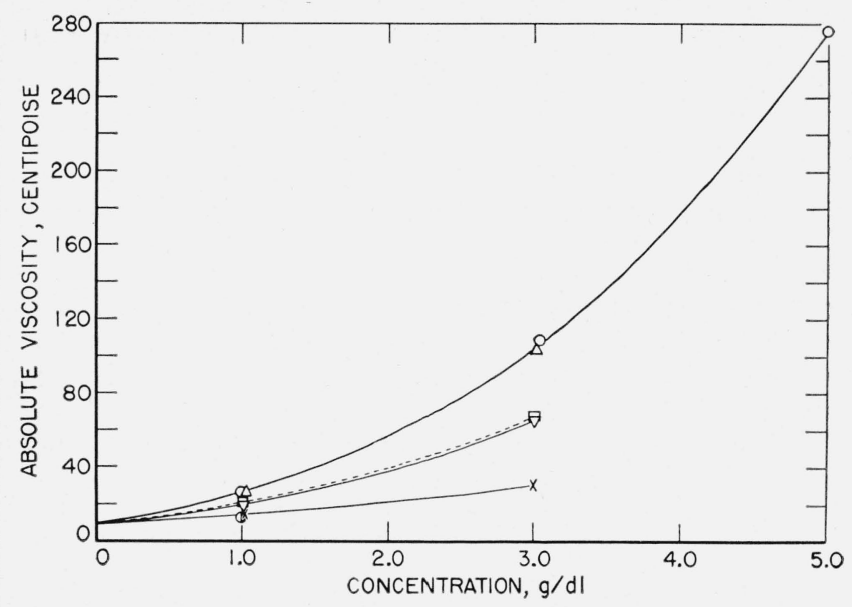

FIGURE 9. Relation between absolute viscosity and concentration of solutions of polyamide 4410.

$\triangle, A-1$, Undegraded, specimen $1 ; \bigcirc, A-2$, undegraded, specimen $2 ; \nabla, \mathrm{B}$, 22-hr ultraviolet; C, C, 168-hr ultraviolet; $\square, \mathrm{D}, 25 \mathrm{hr}$ at $105^{\circ} \mathrm{C} ; \mathrm{X}, \mathrm{E}, 169 \mathrm{hr}$ at $105^{\circ} \mathrm{C} ; \square, \mathrm{F}, 2$ months outdoors; curves $\mathrm{D}$ and $\mathrm{F}$ are identical.

approximately 2 percent causes the film to become brittle, it is reasonable to assume that treated specimens that remain intact have water contents of the same order of magnitude.

It is interesting to examine the consequences of a hypothesis that the lower relative viscosities of specimen $\mathrm{B}$, as compared with solutions of specimen $\mathrm{A}$, are due solely to an increase in water content of $\mathrm{B}$, as compared with the water content of $\mathrm{A}$. Calculation shows that specimen B would require 30-percent moisture to give the results obtained. Therefore, the hypothesis that the lowered viscosity is due only to an increase in water content of the degraded nylon requires an unreasonably high water content.

These results indicate that the effect of water content in the viscosity study is negligible and recalculation of the viscosity results to correct for moisture content is unnecessary.

TABLE 12. Viscosity data for solutions of polyamide 4410 in m-cresol

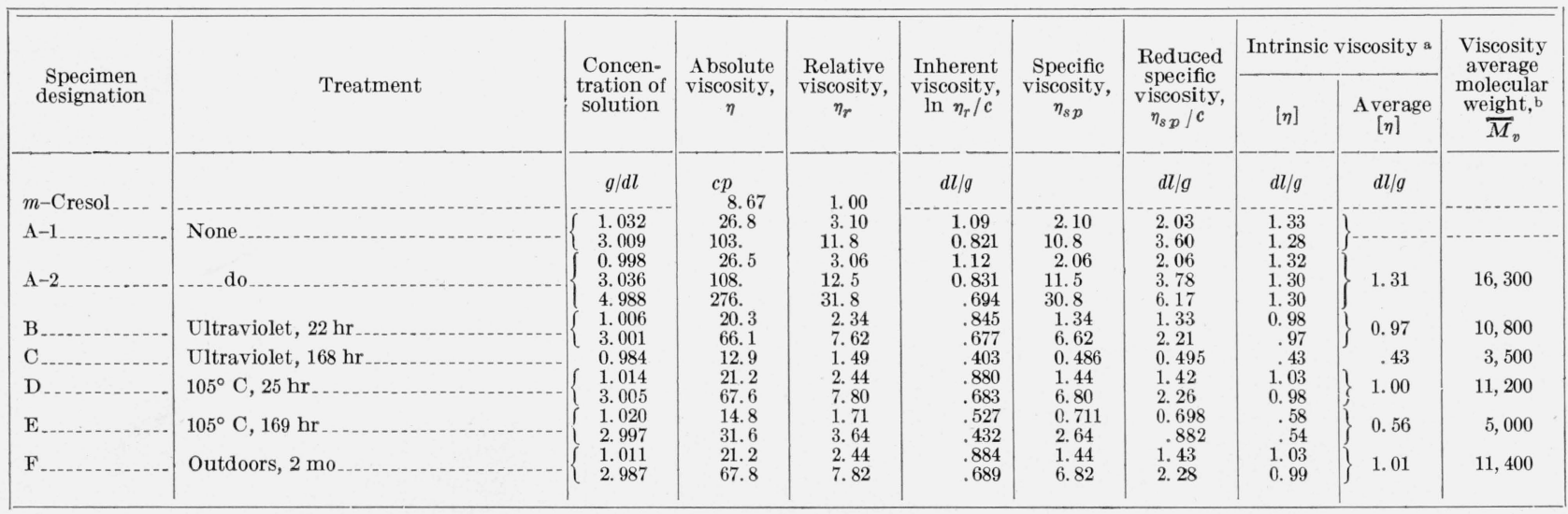

a The intrinsic viscosities were calculated as $3\left(\eta_{r} 1 / 3-1\right) / c$, where $\eta_{r}$ is the relative viscosity and $c$ is the concentration in $g /$ dl. b Estimated viscosity average molecular weight [66] based on the applicability of Taylor's equation and on the use of a different. solvent, since the value for
intrinsic viscosity depends on the solvent [67]

$$
\overline{\boldsymbol{M}}_{v}=13,000[\eta] 1.39 ; 0.9[\eta] m \bullet \text { cresol }=[\eta] \text { formic acid }
$$




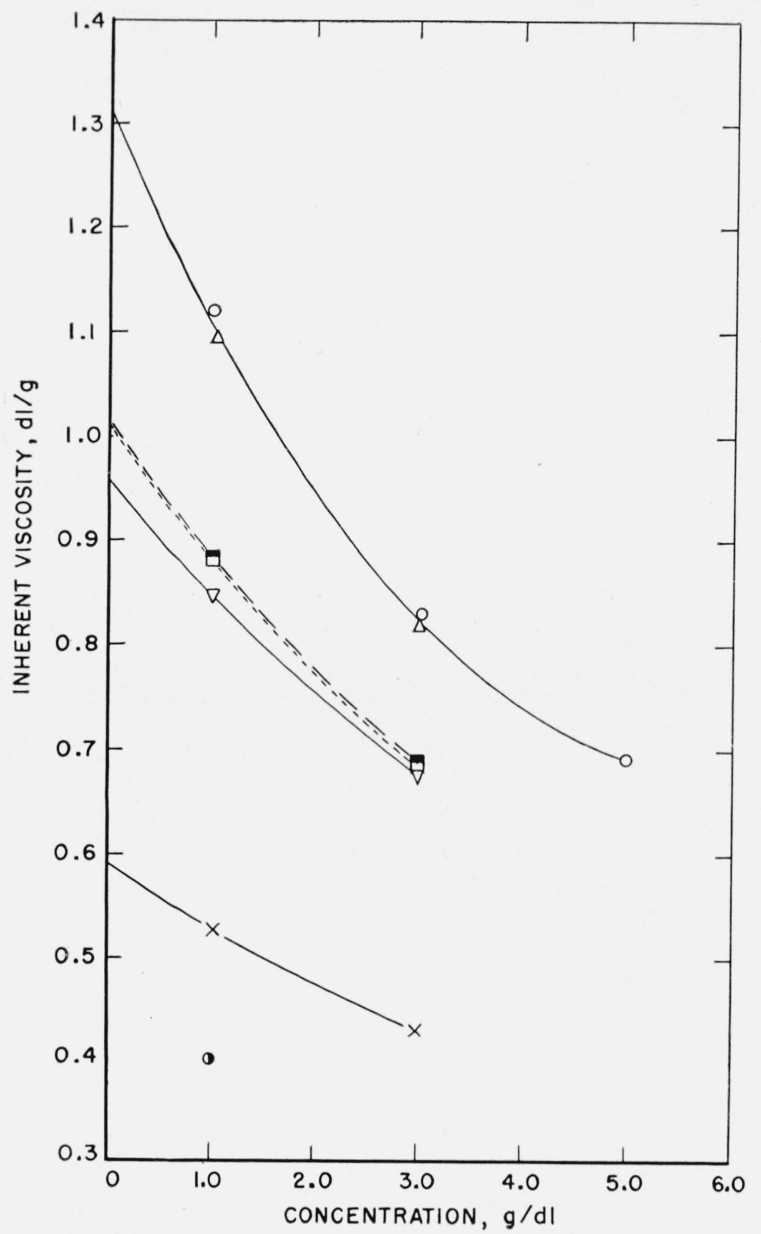

Figure 10. Relation between inherent viscosity and concentration of solutions of polyamide 4410. $\triangle$, A-1, Undegraded, specimen $1 ; \bigcirc, \mathrm{A}-2$, undegraded, specimen $2 ; \nabla, \mathrm{B}$,
22-hr ultraviolet; $\mathrm{C}, \mathrm{C}$ 168-hr ultraviolet; $\square, \mathrm{D}, 25 \mathrm{hr}$ at $105^{\circ} \mathrm{C} ; \mathrm{X}, \mathrm{E}, 169 \mathrm{hr}$ at $105^{\circ} \mathrm{C}$; $, \mathrm{F}, 2$ months outdoors.

\section{Light Microscopy}

\section{With C. P. Saylor}

The changes in films of polyamides as a result of exposure to natural and accelerated weathering were studied with a microscopical technique. Photomicrographs of untreated and treated samples 4406, $4407,4408,4409$, and 4410 were taken. Samples 4407 and 4409 were studied in greater detail to differentiate the two types and to compare their relative resistance to aging.

A petrographic microscope was used to examine the film specimens. Photomicrographs were taken under crossed nicols at magnifications of $\times 600$ and $\times 950$ (oil immersion lens), using a camera arrangement with a filament type lamp as the light source. Unless otherwise stated, a ground glass plate was used in the illuminator during the photographing. The heated specimens were exposed in a vacuum oven, "cracked" with dry air, at $87^{\circ} \mathrm{C}$.

A series of photomicrographs of specimens of nylon

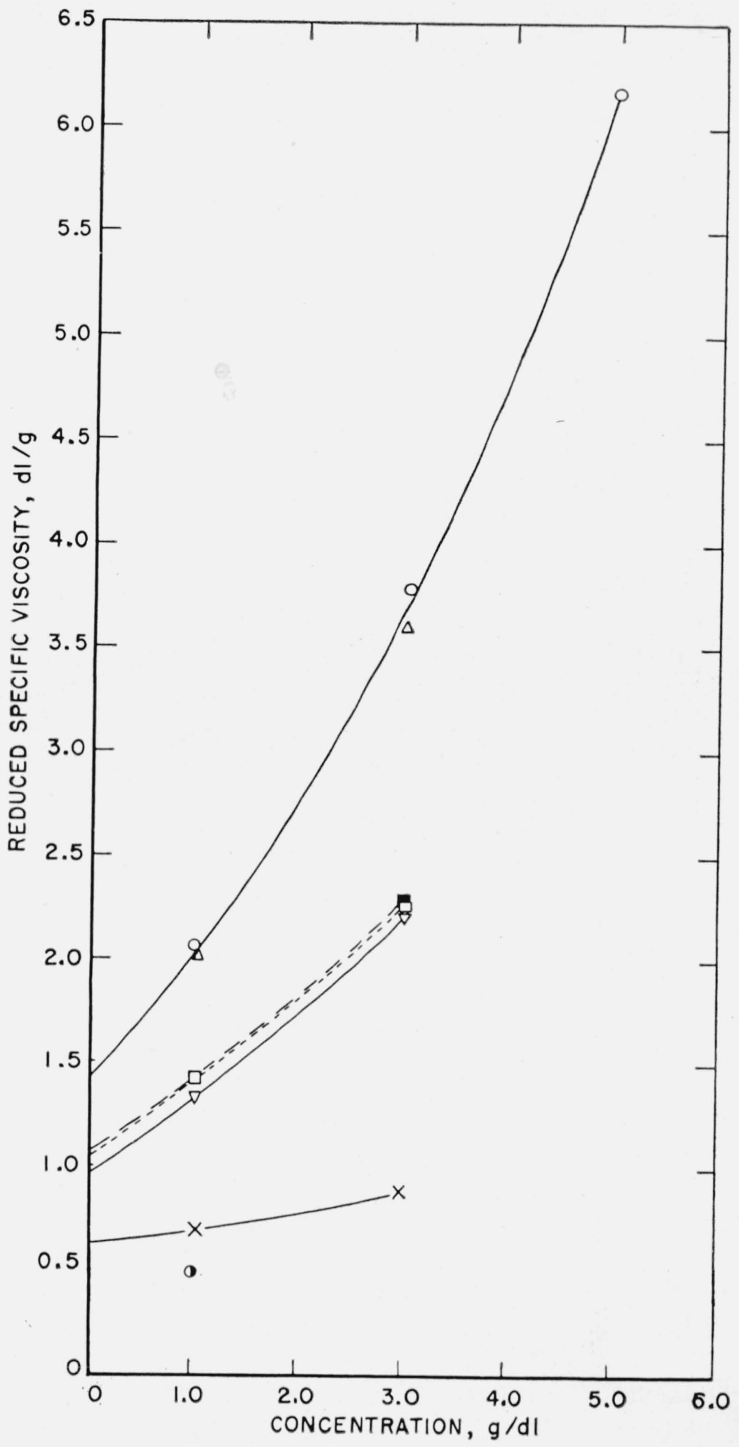

FIgURE 11. Relation between reduced specific viscosity and concentration of solutions of polyamide 4410.

$\triangle, \mathbf{A}-1$, Undegraded, specimen $1 ; \bigcirc, \mathbf{A}-2$, undegraded, specimen $2 ; \nabla, \mathbf{B}$

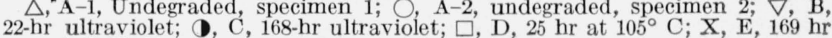
at $105^{\circ} \mathrm{C} ; \mathbf{D}, \mathrm{F}, 2$ months outdoors.

samples 4407 and 4409 before and after exposure to an accelerated weathering treatment and outdoors is shown in figure 13. These photographs were taken at a magnification of $\times 600$ with crossed nicols at extinction. No ground glass was used in the illuminator.

The photomicrograph of an unexposed specimen of sample 4407 is shown in plate $\mathrm{A}$ of figure 13. The grain structure of sample 4407 is smaller than that of sample 4409, as comparison of plates A and C shows. The specimen of sample 4407 that was exposed to the $120-\mathrm{hr}$ accelerated weathering test is shown in plate B. The dark spots, in this case, are attributed to dirt particles attracted by static charge to the surface of the film, or imbedded in the film. These films develop considerable charge when rubbed 


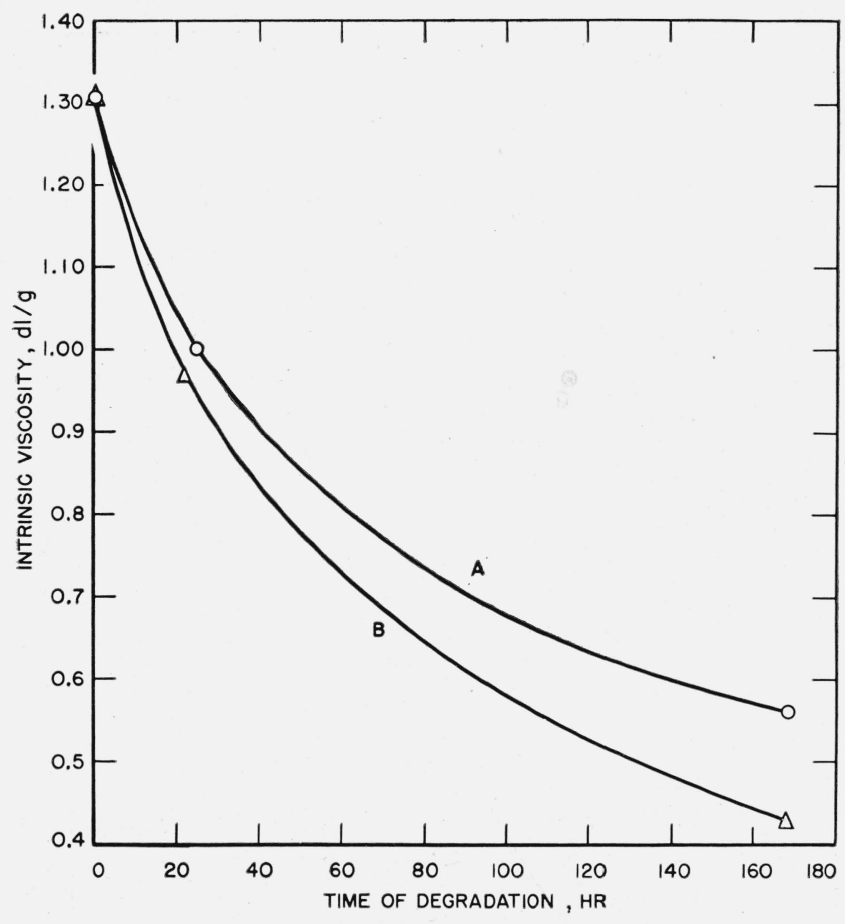

Figure 12. Effect of degradation conditions on intrinsic viscosity of polyamide 4410 .

$\mathrm{A}$, Heated in air oven at $105^{\circ} \mathrm{C}$; B, irradiated with ultraviolet from $\mathrm{S}-1$ in air at $60^{\circ} \mathrm{C}$. Value of intrinsic viscosity of sample weathered outdoors for 2 months was $1.01 \mathrm{dl} / \mathrm{g}$

with a cloth. Both dark and bright lines are observed in plate B. This is a result of the orientation of the specimen under the crossed nicols. These lines become alternately dark and bright as the stage of the microscope is rotated, thus changing the orientation of the film under the crossed nicols.

Comparison of plates $\mathrm{C}$ and $\mathrm{D}$ in figure 13 shows the effect of exposure of specimens of sample 4409 to the 120-hr accelerated weathering test. The density differences in the photomicrographs are not relevant in this series. Bright lines are shown to be dominant in the exposed specimens, particularly after outdoor exposure. Photomicrographs of a specimen of sample 4409 that was exposed outdoors for 2 months are shown in plates E and F. Photomicrograph F was taken with a first-order retardation plate.

At first it was thought that the bright lines in plates $\mathrm{E}$ and $\mathrm{F}$ in figure 13 were caused by scratches on the surface resulting from dirt particles being blown across the surface. However, two later observations tend to throw doubt on this hypothesis: (1) Where samples have been cut by scissors, a bright band appears between crossed nicols. This brightness is much greater than appears at any unaltered part of the original film. It is caused by deformation and flow within the film so that the two directions parallel and perpendicular to the cut edge are no longer nearly equal in refractive index. The interference figures on these edge zones indicate extremely rapid changes in molecular orientation within short dis-

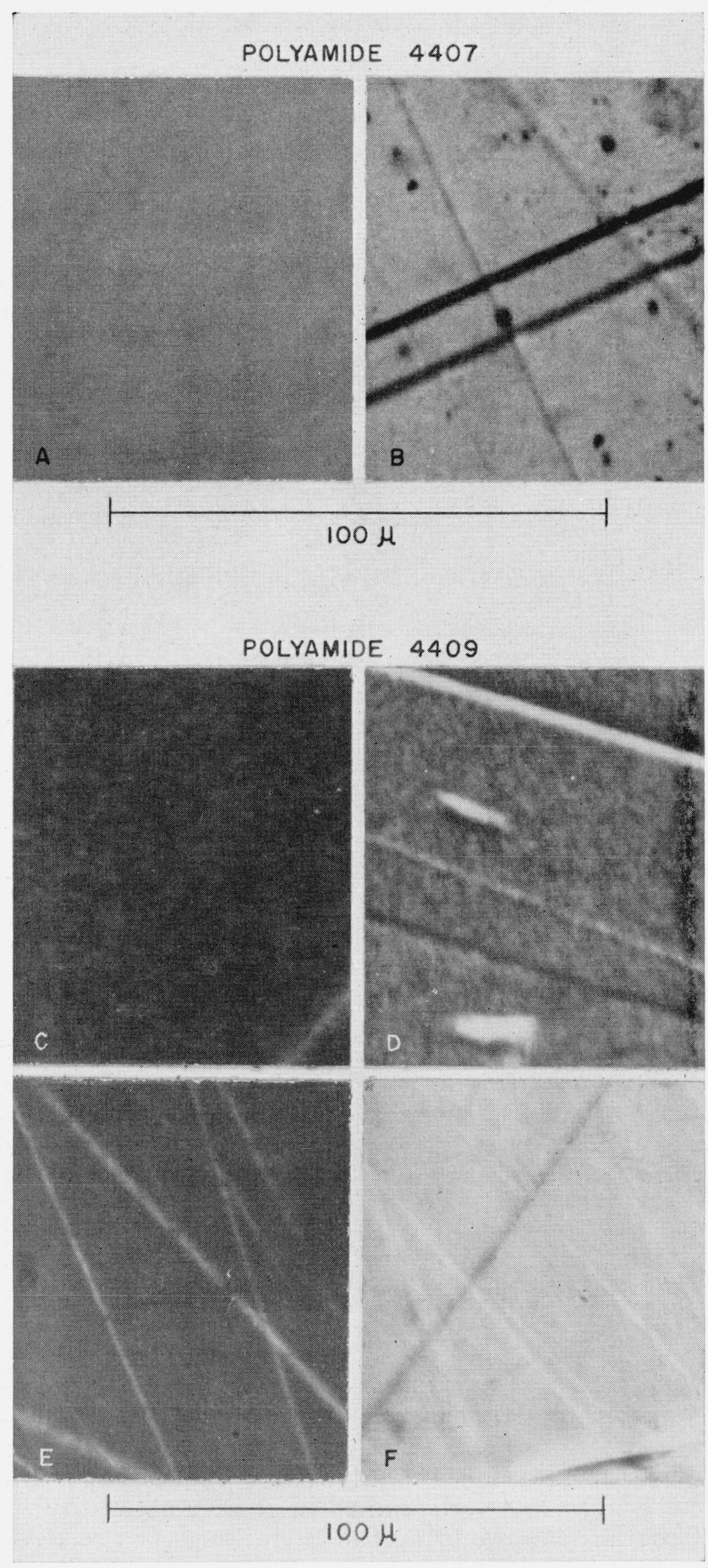

Figure 13. Photomicrographs ( $\times 600$, crossed nicols) of polyamides 4,407 and 4409 .

4407: A, untreated film; B, after 120-hr accelerated weathering test. 4409: C, untreated film; D, after 120-hr accelerated weathering tost: $\mathrm{E}$, after 2 month' door exposure; F, after 2 months' outdoor exposure (first-order retardation plate). 
tances. A somewhat similar effect is shown in the specimen of 4409, which was exposed on the roof. There are stripes on the surface with apparently greater birefringence than the main area of film. This is particularly true when the objective has a small aperture. Interference figures show that these stripes are places where the orientation of the molecules within the plane of the film has been disturbed. (2) Similar bright lines were observed in photomicrographs of untreated specimens (see plate C), and in those which had been exposed to the accelerated weathering test. However, these bright lines appeared to be more dominant in the exposed specimens. These lines may have been caused by slight abrasion (and hence deformation) of the surface, by strains from shrinkage of the film, or by mechanical distortion.

It is stated in the literature [20] that when molten nylon 66 polymer is cooled slowly large spherulites are formed that are visible with a microscope. These spherulites show a characteristic cross shape under crossed nicols. An optically clear material is obtained when the molten polymer is cooled rapidly. The spherulites disappear when the polymer is heated above $250^{\circ} \mathrm{C}$ and are elongated into cylinders on drawing. No formations resembling spherulites as found in rubber [21] and in polyhexamethylene adipamide [22] were found in the nylon films, untreated or treated, used in this investigation.

Another series of photomicrographs of specimens of samples $4406,4407,4408,4409$, and 4410 is shown in figure 14. These photomicrographs were taken with an oil immersion lens at a magnification of $\times 950$ under crossed nicols at maximum brightness. All variable factors such as light intensity, exposure time, temperature of the developer, etc., which would affect the apparent brightness of the final photomicrographs, were kept as constant as possible. No ground glass was used in the illuminator to take the photographs of samples 4409 and 4410 because
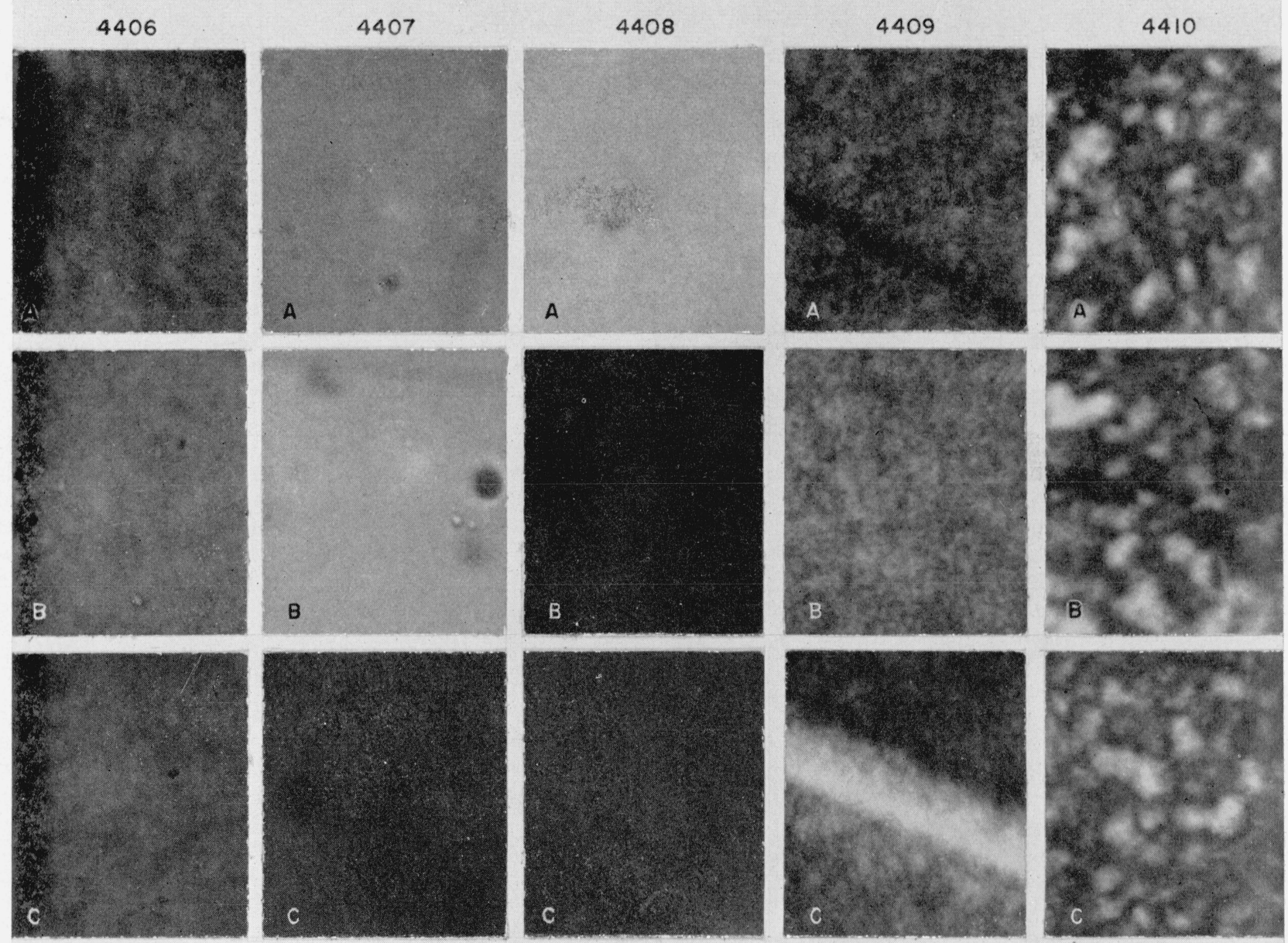

$100 \mu$

Figure 14. Photomicrographs ( $\times$ 950, crossed nicols) of polyamides. A Series, untreated film; B Series, after 2-months outdoor exposure; C Series, after exposure to S-1 sunlamp radiant energy. 


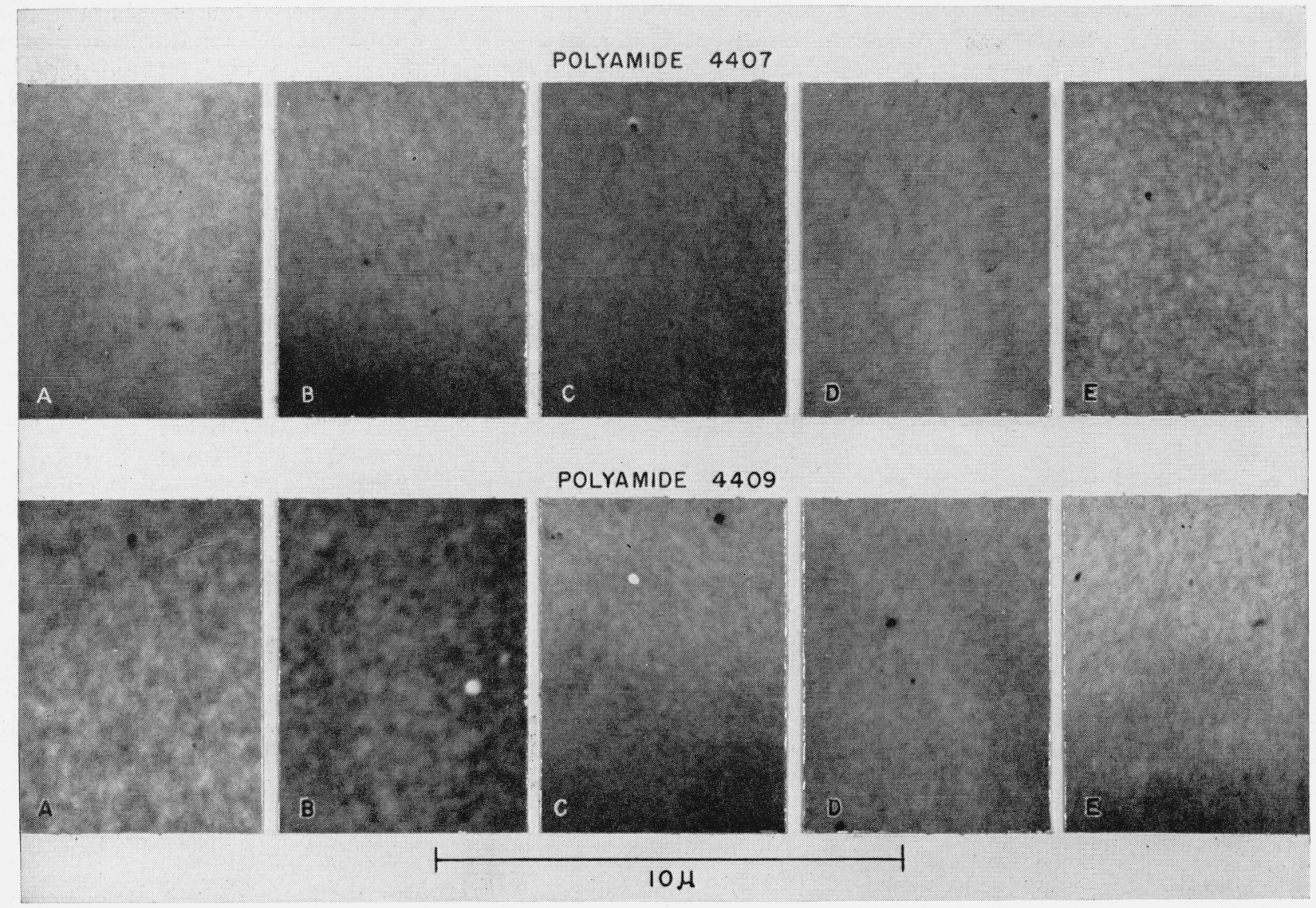

FIGURE 15. Electron micrographs of unshadowed specimens of polyamides 4407 and 4409.

A, Untreated; B, after 168-hr ultraviolet (S-1); C, after 336-hr ultraviolet (S-1); D, after $168 \mathrm{hr}$ at $100^{\circ} \mathrm{C}$ in air oven; E, after 336 hr at $100^{\circ} \mathrm{C}$ in air oven.

these films were relatively quite dark even at maximum brightness. The exposure time for sample 4410 was $0.5 \mathrm{~min}$ instead of $1 \mathrm{~min}$ as used for the others. As more crystalline materials appear brighter under crossed nicols, it was hoped that the comparative brightness of the specimens in the photomicrographs would give some conception of the comparative degree of crystallinity.

The photomicrographs of the untreated specimens are shown in series A in figure 14. All the specimens of these samples are anisotropic. As the stage of the polarizing microscope was rotated, the dark areas changed to bright and vice versa. A marked difference in brightness is observed. Nylon sample 4408 is much brighter than 4409 by comparison. Nylon sample 4410 has no actual maximum brightness, as revolving the stage of the microscope merely reversed the dark and bright areas that are numerically almost equal.

Photomicrographs of the specimens exposed outdoors for 2 months are shown in series B of figure 14. Differences in maximum brightness are shown for nylon samples 4407 and 4408. Nylon sample 4408 appears much darker under crossed nicols, while sample 4407 appears somewhat brighter. The tendency toward generally increased brightness in samples 4406, 4409, and 4410, shown in the photomicrographs, is not great enough to warrant consideration. In nylon sample 4410, however, areas of increased brightness such as those that appear in the lower portion of the photomicrograph are observed. Dark spots are exhibited particularly in samples 4406 and 4407 . Similar spots are observed in untreated specimens (see samples 4407 and 4408, series A of fig. 14) and appear to be present in greater quantity in exposed specimens.

Photomicrographs of the specimens exposed to radiant energy from an S-1 sunlamp at $60^{\circ} \mathrm{C}$ for $186 \mathrm{hr}$ are shown in series C of figure 14. Samples 4406, 4407, and 4408 are much darker under crossed nicols. In general, sample 4409 appears darker as seen in the upper section of the photomicrograph. The bright line was photomicrographed to show the appearance of this type of area in nylon sample 4409. Nylon sample 4410 again shows no extensive change that is visible under the crossed nicols.

A closer comparative examination of nylon samples 4407 and 4409 was made with a petrographic microscope. Specimens of each sample, in the original condition, after exposure on the roof, after $68 \mathrm{hr}$ at $87^{\circ} \mathrm{C}$, and after $168 \mathrm{hr}$ of exposure to ultraviolet radiant energy from an $\mathrm{S}-1$ sunlamp at $60^{\circ} \mathrm{C}$ were 
studied and the results compared. These specimens were stored at 50-percent relative humidity and $25^{\circ}$ $\mathrm{C}$ after treatment. In all instances the specimens are optically negative with the acute bisectrix approximately normal to the film except in small areas. The significance of this is that the long axes of the molecules tend to be more or less parallel to the surface of the film. The orientation as between length and breadth of the film is slight as compared to the tendency to be parallel to the surface of the film. Sample 4407 exhibits a greater optic axial angle than sample 4409. Since the plane of the optic axes is parallel to neither of the edges of the film, this must be construed as accidental rather than as a result of strains introduced during formation of the film.

\section{Electron Microscopy}

With M. Swerdlow and M. J. Reiney

Polyamide samples 4407 and 4409 were examined by an electron microscopic technique before and after exposure to ultraviolet radiant energy and to heat to determine any changes in structure resulting from these treatments. It was established that titanium dioxide, a delusterizing agent for nylon that would interfere with the electron microscope examination, was not present in these samples [23]. The film specimens were prepared by the dipping technique described in section II.

Four slides each of nylon samples 4407 and 4409 were selected on the basis of uniformity, thickness, and cleanliness with the aid of a light microscope. Two of the coated screens were removed from each slide, one for examination of the unexposed material and the other for electron diffraction work. The glass slides with the remaining three coated screens were exposed to ultraviolet radiant energy and to heat at $100^{\circ} \mathrm{C}$. One slide of each sample was exposed to the ultraviolet radiant energy from an S-1 sunlamp for $168 \mathrm{hr}$ and another set for $336 \mathrm{hr}$. The distance between the bulb and the specimens was 6 in., and the temperature of the specimens was about $60^{\circ} \mathrm{C}$. The exposure to heat was made in a circulating-air oven at $100^{\circ} \mathrm{C}$. One slide of each sample was exposed for $168 \mathrm{hr}$ and another for $336 \mathrm{hr}$.

An RCA type EMU transmission electron microscope with an accelerating voltage of $50 \mathrm{kv}$ and an operating pressure of less than $10^{-4} \mathrm{~mm} \mathrm{Hg}$ was used to examine the specimens. Representative areas were selected and micrographs were taken at an exposure of about 10 sec. All the electron micrographs were taken at about 6,000 diameters under constant conditions except that the beam current intensity had to be altered slightly because of variation in film thickness between samples. Shadow casting was done in an RCA type EMV vacuum unit at a pressure not higher than $10^{-4} \mathrm{~mm} \mathrm{Hg}$.

Figure 15 shows a series of micrographs of the surfaces of nylon samples 4407 and 4409 . These surfaces were not shadowed with chromium. men A of each sample gives a view of the surface that is representative of the unexposed films. Specimens $\mathrm{B}$ and $\mathrm{C}$ are representative of the specimens exposed to the ultraviolet radiant energy. Specimens D and E are representative of the specimens exposed to heat in air at $100^{\circ} \mathrm{C}$. A definite grain structure is shown in all the specimens. No definite changes in the structure of the surfaces of these specimens are observed.

The effect of shadowing in emphasizing the surface detail by increasing the contrast, resulting from the oblique deposition of a thin layer of chromium, is shown in figure 16 . The small spherical pieces of dirt shown in these micrographs indicate the appearance of an elevated portion of the surface and its shadow.

Shadowed unexposed specimens of sample 4407 are shown in figure 16 . The more crystalline appearance of specimens $\mathrm{A}$ and $\mathrm{D}$ may be a result of the film-making procedure. The slower the film cools, the greater the degree of molecular orientation. A comparison of the views of the specimens of sample 4407 before and after treatment with ultraviolet radiant energy and with heat shows that exposure to ultraviolet radiant energy appears to increase the degree of molecular orientation, whereas exposure to heat has very little effect.

The shadowed untreated and treated specimens of sample 4409 are also shown in figure 16. Sample 4409 appears to have a larger grain structure than sample 4407. However, the grain structure of the specimens of sample 4409 varies considerably. The exposure to ultraviolet radiant energy and to heat appears to have little effect on the surface structure of sample 4409 when examined with the electron microscope. The effect of shadow casting with chromium is shown quite markedly in view $\mathrm{H}^{\prime}$ of figure 16 ; the right-hand part of $\mathrm{H}^{\prime}$ was shielded by a large foreign particle and is unshadowed, while the left-hand part is shadowed with chromium.

The very thin films used in this part of the work did not develop the amount of splitting observed in the tests in which the original films were exposed to ultraviolet radiant energy. Splitting of the films of sample 4407 was observed with the electron microscope in a few isolated instances, but this was the exception and not the rule. The splitting observed with these thin films was in the top layer only; the film appeared to be laminated, with the top layer split and the bottom one intact. The splitting observed with the films in the original thickness was the usual type in which the split was completely through the film.

\section{Electron Diffraction}

With M. Swerdlow and M. J. Reiney

Samples 4407 and 4409 were examined by electron diffraction technique to determine any changes that may have occurred as a result of exposure to ultraviolet radiant energy and to heat.

The diffraction stage of an RCA type EMU electron microscope was used to make transmission electron 

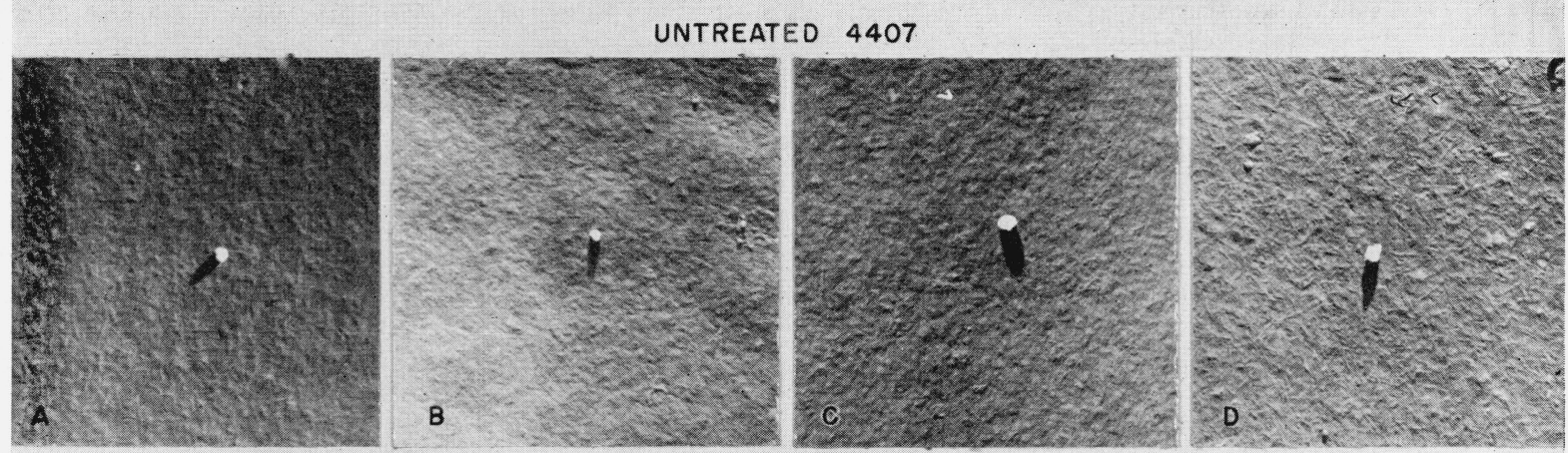

TREATED 4407
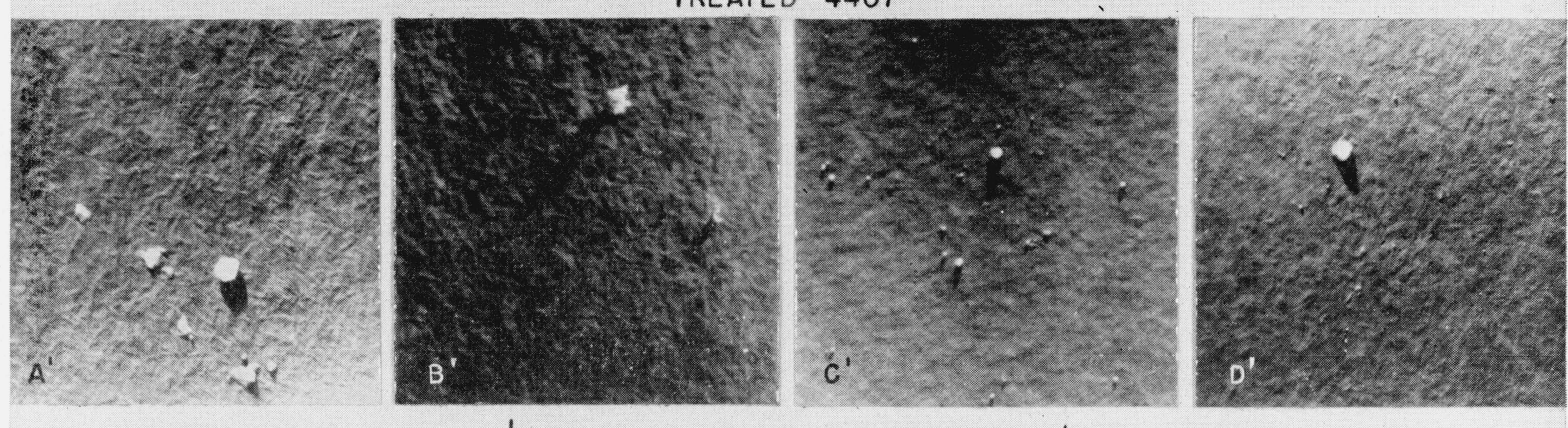

$10 \mu$

UNTREATED 4409
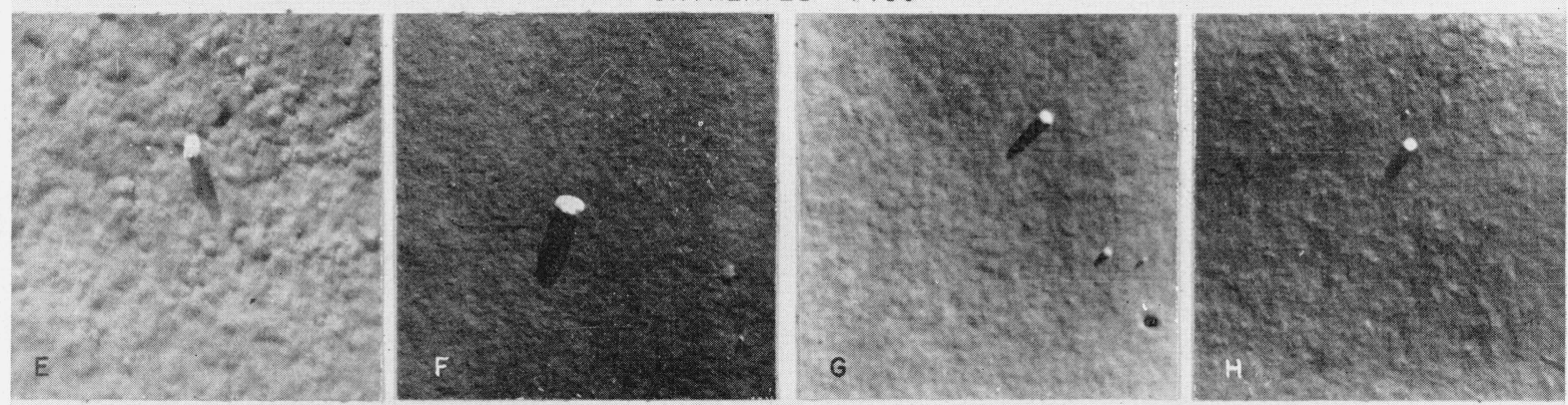

TREATED 4409
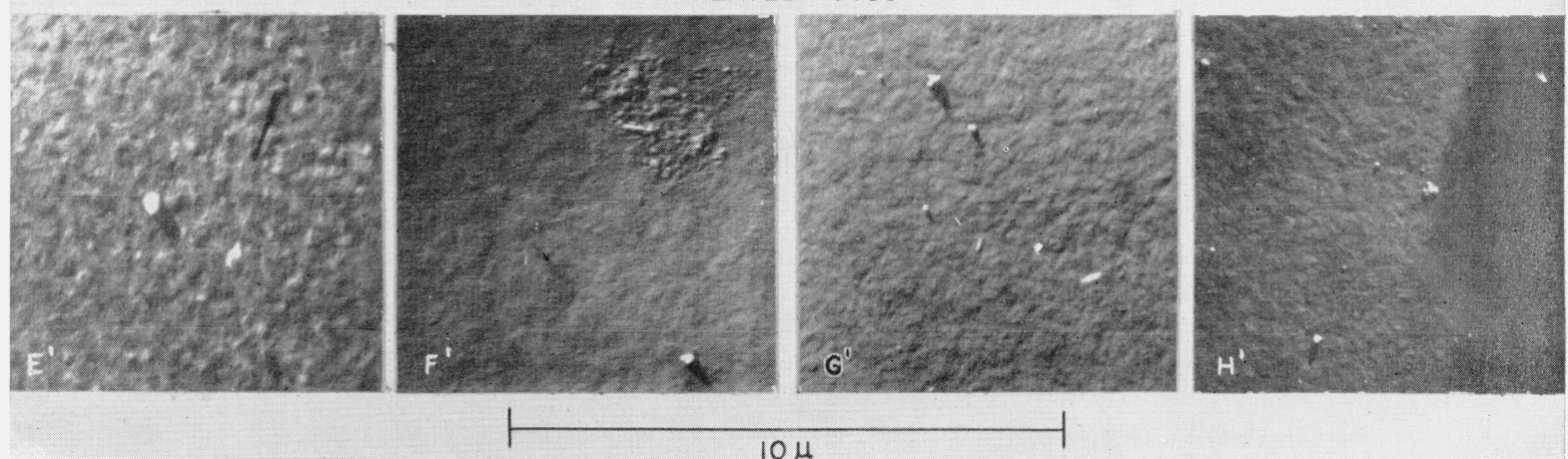

$10 \mu$

FIGURE 16. Electron micrographs of chromium shadowed polyamides 4407 and 4409.

$\mathrm{A}^{\prime}$ and $\mathrm{E}^{\prime}$, Sample of $\mathrm{A}$ and of $\mathrm{E}$ after 168-hr ultraviolet (S-1); $\mathrm{B}^{\prime}$ and $\mathrm{F}^{\prime}$, sample of B and of $\mathrm{F}$ after 336-hr ultraviolet (S-1); $\mathrm{C}^{\prime}$ and $\mathrm{G}^{\prime}$, sample of $\mathrm{C}$ and of $\mathrm{G}$ after $168 \mathrm{hr}$ at $100^{\circ} \mathrm{C}$ in air oven; $\mathrm{D}^{\prime}$ and $\mathrm{H}^{\prime}$, sample of $\mathrm{D}$ and of $\mathrm{H}$ after $336 \mathrm{hr}$ at $100^{\circ} \mathrm{C}$ in air oven. 
diffraction patterns of unexposed and exposed specimens of the samples. Electron diffraction is especially suitable for the study of the structure of thin surface layers and films. The electrons are diffracted much the same way X-rays are by crystalline materials [24]. The thickness of films that can be used with this technique is limited because electrons are scattered a million times more effectively than X-rays. The average thickness of the nylon films used was $0.4 \pm 0.1 \mu$ as determined by an interferometer. The films were made and mounted on screens according to the procedure described in section II.

The electron diffraction patterns of samples 4407 and 4409 showed several diffuse rings. The interplanar spacings in angstrom units that were determined by comparison of the negative with a secondary standard are presented in table 13.

TABLE 13. Electron diffraction spacings of polyamides ${ }^{\text {a }}$

\begin{tabular}{|c|c|c|c|c|c|c|}
\hline \multirow{4}{*}{$\begin{array}{c}\text { Sample } \\
4407 \text { (untreated) }\end{array}$} & \multirow{4}{*}{$\begin{array}{c}\text { Dif- } \\
\text { frac- } \\
\text { tion } \\
\text { ring }\end{array}$} & \multicolumn{5}{|c|}{ Interplanar spacings, in angstrom units } \\
\hline & & $A$ & $B$ & $C$ & $D$ & $B_{a}$ \\
\hline & & $\begin{array}{r}25.15 \\
3.98 \\
2.09 \\
\end{array}$ & $\begin{array}{r}23.89 \\
\text { 3. } 95 \\
2.13 \\
-\end{array}$ & $\begin{array}{r}11.95 \\
3.59 \\
2.06 \\
1.18\end{array}$ & $\begin{array}{r}11.95 \\
4.16 \\
1.97 \\
1.11\end{array}$ & $\begin{array}{r}25.15 \\
4.23 \\
2.02 \\
-\end{array}$ \\
\hline & & $A^{\prime}$ & $B^{\prime}$ & $C^{\prime}$ & $D^{\prime}$ & $B^{\prime}{ }_{a}$ \\
\hline 4407 (treated) ... & $\begin{array}{l}1 \\
2 \\
3 \\
4\end{array}$ & $\begin{array}{l}9.75 \\
4.08 \\
1.95 \\
1.07\end{array}$ & $\begin{array}{r}12.91 \\
3.89 \\
1.99 \\
1.16\end{array}$ & $\begin{array}{l}9.19 \\
3.85 \\
2.03 \\
1.09\end{array}$ & $\begin{array}{r}11.38 \\
3.92 \\
2.06 \\
-\end{array}$ & $\begin{array}{r}10.86 \\
4.02 \\
1.97 \\
1.16\end{array}$ \\
\hline & & A & $B$ & C & $D$ & $D_{a}$ \\
\hline 4409 (untreated) & $\begin{array}{l}1 \\
2 \\
3 \\
4\end{array}$ & $\begin{array}{r}13.65 \\
4.02 \\
2.07 \\
1.08\end{array}$ & $\begin{array}{r}\text { 11. } 95 \\
\text { 3. } 92 \\
\text { 1. } 97 \\
\text { 1. } 096\end{array}$ & $\begin{array}{r}10.86 \\
4.27 \\
1.88 \\
1.11\end{array}$ & $\begin{array}{l}\text { 9. } 18 \\
4.12 \\
2.16 \\
1.99\end{array}$ & $\begin{array}{r}10.84 \\
4.16 \\
2.11 \\
1.15\end{array}$ \\
\hline & & $A^{\prime}$ & $B^{\prime}$ & $C^{\prime}$ & $D^{\prime}$ & $D^{\prime}{ }_{a}$ \\
\hline 4409 (treated) .... & $\begin{array}{l}1 \\
3 \\
3 \\
4\end{array}$ & $\begin{array}{l}9.75 \\
\text { 3. } 95 \\
1.89 \\
1.12\end{array}$ & $\begin{array}{r}10.39 \\
3.82 \\
1.96 \\
1.10\end{array}$ & $\begin{array}{l}9.75 \\
3.79 \\
1.99 \\
1.12\end{array}$ & $\begin{array}{r}10.17 \\
3.73 \\
1.87 \\
1.13\end{array}$ & $\begin{array}{l}\text { 8. } 69 \\
\text { 4. } 12 \\
2.04 \\
1.12\end{array}$ \\
\hline
\end{tabular}

a The patterns with a subscript $a$ were made with an exposure of $7 \mathrm{sec}$; all other exposures were 15 sec.

\section{X-Ray Diffraction}

\section{With H. E. Swanson}

The X-ray diffraction patterns of samples 4407 and 4409 were obtained before and after specimens were exposed to outdoor and accelerated weathering treatments to determine whether or not these treatments cause any changes in structure that might be revealed by this techinque.

The X-ray patterns were obtained with a Philips $\mathrm{X}$-ray spectrometer with various modifidations. $\mathrm{CuK}_{\alpha 1}$ radiation at $40 \mathrm{kv}$ and $15 \mathrm{ma}$ was used. The spacings listed in table 14 were obtained by diffraction of the X-ray beam from the surface of the films. Penetration X-ray patterns were taken on photographic film $2 \mathrm{~cm}$ from the pinhole used to collimate the beam. The polyamide specimen was placed over the pinhole, which was 0.025 in. in diameter.
TABLE 14. Spacings from $X$-ray reflection measurements with polyamides

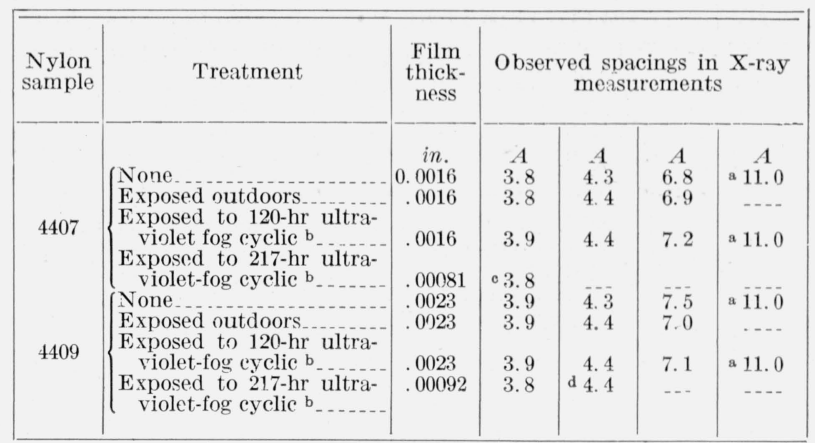

a Very diffuse, low peak.

b Method No. 6021 of Federal Specification L-P-406a.

V Very weak, poor pattern.

d Poor pattern.

The X-ray patterns of samples 4407 and 4409 showed that there is a very slight molecular orientation in sample 4407 and none in sample 4409 . Sample 4407 appeared to be more crystalline than sample 4409. No differences in degree of molecular orientation were observed in the unexposed and exposed specimens of either sample.

Four X-ray spacings were observed with the Geiger-counter spectrometer at approximately 3.8, 4.3, 7, and $11 \mathrm{~A}$. A high concentration of polar bridges along the polyamide chains has been associated with extended chain configurations having the calculated length per repeating unit and side spacings of 3.7 and $4.4 \mathrm{~A}$, respectively [25]. Even though the X-ray patterns showed no molecular orientation for sample 4409 , the presence of the spacings at 3.8 and $4.3 \mathrm{~A}$ indicates that there is some degree of crystallinity [20].

The results of the tests indicate that the 4.3-A spacings are stronger when the nylon sample is penetrated at right angles by the X-rays. This indicates a perpendicular position to the plane of the film. The 3.8-A spacing appears to be more in the plane of the film.

If nylon sample 4409 were completely amorphous, a 4.18-A spacing observed by Baker and Fuller [25] in quenched polyamides would be expected It appears that there is some crystallinity in both samples 4407 and 4409 and that sample 4407 is more crystalline than sample 4409.

\section{Electrical Properties}

\section{With A. H. Scott}

The dielectric constant and dissipation factor of nylon samples 4406 and 4407 were measured before and after exposure to ultraviolet radiant energy to determine whether or not these properties changed sufficiently to indicate the degradation of the materials.

The dielectric constant and dissipation factor of dry 610 nylon polymer have been reported as 3.5 and 0.02 , respectively, at room temperature; at temperatures above $100^{\circ} \mathrm{C}$, the values are much 
greater and are similar to values of polar, hydrogenbonded liquids such as alcohols [20]. Errera and Sack [26] have reported the following dielectric constant values for nylon, presumably the 66 type: 4.2 at $10 \mathrm{kc} / \mathrm{s}, 3.26$ at $500 \mathrm{kc} / \mathrm{s}, 3.15$ at $4 \mathrm{mc} / \mathrm{s}$, and 3.15 at $10 \mathrm{mc} / \mathrm{s}$.

The dielectric constant and dissipation factor measurements were made with a conjugate Schering bridge in accordance with ASTM Method of Test D 150-47T [27]. Tinfoil electrodes were applied to the film, using Vaseline as an adhesive. Measurements were made at 1,000 and $100,000 \mathrm{c} / \mathrm{s}$. The measurements were made at $25^{\circ} \mathrm{C}$ and 50-percent relative humidity after the test specimens had been at these conditions for $24 \mathrm{hr}$. The ultraviolet treatment was made by exposing specimens of the films to radiant energy from an $\mathrm{RS}$ sunlamp for $20 \mathrm{hr}$ in nitrogen at $100^{\circ} \mathrm{C}$.

The tests were designed to determine the electrical uniformity of the nylon samples. Electrodes were placed on the specimens at three different positions, namely, in the center and at two positions off center. The latter two are designated as the second and third positions. The results are presented in table 15 .

The films were found to be electrically nonuniform. The difference in the dielectric constant of different parts of the same specimen is as great as 50 percent. These large differences would tend to obscure changes resulting from exposure of specimens to heat, ultraviolet radiant energy, or other degrading forces. However, the results indicate that the dielectric constant of sample 4406 is not affected by the exposure to ultraviolet radiant energy and that the dielectric constant of sample 4407 is decreased markedly by the exposure to ultraviolet radiant energy. No particular trends are noted in the dissipation factor values.

The dielectric constant of both samples increased as the period of contact with Vaseline increased.
The dissipation factor of sample 4406 increased, and that of sample 4407 decreased at the longer periods of contact with the Vaseline. The reason for these changes was not apparent since any swelling resulting from absorption of Vaseline by the polyamide would cause the dielectric constant to decrease.

\section{Effects of Water and Alcohols}

\section{With M. J. Reiney}

The effects of water, methanol, and ethanol on the polyamide samples were investigated by immersing the films in these liquids before and after exposure to heat, ultraviolet radiant energy, and outdoor weathering. The effects of these particular liquids were investigated because in any actual use the polyamide films come into contact with water and in casting the films alcohols are probably used as the solvents.

The results of the tests made with original untreated specimens of the polyamide film samples are presented in table 16. Continuous immersion in 95percent ethanol and methanol caused the polyamide films of the $66 / 6$ and $66 / 610 / 6$ types to split or disintegrate. Continuous immersion in water caused the 66/6 type films to disintegrate but caused only clouding of the water for the $66 / 610 / 6$ type. Immersion in absolute ethanol had no effect on the $66 / 6$ polymers and disintegrated the $66 / 610 / 6$ polymers.

The effects of alcohol immersion on specimens of the polyamide samples that had been exposed to heat, ultraviolet radiant energy, and outdoor weathering are shown in table 17. Exposure to ultraviolet radiant energy causes an increase in the degree of attack by 95-percent ethanol and methanol. Immersion in 95-percent ethanol for $1 \mathrm{hr}$ had no effect on any of the specimens that had been heated to $87^{\circ} \mathrm{C}$ for $68 \mathrm{hr}$. Exposure outdoors for 2 months had no

TABLE 15. Electrical uniformity of polyamides

\begin{tabular}{|c|c|c|c|c|c|c|c|c|}
\hline \multirow{2}{*}{$\begin{array}{l}\text { Sample } \\
\text { desig- } \\
\text { nation }\end{array}$} & \multirow{2}{*}{$\begin{array}{l}\text { Specimen } \\
\text { number }\end{array}$} & \multirow{2}{*}{$\begin{array}{l}\text { Exposed to } \\
\text { ultraviolet } \\
\text { radiant } \\
\text { energy }\end{array}$} & \multirow{2}{*}{$\begin{array}{c}\text { Tine after } \\
\text { electrodes } \\
\text { were } \\
\text { applied }\end{array}$} & \multirow{2}{*}{ Position of electrodes } & \multicolumn{2}{|c|}{ Dielectric constant at- } & \multicolumn{2}{|c|}{ Dissipation factor at- } \\
\hline & & & & & $10^{3} \mathrm{c} / \mathrm{s}$ & $10^{5} \mathrm{c} / \mathrm{s}$ & $10^{3} \mathrm{c} / \mathrm{s}$ & $10^{5} \mathrm{c} / \mathrm{s}$ \\
\hline 4406 & $\left\{\begin{array}{l}2 \\
2 \ldots \ldots\end{array}\right.$ & No & $\begin{array}{r}h r . \\
0 \\
1 \\
96 \\
144 \\
312 \\
0 \\
0 \\
0 \\
72 \\
264 \\
0 \\
24 \\
0 \\
0 \\
1 \\
2 \\
120 \\
0 \\
0 \\
24 \\
0 \\
0 \\
336 \\
0 \\
2 \\
24 \\
24 \\
0\end{array}$ & 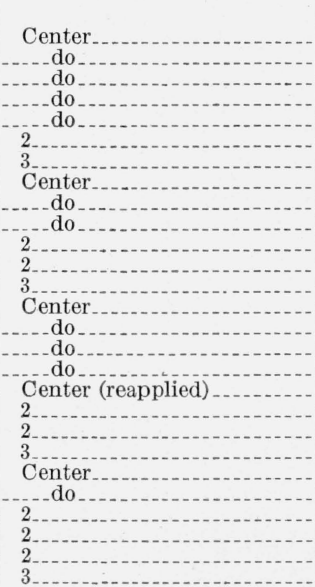 & $\begin{array}{r}6.5 \\
6.7 \\
6.8 \\
7.1 \\
7.1 \\
12.3 \\
11.7 \\
6.4 \\
6.2 \\
6.2 \\
10.8 \\
11.7 \\
11.0 \\
7.9 \\
7.9 \\
7.9 \\
8.3 \\
8.4 \\
9.4 \\
10.1 \\
9.5 \\
4.9 \\
4.8 \\
5.8 \\
-9.0 \\
5.4\end{array}$ & 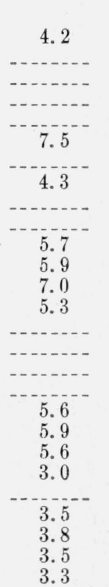 & $\begin{array}{r}0.17 \\
.17 \\
.17 \\
.17 \\
.18 \\
.18 \\
.17 \\
.16 \\
.15 \\
.15 \\
.23 \\
.23 \\
.25 \\
.15 \\
.15 \\
.15 \\
.14 \\
.13 \\
.17 \\
.18 \\
.17 \\
.13 \\
.15 \\
.16 \\
.17 \\
.17\end{array}$ & $\begin{array}{c}0.27 \\
.25 \\
.10 \\
19 \\
20 \\
.20 \\
.16 \\
.18 \\
.19 \\
.13 \\
.11 \\
.17 \\
.18\end{array}$ \\
\hline
\end{tabular}


TABLE 16. Effects of water and alcohol immersion on untreated polyamides a

\begin{tabular}{|c|c|c|c|c|c|c|c|c|c|}
\hline \multirow{2}{*}{$\begin{array}{l}\text { Immersion } \\
\text { med:um }\end{array}$} & \multirow{2}{*}{$\begin{array}{l}\text { Poly- } \\
\text { amide } \\
\text { sample }\end{array}$} & \multicolumn{8}{|c|}{ Degree of attack b after immersion for- } \\
\hline & & 18 days & 31 days & 7 mon & aths & & $18 \mathrm{~m}$ & ont & ths \\
\hline Water, distilled_ & $\left\{\begin{array}{l}4403 \\
4407 \\
4408 \\
4409 \\
4410 \\
4406 \\
4407 \\
4408 \\
4409 \\
4410\end{array}\right.$ & $\begin{array}{l}\text { P2 } \\
\text { P2 } \\
\text { P2 } \\
\text { P2 } \\
\text { P2 } \\
\text { U4 } \\
\text { P4 } \\
\text { P4 } \\
\text { P4 } \\
\text { P3 }\end{array}$ & $\begin{array}{l}\text { U2 } \\
\text { U2 } \\
\text { U2 } \\
\text { U2 } \\
\text { U2 } \\
\text { U4 } \\
\text { U4 } \\
\text { U4 } \\
\text { U4 } \\
\text { U3 }\end{array}$ & $\begin{array}{l}\mathrm{U} 2 \\
\mathrm{U} 2 \\
\mathrm{U} 2 \\
\mathrm{U} 2 \\
\mathrm{U} 2 \mathrm{~N} \\
\mathrm{U} 4 \\
\mathrm{U} 4 \\
\mathrm{U} 4 \\
\mathrm{U} 4 \\
\mathrm{U} 3\end{array}$ & & $\begin{array}{l}\text { U2 } \\
\text { U2; } \\
\text { U2 } \\
\text { U2 } \\
\text { U2 } \\
\text { U4: } \\
\text { U4; } \\
\text { U4 } \\
\text { U5 } \\
\text { U3; }\end{array}$ & $\begin{array}{l}\text { M; S5 } \\
\text { S5 } \\
\text { M; S4 } \\
\text { M; S2 } \\
\text { M; S2 } \\
\text { S4 } \\
\text { S4 } \\
\text { S4 } \\
\text { S5 } \\
\text { S3 }\end{array}$ & ; & $\begin{array}{l}\text { V5 } \\
\text { V5 } \\
\text { V5 } \\
\text { V2 } \\
\text {; V2M } \\
\text { V4 } \\
\text { V4 } \\
\text { V4 } \\
\text { V5 } \\
\text { V3 }\end{array}$ \\
\hline \multirow{3}{*}{$\begin{array}{l}\text { Ethanol, abso- } \\
\text { lute }\end{array}$} & \multirow{3}{*}{$\begin{array}{l}4405 \\
4406 \\
4407 \\
4408 \\
4409 \\
4410\end{array}$} & 1 hour & 24 hours & \multicolumn{2}{|c|}{ rs 20 days } & \multicolumn{2}{|c|}{4 months } & \multicolumn{2}{|c|}{15 months } \\
\hline & & $\begin{array}{l}\text { V1 } \\
\text { V1 } \\
\text { V1 } \\
\text { V1 } \\
\text { V1 } \\
\text { V1 }\end{array}$ & $\begin{array}{l}\text { V1 } \\
\text { V1 } \\
\text { V1 } \\
\text { V1 } \\
\text { V1 } \\
\text { V3 }\end{array}$ & $\begin{array}{l}\text { V1 } \\
\text { V1 } \\
\text { V1 } \\
\text { V1 } \\
\text { V1 } \\
\text { V3 }\end{array}$ & & $\begin{array}{l}\text { U1; } \\
\text { U1; } \\
\text { U1; } \\
\text { U1; } \\
\text { U3; } \\
\text { U3; }\end{array}$ & $\begin{array}{l}\text { V1 } \\
\text { V1 } \\
\text { V1 } \\
\text { V1 } \\
\text { V3 } \\
\text { V3 }\end{array}$ & & $\begin{array}{l}\text { V1 } \\
\text { V1 } \\
\text { V1 } \\
\text { V1 } \\
\text { V4 } \\
\text { V4 }\end{array}$ \\
\hline & & $5 \mathrm{~min}$ & $30 \mathrm{~min}$ & 3 days & $1 \mathrm{mo}$ & onth & $\begin{array}{c}6 \\
\text { mont }\end{array}$ & & $\begin{array}{c}16 \\
\text { months }\end{array}$ \\
\hline $\begin{array}{l}\text { Methanol, ab- } \\
\text { solute. }\end{array}$ & $\begin{array}{l}4405 \\
4406 \\
4407 \\
4408 \\
4409 \\
4410\end{array}$ & $\begin{array}{c}\mathrm{U} 2 \\
\mathrm{U} 3 \\
\mathrm{U} 2 \\
\mathrm{U} 2 \\
\mathrm{U} 3 \\
\mathrm{U} 5 ; \mathrm{V} 5\end{array}$ & $\begin{array}{l}\text { V4 } \\
\text { V4 } \\
\text { V3 } \\
\text { V3 } \\
\text { V5 } \\
\text { V5 }\end{array}$ & $\begin{array}{l}\text { V4 } \\
\text { V4 } \\
\text { V3 } \\
\text { V3 } \\
\text { V5 } \\
\text { V5 }\end{array}$ & $\begin{array}{l}\text { V } \\
\text { V } \\
\text { V: } \\
\text { V } \\
\text { V } \\
\text { V }\end{array}$ & $\begin{array}{l}74 \\
74 \\
73 \\
73 \\
5 \\
5\end{array}$ & $\begin{array}{l}\text { V4 } \\
\text { V4 } \\
\text { V4 } \\
\text { V3 } \\
\text { V5 } \\
\text { V5 }\end{array}$ & & $\begin{array}{l}\text { V4 } \\
\text { V4 } \\
\text { V4 } \\
\text { V4 } \\
\text { V5 } \\
\text { V5 }\end{array}$ \\
\hline
\end{tabular}

a Pieces of the films approximately 2 in..$^{2}$ in area were placed in a test tube or in a wide-mouthed bottle and covered with the test liquids. The containers were stoppered and allowed to stand at $21^{\circ}$ to $26^{\circ} \mathrm{C}$. The specimens were examined at various time intervals. The test specimens were all conditioned at $25^{\circ} \mathrm{C}$ and 50-percent relative humidity prior to immersion in the liquids. The films were examined by observing the changes in appearance ofter standing undisthe container, and after probing the test films with a glas turbed, after shaking the container, and after probing the test fims with a glass rod.

$\mathrm{b}$ Code for indicating degree of attack on film: $\mathrm{U}=$ undisturbed; $\mathrm{P}=$ probed gently with a glass rod; $S=$ after gentle shaking: $V=$ after vigorous shaking; $1=$ unaffected; $2=$ sediment or cloud in liquid, film intact; $3=$ cracks through film; $4=$ broken into large pieces; $5=$ broken into small pieces; $6=$ soluble; $\mathrm{M}=$ developed a green-mold growth

effect on the degree of attack by methanol. Exposure to ultraviolet radiant energy increased the degree of attack by methanol.

The behavior of sample 4410 , a $66 / 610 / 6$ polymer, is different from that of the other polymers. Before exposure the specimens are more resistant to water and 95-percent ethanol, less resistant to absolute ethanol and methanol, and after exposure to ultraviolet radiant energy are affected more by absolute ethanol and methanol.
TABLE 17. Effects of alcohol immersion on polyamides exposed to heat and ultraviolet radiant energy

\begin{tabular}{|c|c|c|c|c|c|}
\hline \multirow{2}{*}{$\begin{array}{l}\text { Immersion } \\
\text { medium }\end{array}$} & \multirow{2}{*}{$\begin{array}{l}\text { Poly- } \\
\text { amide } \\
\text { sample }\end{array}$} & \multirow{2}{*}{$\begin{array}{l}\text { Exposure prior to } \\
\text { immersion }^{\mathrm{a}}\end{array}$} & \multicolumn{3}{|c|}{$\begin{array}{l}\text { Degree of attack } \mathrm{b} \text { after } \\
\text { immersion for- }\end{array}$} \\
\hline & & & $5 \mathrm{~min}$ & $30 \mathrm{~min}$ & $60 \mathrm{~min}$ \\
\hline \multirow[t]{2}{*}{ Ethanol, $95 \%$} & $\left\{\begin{array}{l}4406 \\
4407 \\
4408 \\
4409 \\
4410 \\
4406 \\
4407 \\
4408 \\
4409 \\
4410\end{array}\right.$ & $\left\{\begin{array}{l}\text { Ultraviolet; } 168 \mathrm{hr} \\
87^{\circ} \mathrm{C} ; 68 \mathrm{hr} \ldots\end{array}\right.$ & $\left\{\begin{array}{l}V 1 \\
V 1 \\
V 1 \\
V 1 \\
V 6 \\
V 1 \\
V 1 \\
V 1 \\
V 1 \\
V 1\end{array}\right.$ & $\begin{array}{l}\text { V5 } \\
\text { V5 } \\
\text { V4 } \\
\text { V5 } \\
\text { V6 } \\
\text { V1 } \\
\text { V1 } \\
\text { V1 } \\
\text { V1 } \\
\text { V1 }\end{array}$ & $\begin{array}{l}\text { V5 } \\
\text { V5 } \\
\text { V4 } \\
\text { V5 } \\
\text { V6 } \\
\text { V1 } \\
\text { V1 } \\
\text { V1 } \\
\text { V1 } \\
\text { V1 }\end{array}$ \\
\hline & & & \multicolumn{2}{|c|}{$5 \mathrm{~min}$} & $\begin{array}{c}10 \\
\text { months }\end{array}$ \\
\hline $\begin{array}{l}\text { Methanol, ab- } \\
\text { solute. }\end{array}$ & $\left\{\begin{array}{l}4406 \\
4407 \\
4408 \\
4409 \\
4410 \\
4406 \\
4407 \\
4408 \\
4409 \\
4410\end{array}\right.$ & $\begin{array}{l}\text { Ultraviolet; } 168 \mathrm{hr} \\
\text { Outdoors; } 2 \text { months.. }\end{array}$ & & 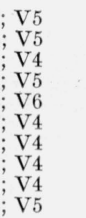 & $\begin{array}{l}\text { V5 } \\
\text { V5 } \\
\text { V5 } \\
\text { V5 } \\
\text { V6 } \\
\text { V4 } \\
\text { V4 } \\
\text { V4 } \\
\text { V5 } \\
\text { V5 }\end{array}$ \\
\hline
\end{tabular}

a The exposure to ultraviolet radiant energy was made with an S-1 sunlamp. The heating at $87^{\circ} \mathrm{C}$ was done in a vacuum oven.

b. See table 16 for code indicating degree of attack.

\section{Discussion of Results}

\section{Changes in Molecular Constitution}

(a) Mass Spectrometry

The presence of the products detected by mass spectrometry, namely, water, carbon dioxide, ethanol, carbon monoxide, and hydrocarbons, may be explained as follows:

Most of the water was absorbed on the polymer molecules. A small part of the water may have resulted from a reaction of the type:
[A]

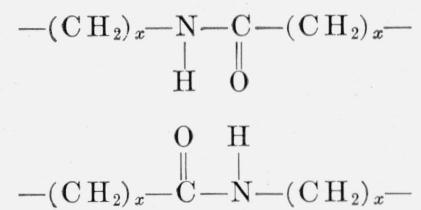

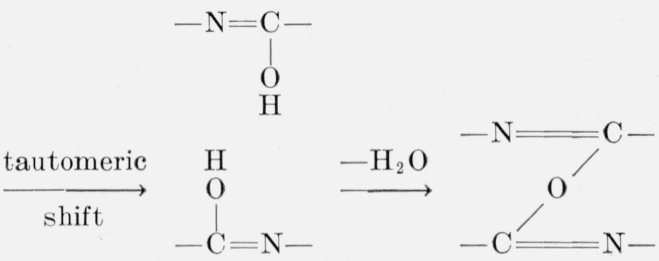


Such a reaction would result in cross linking of the polyamide chains. However, if cross linking did occur as a result of the treatments it was not sufficient to affect the solubility of the polymers in ethanol.
Carbon monoxide was evolved in all the experiments in which the specimens were exposed at temperatures of $90^{\circ}$ to $100^{\circ} \mathrm{C}$. Hydrocarbons were found in all experiments in which carbon monoxide was detected. A possible source of these two compounds is as follows:

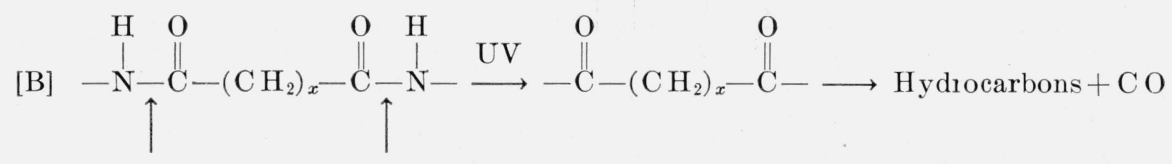

The arrows indicate the points of cleavage in the polymer chain. The carbonyl group of the peptide linkage absorbs energy at $280 \mathrm{~m} \mu$, and this energy apparently results in the scission of the bond between the imine group and the carbonyl group.

Presumably most of the carbon dioxide shown by the analysis was originally sorbed by the polymer. In the experiments made at the higher temperatures and/or with ultraviolet radiant energy, a small amount may be formed by the decarboxylation of the chain ends. Decarboxylation at temperatures of $100^{\circ} \mathrm{C}$ appears to be reasonable.

The ethanol evolved from these films is probably residual solvent. The specimens used in most of the experiments were studied in the condition in which they were received. The literature [28] indicates that sample 4406 is similar to the German Igamid $5 \mathrm{~A}$, which was made by casting the film from solution of the polyamide in ethanol. Residual ethanol could be attached at the peptide linkage during manufacture and act as a dipole associated plasticizer. The ethanol found in the products obtained at the milder conditions was evolved from the polyamide film when the apparatus was evacuated (see section III).

\section{(b) Pyrolysis}

Water was one of the gaseous degradation products resulting from pyrolysis of these polyamides. The conditioning period in which the films were heated for $2 \mathrm{hr}$ at $150^{\circ} \mathrm{C}$ in vacuum should have removed sorbed water and gases. Water may be formed by reaction $[\mathrm{A}]$. The probability of reaction $[\mathrm{A}]$ occurring in sample 4407, where there is the possibility of more peptide linkages in proximity to each other, is greater than in nylon sample 4409 where the formulation suggests a more dispersed dipole population. It is interesting to note that the water produced on pyrolysis of 4409 is almost insignificant. This water represents about 0.6 percent of the total oxygen of the polymer. With nylon 4407, 9.7 percent of the total oxygen of the polymer was evolved as water. The mechanism proposed above would lead to cross linking of the polymer. A relatively small percentage of cross linking leads to insolubility. The residues of these pyrolyses showed only partial solubility in ethanol; but no quantitative study of the relative solubility of samples 4407 and 4409 was made
The cyclopentanone formed in the pyrolysis experiments may be accounted for in two ways. The polymer molecule may break as follows:

[C]<smiles>CNCCCCN(C)C(=O)CCCCC(=O)N(C)CCNC</smiles>

Scission at these places is logical since the $\mathrm{C}-\mathrm{N}$ bond is weaker than the $\mathrm{C}-\mathrm{C}$ bond, $66 \mathrm{kcal}$ compared to $82.5 \mathrm{kcal}$ [29]. The radical produced may split off carbon monoxide and form cyclopentanone:

[D]<smiles>CC(=O)CCCC=O</smiles>

If this mechanism is correct and if it represents the only source of cyclopentanone, cyclopentanone and carbon monoxide should be produced in the molar ratio of $1: 1$, but the observed ratio was $4: 1$.

Another possible mechanism to explain formation of the cyclopentanone is as follows. If adipic acid terminated the polymer chain, a reaction of the following type may occur:

[E]<smiles>[R7]OC=CC1C(=O)CCC1C</smiles>

If a slight excess of adipic acid were used in the manufacture of the polymer, a large portion of the chain ends would be carboxyl groups. 
It is possible that cyclopentanone is produced by both mechanisms described. There is sufficient carbon dioxide and carbon monoxide to account for these mechanisms. The moles of cyclopentanone, carbon dioxide, and carbon monoxide produced are about $0.017,0.08$, and 0.004 , respectively, for sample 4407.

A very small amount of cyclopentanone was found in the products from sample 4409. This polymer contains some adipic acid salt. The ratio of cyclopentanone to adipic acid component for sample 4407 is about 40 times the same ratio for sample 4409. Evidently the sebacic acid component markedly affects the course of the reaction. If the ten carbon unit breaks out in a manner similar to the reaction in equation $[\mathrm{C}]$, the production of cyclopentanone would not be expected. If a ten carbon cyclic ketone formed, its existence would be transitory at the temperatures of the experiment considering the well-known weakness of ten carbon rings. It should be noted that no carbon monoxide was produced by sample 4409 .

The carbon dioxide found is in excess of the maximum possible calculated on the basis of two carboxyl groups per molecular chain. If a molecular weight of 16,000 is assumed (table 12), the total possible mole percent of carbon dioxide that may be generated is about 0.3 percent; the mole percent of carbon dioxide found is about 3.5 and 4.6 percent for samples 4407 and 4409, respectively. This shows that a large part of the carbon dioxide was sorbed on the original material or comes from parts of the chains other than the ends.

The amounts of oxygen in samples 4407 and 4409 are 15.2 and 14.2 percent, respectively. The amounts of oxygen found in the gaseous fractions are about 2.9 and 3.3 percent, respectively. Although the gaseous fractions constituted only 5 percent of the weight of the polymer, these fractions contained 19 percent of the oxygen in sample 4407 and 23 percent of the oxygen in sample 4409 . This can be explained on the basis that the $\mathrm{C}-\mathrm{N}$ bonds break as indicated in equation $[\mathrm{C}]$ and that the fragment broken out decomposes as indicated in equation $[\mathrm{B}]$ or $[\mathrm{D}]$.

An obvious postulate to account for the large amount of carbon dioxide and hydrocarbons formed on the pyrolysis of these polyamides is that the $\mathrm{C}-\mathrm{N}$ bonds break as indicated in equation $[\mathrm{C}]$ and that the fragment, of either six or ten carbon units, decomposes by some unknown mechanism to give carbon dioxide and hydrocarbons. In the case of the six carbon unit, part but not all of the fragment gives cyclopentanone and carbon monoxide as shown in equation [D].

\section{(c) Ultraviolet Transmission}

Nylon is a polypeptide, and absorption characteristics similar to polypeptides and proteins would be expected. A region of selective absorption at approximately $280 \mathrm{~m} \mu$ has been attributed to the peptide group $[30,31]$ and more particularly to the carbonyl unit of this group [32]. Thus it seems probable that the absorption in the region of $280 \mathrm{~m} \mu$ found in the polyamides is caused by the peptide group and more specifically by the carbonyl unit in this group.

The absorption band between 260 and $330 \mathrm{~m} \mu$ with the polyamides may also be attributed in part to an associated structure between the peptide group and water or ethanol. The loss of the water and/or ethanol by the polyamides may cause an increase in the transmission in this region. The results obtained in this investigation show that exposure to ultraviolet radiant energy causes the disappearance of this absorption band; however, soaking the exposed specimens in water or ethanol does not cause it to return.

Anslow and Nassar [30] exposed solutions of egg albumin to ultraviolet radiant energy and found that the solutions first became rapidly more absorptive and after several hours of exposure to the radiation became less absorptive. They attributed this to breaking of the peptide linkage followed by recombinations producing hydrophobic molecules. About 4.4 electron-volts were required to break the peptide linkage. The effect of solvents such as aqueous sodium hydroxide and ethanol was to reduce the energy required to break the peptide linkage in egg albumin. In fact, exposure to sunlight through ordinary glass was sufficient to effect dissociation in such solutions.

Carpenter [33] exposed benzylstearylamine and $\beta$-phenylethylstearylamine to ultraviolet radiant energy and observed that both were decomposed. He found that peptide groups adjacent to side chains such as aromatic groups can be decomposed on exposure to ultraviolet radiant energy with the liberation of the absorbing amino acid from the molecule. Mitchell [34] states that exposure to ultraviolet radiant energy produces hydrolysis of peptide groups. The following reaction has been suggested [35] for the photochemical hydrolysis of stearic anilide:

$[\mathrm{F}]$

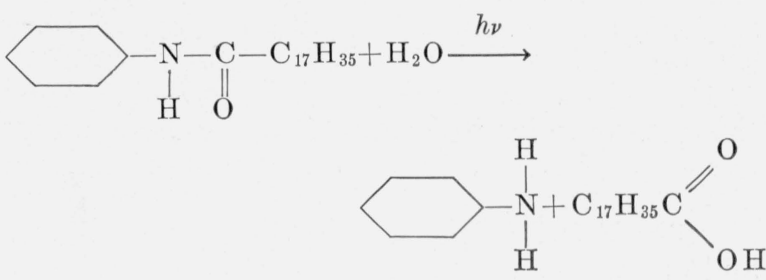

Peptones and proteins were found to yield aldehydes, ammonia, and carbon dioxide when exposed to ultraviolet radiant energy in the presence of oxygen. The decomposition of amino acids by ultraviolet radiant energy in the presence of oxygen was found to be as follows [36]:<smiles>[R]OC(=O)C([R])N</smiles> 
Exposure of a dilute solution of protein to ultraviolet radiant energy in the presence of oxygen resulted in the disappearance of the characteristic transmission minimum at $280 \mathrm{~m} \mu$ [37]. The effect was considerably slower in nitrogen. The products resulting from the degradation of the protein caused an over-all decrease in the total transmission of the solution.

It is known that peptide groups form hydrogen bridges, possibly of the following nature:

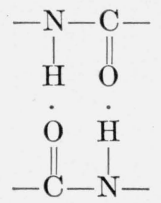

It is probable that denaturation by agents such as ethanol [38] causes these hydrogen bridges to be broken. The ethanol used to dissolve the nylon in making the film may break the hydrogen bridge and give a structure such as

$$
\begin{aligned}
& \begin{array}{cc}
-\mathrm{N}-\mathrm{C}- \\
\vdots & \| \\
\mathrm{H} & \mathrm{O}
\end{array} \\
& \text { [I] } \mathrm{C}_{2} \mathrm{H}_{5}-\mathrm{OH} \quad \mathrm{HO}-\mathrm{C}_{2} \mathrm{H}_{5} \\
& \begin{array}{c}
\dot{\mathrm{O}} \mathrm{H} \\
-\mathrm{C}-\mathrm{N}-
\end{array}
\end{aligned}
$$

or some similar type of structure.

Exposure to heat and to ultraviolet radiant energy could eliminate the ethanol since the energy involved in a hydrogen bridge is only about 5 kcal [38]. However, if both these treatments remove ethanol, the structures left in the polyamide must be somewhat different; heating does not eliminate the absorption but does cause an over-all decrease in transmission, whereas ultraviolet radiant energy causes an increase in transmission so that the absorption band is removed. Water may be bound in a manner similar to that holding the ethanol.

The following hypothesis is suggested to explain the difference in the behavior of these polyamides on exposure to heat and to ultraviolet radiant energy. The heat may cause breakdown of the associated complex between the carbonyl group and the ethanol and/or water, resulting in an over-all decrease in transmission. If the absorption in the region of $280 \mathrm{~m} \mu$ is attributed to the carbonyl group, it would not be appreciably affected by elimination of the complex. The ultraviolet radiant energy causes some reaction to take place that eliminates in part the absorption supposedly characteristic of the carbonyl and peptide groups. The greatest change in transmission in the region of $280 \mathrm{~m} \mu$, observed with sample 4407 , was about 9 percent, that is, from 48 to 57 percent.

It may be that the characteristic dip can be attributed to structures such as that shown in [I] and that the structure shown in $[\mathrm{H}]$ has a somewhat greater transmission. The reaction in the presence of ultraviolet radiant energy could be as follows:

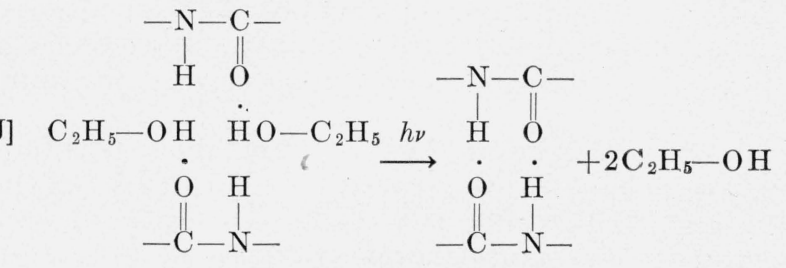

Another type of cross-linking reaction that eliminates the carbonyl group [39] has been suggested for proteins as follows:

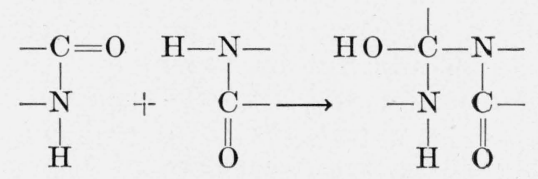

It has been found that the exposure of spread films of protein (the completely uncoiled form of the molecules) causes some degree of coiling, evident through collapse of the film [40]. The coagulation of proteins with ultraviolet radiant energy has been reported by many investigators [41]. This suggests another possible explanation for the splitting and brittleness of the polyamide films observed after exposure to sunlight.

The splitting of the $\mathrm{C}-\mathrm{N}$ bond and removal of $\mathrm{C}=\mathrm{O}$ as a result of ultraviolet exposure are possible and could be responsible for the changes in the ultraviolet spectra.

\section{(d) Infrared Transmission}

The infrared transmission curves of the polyamides are interpreted as follows: The absorption of the imine group (NH), which is ordinarily at 2.83 to $2.93 \mu$, is relatively weak. However, a shift to a longer wavelength with increased intensity of absorption occurs with bridging, indicating that the $3-\mu$ band is probably caused by linear NH.O bridging [42 to 44]. Absorptions at 3.36 and $3.42 \mu$ are usually a result of carbon-hydrogen bond stretching. The intense absorption at $6.1 \mu$ is attributed to the carbonyl group, which usually absorbs at 5.76 to 5.84 microns but is displaced to longer wavelength in nylon 66 and amides in general probably as a result of interaction between the carbonyl and imine groups [42]. The intense absorption at $6.46 \mu$ may result from $\mathrm{N}-\mathrm{H}$ bending and could cause a harmonic effect at $3.2 \mu$.

The doublet band at 6.8 and $7.05 \mu$ has been observed in diallyl adipate [45]. This pair of bands may be connected with $\mathrm{CH}_{2}$ deformations, such as $-\mathrm{CH}_{2}-$ and $=\mathrm{CH}_{2}$ [42]. A band at $7.3 \mu$ is attributed, in some cases, to $-\mathrm{CH}_{3}$ deformation. Single bond stretching might absorb in this region, and the band has been observed in diallyl adipate [45]. Thompson and Torkington [42] claim that in polyamides "much of the absorption between 8.34 and $5.88 \mu$ must be due to vibrations of the $-\mathrm{C}-\mathrm{CO}-\mathrm{NH}-\mathrm{C}-$ part of the structure". 
The absorption at about $9.0 \mu$ was attributed to the hydroxyl group in the case of polyvinyl alcohol by Thompson and Torkington [42]. From $14.3 \mu$ to lower frequencies broad absorption has been observed with oxygenated hydrocarbons and some oxidized hydrocarbon polymers. Methyl alcohol has a broad absorption band here according to Thompson and Torkington.

In the present study no extensive changes were revealed by the infrared transmission measurements. In some cases, structural differences of significance for physical properties cannot be detected by infrared methods because the relative number of chemical linkages affected is too small [46]. Apparently the degradation of nylon under the conditions used in this study results in either a change in a small proportion of the chemical linkages or in alterations in chemical structure that are not accompanied by a change in infrared absorption, or both.

\section{(e) Viscosity Measurements}

It seems probable that some chain scission occurred during the treatments, as shown by the lowering of $\eta, \ln \eta_{\tau} / c$, and $\eta_{s p} / c$ (table 12 and figs. 9 to 12). The data obtained on solutions of specimens $\mathrm{D}$ and $\mathrm{E}$ show that the difference in degree of degradation is quite pronounced. No measurement was made with the 3 -percent solution of specimen $\mathrm{C}$ since there was evidence of contamination. Nevertheless, by comparing the results obtained from the 1-percent solution of specimen $\mathrm{C}$ with those from the 1-percent solution of specimen $\mathrm{B}$, it is evident that the degree of degradation exhibited by specimen $\mathrm{C}$ shows the same relationship to that of specimen B as that observed for specimens E and D.

The applicability of Baker's equation [47]

$$
\eta_{r}=\left(1+\frac{[\eta] c}{z}\right)^{z}
$$

to the polyamide solutions was examined. The value of $z=3$ was found to fit the data adequately. The values of intrinsic viscosity, $[\eta]$, calculated as

$$
[\eta]=3\left(\eta_{r}^{1 / 3}-1\right) / c,
$$

are tabulated in table 12 . The agreement between values of $[\eta]$ obtained for the same specimen but with solutions of different concentrations is fair. Figure 12 is a plot of the values of $[\eta]$ versus the time of exposure to the degrading treatment.

Taylor [5] has expressed the relation between the intrinsic viscosity of nylon fractions in formic acid and the molecular weight as $\bar{M}_{N}=13,000[\eta]^{1.39}$, where $\bar{M}_{N}$ is the number-average molecular weight and $[\eta]$ is the intrinsic viscosity in formic acid. The measurements of intrinsic viscosity in this laboratory on sample 4410 were made in $m$-cresol. In 90-percent formic acid the intrinsic viscosity values are approximately 0.9 of those determined in $m$-cresol [20]. Application of Taylor's relation to the intrinsic viscosities of unfractionated polymers leads to a viscosity-average molecular weight $\left(\bar{M}_{v}\right)$.

Calculations from the results presented in table 12 indicate that 0.4 percent of all chain bonds were broken in the specimen degraded by exposure to ultraviolet radiant energy for $168 \mathrm{hr}$, the treatment that resulted in the greatest decrease in intrinsic viscosity. Since the strength of the $\mathrm{C}-\mathrm{N}$ bond is rather weak compared to the $\mathrm{C}-\mathrm{C}$ bond, the chain break probably occurs at the peptide linkage. If this is the case, about 3.5 percent of the peptide linkages were broken in this specimen.

\section{Changes in Molecular Orientation}

Investigations were made to detect any changes in molecular orientation or crystallinity of the polyamides under study. The terms "molecular orientation" and "crystallinity" are used in this discussion to describe a condition or state in which sections of the macromolecules are more or less situated spatially in some definite pattern or alinement to one another. The development of crystallinity in films of polyamides would be expected to lead to increased brittleness and splitting with a corresponding limitation of plastic flow. A decrease in the water or alcohol content below a specific minimum value would also produce the same changes in physical properties.

There appear to be two types of molecular orientation possible in polyamides. One is hydrogen bridging through adjacent peptide groups. This is also referred to as intermolecular bridging and dipole association. The higher the degree of dipole association, the greater the degree of crystallinity attributable to hydrogen bridging. The other type is hydrocarbon packing or alinement of the polymethylenic sections between the peptide groups. It has been shown that smaller polymer molecules increase the possibility of more crystallinity or local order [48] and that molecular size has a determining effect on the uniformity of properties [49].

There are two other factors that may affect the degree of crystallinity. One is the association of molecules of water and alcohol by hydrogen bridges at the peptide groups. The other is the dispersion of liquids or gases in the form of minute spherical inclusions in the body of the polymer. The presence of molecules such as water and alcohol in any way in the matrix will reduce the potential for molecular orientation because of spatial factors.

On the basis of chemical constitution, the polyamides used in this investigation can be divided roughly into two classes as regards possibility of molecular orientation. Samples 4405, 4406, 4407, and 4408 would be expected to have or develop a higher degree of dipole association than samples 4409 and 4410 because of the regularity in the spacing of the peptides. The 10-carbon acid along with the 6 -carbon acid in samples 4409 and 4410 creates an irregularity and causes the displacement of successive peptide groups along the chain. The caprolactam that is present in both classes also tends to create irregularity. This situation is analogous to the one 
described by Baker and Fuller [18] for a 50:50 composition of a $66 / 610$ polymer, which shows the effect of copolymerization in decreasing the concentration of polar groups in the average planes. The unequal polymethylene group spacings cause some of the polar peptide groups to fall along the polymer chain where they cannot contribute to dipole interaction.

\section{(a) Miscroscopic Examination}

As all of these samples exhibit relatively small optic axial angles, and since the acute bisectrix is approximately normal to the film, microscopical examinations made with crossed nicols, especially with objectives of small aperture, are extraordinarily sensitive to slight changes in optical directions. This is interpreted to be the reason for the large difference in brightness exhibited in the photomicrographs of figure 14 .

The effect caused by cutting the film with scissors is noticeably less on the samples that were exposed to ultraviolet radiant energy. This is probably because the greater brittleness has limited plastic flow under the stress of the cutting edge.

Each of the samples exhibits dark spots with lowpower lenses. With higher power lenses it can be seen that many of the spots are transparent and only appear dark because of the scattering of light that they have caused. The larger spots occur in the untreated film as nearly spherical liquid, or at least optically amorphous, inclusions. They have refractive indices noticeably but not greatly less than the rest of the films. With exposure these spherical inclusions shrink somewhat, with attendant strain in the surrounding plastic, and their refractive index becomes much less than that of the rest of the film. The most plausible explanation is that a dispersed liquid has diffused out and been replaced by air or vapor.

These polyamide films are anisotropic. Sample 4410 is apparently quite heterogeneous as compared to sample 4408 , which appears to be very homogeneous. Sample 4410 shows less effects from the exposures to ultraviolet radiant energy than sample 4408.

The bright lines observed in both untreated and treated specimens are apparently places where the orientation of the molecules within the plane of the film has been disturbed. These lines may have been caused by slight abrasion (hence, deformation) of the surface, by strains from shrinkage of the film, or by mechanical distortion.

\section{(b) Electron Miscroscopic Examination}

The electron micrographs of the unshadowed surfaces of the untreated specimens and of those exposed to ultraviolet radiant energy and to heat show no appreciable differences as a result of the exposures. The examination of the shadowed surfaces was more fruitful.

The electron micrographs of the shadowed surfaces of the untreated samples and of those exposed to ultraviolet radiant energy show that the crystal- linity of sample 4407 appears to be increased and that of sample 4409 not affected as a result of the treatment. Exposure to heat appears to have no effect on the crystallinity of samples 4407 and 4409 . Exposure to ultraviolet radiant energy may permit rotation of a segment of the polymer chain into a more highly ordered state. If this is the situation, then sample 4407 would be affected more than sample 4409.

Some of the difference in grain structure between samples 4407 and 4409 may be caused by differences in rate of cooling.

\section{(c) Electron Diffraction}

Assuming that the spacing in the region of $4.0 \mathrm{~A}$ (see table 13) represents hydrogen-bridged peptide linkage, the intensity of this ring should be proportional to the degree of order in the molecular chains. Positive determination of the crystallinity from such criteria as the intensity and width of the lines could not be made even with such measuring devices as the recording densitometer and the comparator because of the diffuse background and halolike character of the patterns. Visual estimation of the intensity and width of the rings was made by several experienced observers. There was no correlation between their observations and the treatments to which the films were subjected.

These electron diffraction studies revealed no changes in the degree of molecular orientation of the polyamides as a result of exposure to heat and to ultraviolet radiant energy.

\section{(d) X-Ray Diffraction}

The results obtained with the X-ray penetration photographs show some correlation with those expected on the basis of chemical constitution. Sample 4407 appears to be more crystalline than sample 4409. The differences are sufficient to identify the samples.

Like proteins, the sorption of water has a marked effect on the physical properties of polyamides. The effect of water and of ethanol on samples 4407 and 4409 was studied with X-ray diffraction techniques. Specimens of each sample were subjected to the following treatments for 1 month: (1) dried over magnesium perchlorate, (2) conditioned at 50 -percent relative humidity, (3) immersed in distilled water, and (4) immersed in 95-percent ethanol, respectively. The spacings and intensities obtained by measuring the X-ray reflections with a Geigercounter spectrometer are so similar that no definite trends can be recognized. There appears to be a tendency for the 4.3-A spacing to decrease in intensity from the dry to the wet specimens.

It is possible that the $7-\mathrm{A}$ spacing observed may be an identity period along the polymer chain. The increase in this spacing on exposure of sample 4407 to ultraviolet radiant energy may be attributed to the unkinking of the chain when dipole associated compounds, such as water, ethanol, or caprolactam, leave the polymer. This would permit bridging at the peptide groups and tend to extend the chain. 
In the case of sample 4409, the chain may tend to kink on exposure to ultraviolet radiant energy. This may be explained by interference between the polar groups and by a tendency of the longer methylene chain to twist. As the polar linkages are broken, the longer hydrocarbon chain section may coil, thus causing a decrease in the spacing. These phenomena would be related to the action of any dipole associated plasticizer.

Spacings at 17.4 and $26 \mathrm{~A}$ were observed by Baker and Fuller [25] and were associated with the identity period spacings. These spacings were observed to change on retraction of the material. Sponsler, Bath, and Ellis [50] state that for gelatine the 11-A side chain spacing may be expected to disappear when the water content is great enough to make the side chain spacing so large that the layers become too distorted to form diffraction patterns.

There is evidence that the weakening of intermolecular forces may allow rotations to occur that would result in more complete lattice formations $[25,51]$. The theory of rotation and further polymerization in the solid state may be explained by the "Segment theory of chain polymers" [51]. The probability of a given segment rotating is determined by the concentration of energy in the segment. This is shown in the annealing work done on linear polyamides by Fuller, Baker, and Pope [51]. Both amorphous and crystalline regions can exist in the film. Crystalline regions might be formed if sufficient energy is distributed along the molecular chain.

The splitting observed on exposure to heat and to ultraviolet radiant energy may be attributed to a rearrangement to a more crystalline state. In this case, evidence of increased crystallinity would be expected in the X-ray patterns; however, no increase in crystallinity was observed.

X-ray studies by Baker [52] and Brill [53] show that hydrogen bond rupture occurs on heating polyamides. A study of the rupture of intermolecular forces in molten nylon suggests that some of the intermolecular bonds rupture before melting, and thus permit "rotational movements and realinements inferred from X-ray diffraction data" [54].

\section{(e) Electrical Measurements}

The polyamides used in this investigation are electrically nonuniform to a high degree. This variation in electrical properties tends to obscure changes that might arise from alterations in molecular orientation due to exposure to heat, ultraviolet radiant energy, and other degrading forces. However, the results obtained indicate tentatively that exposure to ultraviolet radiant energy reduces the dielectric constant of sample 4406 slightly and that of sample 4407 markedly.

It seems highly probable that the nonuniform results reported here may be connected with local variations in the degree of dipole association. The change in dielectric constant with respect to time when the electrodes are not moved may be attributed to a change in the degree of dipole association under the influence of the electrical field. Changes in the degree of association of water at the free dipoles may also be a factor. Baker and Yager [55] have discussed the effect of hydrogen bridging in nylon on dielectric measurements.

\section{(f) Effect of Water and Alcohols}

The apparent relation between the degree of molecular orientation and degree of attack by liquid may be explained by the following hypothesis: Since the degree of intermolecular bridging in samples 4409 and 4410 is less than in the other samples, more unbridged carbonyl groups are available in samples 4409 and 4410 to associate with the liquid. The decreased degree of attack by the water in samples 4409 and 4410 is explained by the water molecules being sufficiently small to remain between the polymer chains without causing linear and lateral disorder sufficient to weaken the intermolecular forces holding them together. The alcohol molecules, on the other hand, are sufficiently large to cause enough disorder to weaken the intermolecular forces holding the polymer molecules together and permit further attack by the solvent.

The attack by water on samples 4406, 4407, and 4408 may be directly at peptides that are hydrogen bridged. Water being a very strong polar solvent may cause dissociation of the existing bridge and be held between the peptides causing a resultant strain on the molecular relations.

Ethanol, a larger molecule, apparently cannot interleave between chains of samples 4406, 4407, and 4408. Absolute ethanol does not show effects that indicate that it is breaking intermolecular bridges between adjacent peptides. In the case of samples 4409 and 4410, with more free dipoles and possibly less packing between the polymer chains, ethanol possibly can be absorbed. The size of the ethanol molecule, however, strains the chain configurations of these polymers.

The effects observed with 95-percent ethanol seem to indicate a preferential absorption of the water in samples 4406, 4407, and 4408. Samples 4409 and 4410 show effects similar to absolute ethanol. In general, cosolvent effects result.

Methanol represents a molecule of intermediate size. The data seem to indicate that the main attack by methanol is at unassociated dipoles. The association of a polar liquid at a free dipole may displace polymer chains with resultant strain that may make intermolecular bridging between the polymer chains more susceptible to attack by the polar solvent.

Methanol attack is greater after exposure of the films to ultraviolet radiant energy. Considering the immediate attack to be at free dipoles in the polymer, it seems logical to assume that exposure to ultraviolet radiant energy releases intermolecularly bridged peptides, thus causing a decrease in the degree of crystallinity. A decrease in molecular weight may also result in increased attack by methanol because of increased association at chain ends. 
Hill and Walker [56] in their work on polymer constitution show that the melting point of a crystalline polymer depends on the arrangement of the molecules and the relative amount of intermolecular forces between the molecules in the crystal lattice. Polyamides with high melting points have peptide arrangements that permit a high degree of bonding between carbonyl and amino groups in adjacent molecules. The data obtained by Biggs, Frosch, and Erickson [57] on the effect of varying the degree of $N$-alkylation on the melting points of polyamides support the view that hydrogen bridging is the main cause of the high melting points observed. Additional information on the effect of hydrogen bonding on melting points is reported by Baker and Fuller [20, 25].

The relation between the melting points of the original polyamide samples used in this investigation and the final effects of the liquids are shown in table 18 , in which the materials are arranged in order of decreasing melting point. If the melting points of these polyamides, which are similar in chemical constitution, are an indication of the intermolecular forces or the degree of crystallinity, the data in the above table indicate that the more crystalline polymers are more readily attacked by the water and the less crystalline polymers are more readily attacked by the absolute ethanol and methanol. The effect of the 95-percent ethanol is erratic, since the mixture exhibits cosolvent effects.

The relation between the effects of absolute methanol and the melting points of the original and exposed samples is shown in table 19. The effect of absolute methanol on the original untreated specimens is about the same as that on specimens exposed outdoors, and the melting points are practically the same. The melting points of the specimens exposed to ultraviolet radiant energy are less than those of unexposed specimens, and the effects of the absolute methanol are greater. If this is interpreted in terms of the hypothesis advanced above, it is indicated that there is little or no change in crystallinity in the specimens exposed outdoors and a decrease in crystallinity in the specimens exposed to ultraviolet radiant energy in the laboratory.

TABLE 18. Relation between effects of liquids and the melting poirts of the polyamides

\begin{tabular}{|c|c|c|c|c|c|c|}
\hline \multirow{3}{*}{$\begin{array}{l}\text { Sample } \\
\text { designa- } \\
\text { tion }\end{array}$} & \multicolumn{6}{|c|}{ Degree of attack a } \\
\hline & \multirow{2}{*}{ Melting point } & \multirow{2}{*}{$\begin{array}{l}\text { Water, } \\
18 \mathrm{mo}\end{array}$} & \multirow{2}{*}{$\begin{array}{c}95 \% \\
\text { ethanol, } \\
18 \mathrm{mo}\end{array}$} & \multirow{2}{*}{$\begin{array}{c}\text { Ethanol, } \\
15 \mathrm{mo}\end{array}$} & \multicolumn{2}{|c|}{ Methanol } \\
\hline & & & & & $30 \mathrm{~min}$ & $16 \mathrm{mo}$ \\
\hline $\begin{array}{l}4407 \\
4408\end{array}$ & $\begin{array}{c}{ }^{\circ} C \\
188 \text { to } 190 \\
186 \text { to } 191\end{array}$ & $\begin{array}{l}5 \\
5\end{array}$ & $\begin{array}{l}4 \\
4\end{array}$ & $\begin{array}{l}1 \\
1\end{array}$ & $\begin{array}{l}3 \\
3\end{array}$ & $\begin{array}{l}4 \\
4\end{array}$ \\
\hline $\begin{array}{l}4405 \\
4406\end{array}$ & $\begin{array}{l}179: \text { o } 180 \\
179 \text { to } 180\end{array}$ & 5 & 4 & $\begin{array}{l}1 \\
1\end{array}$ & $\begin{array}{l}4 \\
4\end{array}$ & $\begin{array}{l}4 \\
4\end{array}$ \\
\hline $\begin{array}{l}4409 \\
4410\end{array}$ & $\begin{array}{l}165 \text { to } 167 \\
161 \text { to } 163\end{array}$ & $\begin{array}{l}2 \\
2\end{array}$ & $\begin{array}{l}5 \\
3\end{array}$ & $\begin{array}{l}4 \\
4\end{array}$ & $\begin{array}{l}5 \\
5\end{array}$ & $\begin{array}{l}5 \\
5\end{array}$ \\
\hline
\end{tabular}

a See table 16 for code indicating degree of attack.
TABLE 19. Relation between effects of methanol immersion and melting points of original and exposed polyamides

\begin{tabular}{|c|c|c|c|c|c|c|}
\hline \multirow{2}{*}{$\begin{array}{l}\text { Polya- } \\
\text { mide } \\
\text { sample }\end{array}$} & \multicolumn{2}{|c|}{ Untreated } & \multicolumn{2}{|c|}{$\begin{array}{l}\text { Exposed to ultra- } \\
\text { violet }\end{array}$} & \multicolumn{2}{|c|}{$\begin{array}{l}\text { Exposed outdoors } \\
2 \text { months }\end{array}$} \\
\hline & $\begin{array}{l}\text { Melting } \\
\text { point }\end{array}$ & $\begin{array}{l}\text { Effect } \\
\text { of meth- } \\
\text { anol a }\end{array}$ & $\begin{array}{l}\text { Melting } \\
\text { point }\end{array}$ & $\begin{array}{l}\text { Effect } \\
\text { of meth- } \\
\text { anol a }\end{array}$ & $\begin{array}{l}\text { Melting } \\
\text { pcint }\end{array}$ & $\begin{array}{l}\text { Effect } \\
\text { of meth- } \\
\text { anol a }\end{array}$ \\
\hline 4405 & $\begin{array}{c}{ }^{\circ} C \\
179 \text { to } 180\end{array}$ & 4 & ${ }^{\circ} \mathrm{C}$ & & ${ }^{\circ} C$ & \\
\hline 4406 & 179 to 180 & 4 & 163 to 170 & 5 & 180 to 183 & 4 \\
\hline 4407 & 188 to 190 & 4 & 173 to 178 & 5 & 188 to 189 & 4 \\
\hline 4408 & 186 to 191 & 4 & 180 to 182 & 5 & 190 to 191 & 4 \\
\hline 4409 & 165 to 167 & 5 & 152 to 160 & 5 & 162 to 169 & 5 \\
\hline 4410 & 161 to 163 & 5 & 145 to 151 & 6 & 164 to 166 & 5 \\
\hline
\end{tabular}

a See table 16 for code indicating degree of attack.

\section{Relative Effects of Environmental Conditions}

The present study indicates that exposure of polyamides to ultraviolet radiant energy results in degradation. This is attributed to absorption of the short wavelengths by the carbonyl groups of the polymer with a resultant breaking of adjacent $\mathrm{C}-\mathrm{N}$ bonds. Strongly bound water or organic liquids that act as a plasticizer are also removed. The net result is a decrease in strength and an increase in brittleness.

The viscosity, mass spectrometric, and ultraviolet transmission studies show that the polyamides are affected by exposure to heat. This effect is less pronounced than that caused by exposure to ultraviolet radiant energy and may be of a different type or order.

\section{Relation Between Stability and Chemical Constitution}

The $66 / 610 / 6$ polyamides have compositions that should be favorable to less intermolecular bridging than the 66/6 polyamides. However, factors such as cooling rate from the molten state, which apparently has a considerable effect on the degree of association between chains, must be considered. It has been suggested [58] that a 66/610 (30:70) polymer is qualitatively less crystalline and consequently has a lower melting point than a 66 polymer. One can expect that the more heterogeneous the chemical composition of a polyamide is, the more resistance it will have to degradation.

The carbonyl groups in the polymer are a seat of ultraviolet absorption and consequently are detrimental to stability of the molecule. The adjacent, comparably weak, $\mathrm{C}-\mathrm{N}$ bond is an arrangement that is susceptible to chain scission.

A superpolyamide with properties similar to the 66 polymer has been prepared from piperazine and dicarboxylic acids and is thought to contain no hydrogen bridges between molecules [59]. The resistance of polyamides to embrittlement on degradation increases when an amino hydrogen of an aromatic amine having at least two cyclic nuclei (e. g., $\beta$-naphthylamine or phenothiazine) is incorporated in the polymer molecule [60]. It is also reported 
that the stability of polyamides to heat and light is increased by adding 0.5 to 4 mole percent of an amide-forming aromatic compound in the monomer mixture prior to condensation [61]. Plasticization of polyamides has also been suggested [62, 63]. Methylation of a fraction of the amide bonds results in polymer molecules with the same strength as the original ones but eliminates the possibility of the formation of hydrogen bridges $[25,64] . \quad N$-substituted polyamides obtained when mixtures of disecondary, secondary-primary, and diprimary amines are polymerized with dibasic acids have less hydrogen bridging and molecular interaction because of the lateral substituents [65]. The amount of $N$-substitution determines the properties of the polyamides; they can be varied from the hard tough polymers of the unsubstituted types to the soft tacky polymers of the 100-percent substituted types. Higher alkyl- $N$-substituted 610 polymers are less crystalline, have less potential crystallinity, and possess a higher degree of long-range elasticity than methyl- $N$-substituted 610 polymers. The basic idea involved in modifying these chemical structures is to prevent proximity of dipoles between the molecules.

\section{Improvement of Service Life of Polyamides}

The service life of polyamides could be extended by adding materials that will absorb the ultraviolet radiant energy instead of allowing the short wavelengths to be absorbed by the carbonyl group in the polyamide or by coating or covering with a material that would keep the ultraviolet radiant energy from getting to the carbonyl group. It appears unnecessary to protect from heat except under extraordinary circumstances. Maintaining the water content at a relatively high value would also extend the service life. Precautions should also be taken to prevent the loss of organic liquids or if they are lost to make certain that they are replaced with water or some other material capable of forming a similar associated complex. The absorption of excess amounts of water should be avoided since they cause a change in the strength properties. Water and organic liquids held in this manner act as volatile plasticizers. The use of less volatile water-insoluble materials that would be bound in a manner similar to the way water and alcohols are held is suggested.

The detrimental effects of changes in crystallinity or order on degradation may be remedied partially by changing the chemical constitution as mentioned in section XVI, 4 . The changes in chemical constitution would need to be carefully controlled to retain the desirable physical characteristics. On the basis of our present limited knowledge of such effects, experimentation is the only method of determining how much of the problem can be solved by this method. It appears that as long as the peptide group is present, a definite focal point of attack for degradation exists. The addition of groups, such as phenyl, may only act as radiant energy absorbers and may be capable of transferring this absorbed energy to the weaker $\mathrm{C}-\mathrm{N}$ bond causing it to break. The resulting smaller polymer molecules would be prevented from crystallizing by the presence of the large side groups. However, it is probable that any appreciable increases in stability by changes in chemical constitution would also produce soft tacky polymers.

\section{Summary}

The degradation of polyamides may involve the following: (1) change in chemical structure of the polymer molecule, (2) change in crystallinity (molecular orientation) including effects produced by hydrocarbon packing, dipole rearrangement, and hydrogen bridging, (3) change in the amount of molecularly associated materials that have a plasticizing effect, such as water and ethanol.

Infrared transmission studies of samples before and after exposure to heat and ultraviolet radiant energy show that there are no fundamental changes in the repeating unit of chemical structure of the polyamide molecule as a result of such treatment. Viscosity measurements show that the molecular weight decreases with the severity of the exposure conditions and with an increase in the period of exposure. The decreased resistance to immersion in water and alcohols as the material is degraded also indicates a decrease in molecular weight. It is concluded from these studies that the polymer molecule breaks into smaller molecules. The results of the mass spectrometric and pyrolysis studies show that the polymer molecule breaks at the $\mathrm{C}-\mathrm{N}$ bond of the peptide group and that the nitrogen atom remains attached to the polymer molecule. From the nature of the products it is evident that $\mathrm{C}-\mathrm{N}$ bonds in adjacent peptide groups of a molecule break, releasing a bicarbonyl polymethylene fragment. This bicarbonyl polymethylene fragment reacts to form water, carbon monoxide, carbon dioxide, hydrocarbons, and cyclopentanone, the particular products depending on the exposure conditions. The breaking of a very small proportion of the $\mathrm{C}-\mathrm{N}$ bonds would result in an appreciable decrease in molecular weight and an appreciable change in physical characteristics.

The evidence for a change in crystallinity on exposure of the polyamides to heat and ultraviolet radiant energy is not as positive as that for a change in chemical structure and composition. The results of the light and electron microscopical studies suggest an increase in crystallinity particularly on exposure to ultraviolet radiant energy. The electron diffraction, X-ray diffraction, and electrical studies fail to reveal any changes in crystallinity. The increased degree of attack by alcohols after exposure to ultraviolet radiant energy may be attributed either to the reduction in molecular weight or to reduced crystallinity.

The loss of water, alcohols, or similarly dipole associated materials results in appreciable changes in physical characteristics. These small molecules are probably bound by hydrogen bridging to the oxygen 
of the peptide group or some other associated molecular complex. They act as plasticizers for the polyamides. The results of the mass spectrometric, ultraviolet transmission, microscopic, and mechanical property studies show that sorbed water and ethanol are released on exposure to ultraviolet radiant energy. The loss of associated molecules as well as a decrease in the size of the polymer molecules will tend to foster an increase in crystallinity.

The results of the investigation show clearly that no single method gives a complete picture but that correlation of the results from several of the methods gives an insight into the mechanism of degradation of polyamides.

This investigation was sponsored by and conducted with the financial assistance of the Chemicals and Plastics Section, Research and Development Branch, Military Planning Division, Office of the Quartermaster General, Department of the Army. In particular, the efforts of Warren Stubblebine and Ladislav Boor are gratefully acknowledged.

Encouragement by the Committee on Plastics and Elastomers of the National Research Council Advisory Board on Quartermaster Research and Development (Robert Burns, Chairman, and Frank Y. Speight, Technical Aide) is acknowledged.

The help of many others at this Bureau is also appreciated. The assistance of Sanford B. Newman and Emil Borysko in taking the light photomicrographs and Leonardo Testa in the construction of the equipment used is acknowledged.

\section{References}

[1] F. W. Reinhart, Degradation of plastics, SPE News 4, No. 7, 3 (Sept. 1948).

[2] J. Boulton and D. L. C. Jackson, The fluidity of nylon solutions in $m$-cresol: measurement of chemical damage in nylon textiles, J. Soc. Dyers Colourists 59, 21 (1943).

[3] J. Boulton and D. L. C. Jackson, The fluidity of nylon solutions in $m$-cresol: Part II, J. Soc. Dyers Colourists 61, 40 (1945),

[4] K. Hosino, Studies of synthetic fibers. 1. Decomposition and synthesis of nylon, J. Chem. Soc. Japan 61, 475 (1940).

[5] G. B. Taylor, The relation of the viscosity of nylon solutions in formic acid to molecular weight as determined by end-group measurements. J. Am. Chem. Soc. 69, 635 (1947).

[6] W. R. Peterson, Degradation of synthetic linear polyamides, U. S. Patent 2,348,751 (May 16, 1944).

[7] C. S. Fuller, Heat-oxygen treatment of polyamides, U. S. Patent 2,364,204 (Dec. 5, 1944).

[8] R. A. Stillings and R. J. Van Nostrand, The action of ultraviolet light upon cellulose. I. Irradiation effects. II. Post-irradiation effects, J. Am. Chem. Soc. 66, 753 (1944).

[9] Plastics, organic: general specifications, test methods, Federal Specification L-P-406a (Government Printing Office, Washington, D. C., Jan. 24, 1944).

[10] Rubber goods: general specifications (methods of physical tests and chemical analyses), Federal Specification ZZ-R-601a (Government Printing Office, Washington, D. C., June 25, 1940).

[11] T. Alfrey, Jr., Mechanical behavior of high polymers (Interscience Publishers, New York, N. Y., 1948).
[12] H. Leaderman, Proposed nomenclature for elastic and inelastic behavior of high polymers, J. Colloid Sci. 4, 193 (1949).

[13] Standard method of test for internal tearing resistance of paper, D 689-44, A STM Standards 1946, Part III-B (Am. Soc. Test. Mats., Philadelphia, Pa.).

[14] S. L. Madorsky and S. Straus, Pyrolytic fractionation of polystyrene in a high vacuum and mass spectrometer analysis of some of the fractions, Ind. Eng. Chem. 40, 848 (1948); J. Research NBS 40, 417 (1948) RP1886.

[15] L. F. Feiser and M. Feiser, Organic Chemistry (D. C. Health and Co., Boston, Mass., 1944).

[16] American Society for Testing Materials tentative method of test for kinematic viscosity D 445-46T.

[17] J. W. MeElwain, Pump for volatile or toxic liquids in viscometers, Anal. Chem. 21, 194 (Jan. 1949).

[18] W. O. Baker and C. S. Fuller, Macromolecular disorder in linear polyamides. Relation of structure to physical properties of copolyamides, J. Am. Chem. Soc. 64, 2399 (1942).

[19] W. O. Baker and C. S. Fuller, Intermolecular forces and chain configuration in linear polymers - The effect of $N$-methylation on the X-ray structures and properties of linear polyamides, J. Am. Chem. Soc. 65, 1120 (1943).

[20] J. B. Nichols, The colloid aspects of nylon. Published in Colloid Chemistry by J. Alexander 6, 1077 (Reinhold Publishing Corp., New York, N. Y., 1946).

[21] W. H. Smith and C. P. Saylor, Optical and dimensional changes which accompany the freezing and melting of hevea rubber, J. Research NBS 21, 257 (1938) RP1129.

[22] C. M. Langkammerer and W. E. Catlin, Spherulite formation in polyhexamethylene adipamide, J. Polymer Sci 3, 305 (1948).

23] J. B. Speakman and A. K. Saville, Some physical properties of nylon, J. Textile Inst. 37, 271 (1946).

[24] G. P. Thomson, Electron diffraction, J. Inst. Metals 69, 191 (1943).

[25] W. O. Baker and C. S. Fuller, Intermolecular forces and chain configuration in linear polymers. The effect of $\mathrm{N}$-methylation on the X-ray structures and properties of linear polyamides. Annals of the New York Academy of Sciences 44, Art. 4, 329 (Nov. 12, 1943).

[26] J. Errera and H. S. Sack, Dielectric properties of animal fibers, Ind. Eng. Chem. 35, 712 (1943).

[27] American Society for Testing Materials tentative methods of test for power factor and dielectric constant of electrical insulating materials, D 150-47T.

[28] J. M. DeBell, W. C. Goggin, and W. E. Gloor, German plastics practice (DeBell \& Richardson, Inc., Hazardville, Conn., 1946).

[29] F. O. Rice and K. Rice, The aliphatic free radicals (The Johns Hopkins University Press, Baltimore, Md., 1935).

[30] G. A. Anslow and S. C. Nassar, The absorption of ultraviolet energy by the peptide linkage, J. Opt. Soc. Am. 31, 118 (1941).

[31] G. A. Anslow and E. R. Lyman, A. spectrophotometric study of glutathione, J. Opt. Soc. Am. 31, 114 (1941).

[32] I. M. Klotz, Ultraviolet absorption spectroscopy, J. Chem. Education 22, 328 (1945).

[33] D. C. Carpenter, Splitting the CONH linkage by means of ultraviolet light, J. Am. Chem. Soc. 62, 289 (1940).

[34] J. S. Mitchell, Recent advances in the study of monolayers, Nature 13\%, 502 (1936).

[35] E. K. Rideal and J. S. Mitchell, Photochemical reactions in monolayers. I. Photochemical properties of the ketoimino linkage, Proc. Roy. Soc. (London) [A] 159, 206 (1937).

[36] A. J. Allen, R. E. Steiger, M. A. Magill, and R. G. Franklin, XXIII, Amino-acids, acyl-amino-acids, dipeptides, acyl-dipeptides, and derivatives of these compounds. II. Effects of irradiation with cathode rays and ultraviolet light, J. Biochem. 31, 195 (1937).

[37] J. P. Becher and P. Szendrö, Spectroscopic and chemical investigations of the degradation of proteins by ultraviolet rays, Pfügers Archiv für die Gesamte Physiologie des Menschen und der Tiere 228, 755 (1931).

[38] A. E. Mirsky and Linus Pauling, On the structure of native, denatured, and coagulated proteins, Proc. Nat. Acad. Sci. 22, 439 (1936). 
[39] D. M. Wrinch, On the pattern of proteins, Proc. Roy. Soc. (London) [A] 160, 59 (1937).

[40] H. Neurath, The influence of denaturation on the spreading of proteins on a water surface, J. Phys. Chem. 40, 361 (1936).

[41] C. Ellis and A. A. Wells, The chemical action of ultraviolet rays (The Chem. Catalog Co., New York, N. Y., 1925).

[42] H. W. Thompson and P. Torkington, The infrared spectra of compounds of high molecular weight, Trans. Faraday Soc. 41, 246 (1945).

[43] A. M. Buswell, Karl F. Krebs, and W. H. Rodebush, The infrared absorption of proteins in the $3 \mu$ region, $\mathrm{J}$. Phys. Chem. 44, 1126 (1940).

[44] S. E. Darmon and G. B. B. M. Sutherland, Infrared spectra and structure of natural and synthetic polypeptides, J. Am. Chem. Soc. 69, 2074 (1947).

[45] R. B. Barnes, R. C. Gore, U. Liddel, and V. Z. Williams, Infrared spectroscopy (Reinhold Publishing Corp., New York, N. Y., 1944).

[46] J. E. Field, D. E. Woodford, and S. D. Gehman, Applications of infrared methods in the structural examination of synthetic rubber, J. Applied Phys. 17, 386 (1946).

[47] Frank Baker, The viscosity of cellulose nitrate solutions, J. Chem. Soc. 103, 1653 (1913).

[48] W. O. Baker and C. S. Fuller, Thermal evidence of crystallinity in linear polymers, Ind. Eng. Chem. 38, 272 (1946).

[49] D. D. Coffman, G. J. Berchet, W. R. Peterson, and E. W. Spanagel, Polymeric amides from diamines and diabasic acids, J. Polymer Sci. 2, 306 (1947).

[50] O. L. Sponsler, J. D. Bath, and J. W. Ellis, Water bound to gelatin as shown by molecular structure studies, J. Phys. Chem. 44, 996 (1940).

[51] C. S. Fuller, W. O. Baker, and N. R. Pope, Crystalline behavior of linear polyamides. Effect of heat treatment, J. Am. Chem. Soc. 62, 3275 (1940).

[52] W. O. Baker, Nature of the solid state of chain poly mers S. B. Twiss, Advancing fronts in chemistry, vol. I, High Polymers, chapter 8 (Reinhold Publishing Corp., New York, N. Y., 1945).
[53] R. Brill, Behavior of polyamides on heating, J. prakt. Chem. 161, 49 (1942).

[54] Leonard Glatt and J. W. Ellis, Near infrared absorption of nylon films: dichroism and rupture of NH.O bonds on melting, J. Chem. Phys. 16, 551 (1948).

[55] W. O. Baker and W. A. Yager, The relation of dielectric properties to structure of crystalline polymers. II. Linear polyamides, J. Am. Chem. Soc. 64, 2171 (1942).

[56] R. Hill and E. E. Walker, Polymer constitution and fiber properties, J. Polymer Sci. 3, 609 (1948).

[57] B. S. Biggs, C. J. Frosch, and R. H. Erickson, Melting points of $N$-substituted polyamides, Ind. Eng. Chem. 38, 1016 (1946).

[58] W. E. Catlin, E. P. Czerwin, and R. H. Wiley, Multiingredient polyamides, J. Polymer Sci. 2, 412 (1947).

[59] I. C. Funcke, Uber die zwischen linearen Kettenmolekülen mit Peptidbindungen wirkenden intermolekularen Kräfte, Naturwissenschaften 29, 517 (1941).

[60] E. I. du Pont de Nemours and Co. and G. D. Graves, Polymeric materials, Brit. Patent 549,370 (Nov. 18, 1942).

[61] G. B. Taylor, Improved polyamides, U. S. Patent 2,374,145 (April 17, 1945).

[62] C. Coolidge, Plasticizing synthetic linear polyamides for making sheets, filaments, etc., U. S. Patent 2,265,119 (Dec. 2, 1942).

[63] M. M. Brubaker, Plasticized polyamides, U. S. Patent 2,374,576 (April 24, 1945).

[64] H. Mark, The mechanical properties of high polymers, Trans. Faraday Soc. 43, 451 (1947).

[65] E. L. Wittbecker, R. C. Houtz, and W. W. Watkins, Elastic $N$-substituted polyamides, Ind. Eng. Chem. 40, 875 (May 1948)

[66] A. I. Goldberg, W. P. Hohenstein, and H. Mark, Intrinsic viscosity - molecular weight relationship for polystyrene, J. Polymer Sci. 2, 503 (1947).

[67] P. J. Flory, Molecular weights and intrinsic viscosities of polyisobutylenes, J. Am. Chem. Soc. 65, 372 (1943).

Washington, July 21, 1950. 